\title{
Embodied revelation: The threat of sudden cardiac death for implantable cardioverter defibrillator candidates
}

\author{
Vera Barton-Caro \\ West Virginia University
}

Follow this and additional works at: https://researchrepository.wvu.edu/etd

\section{Recommended Citation}

Barton-Caro, Vera, "Embodied revelation: The threat of sudden cardiac death for implantable cardioverter defibrillator candidates" (2013). Graduate Theses, Dissertations, and Problem Reports. 199.

https://researchrepository.wvu.edu/etd/199

This Dissertation is protected by copyright and/or related rights. It has been brought to you by the The Research Repository @ WVU with permission from the rights-holder(s). You are free to use this Dissertation in any way that is permitted by the copyright and related rights legislation that applies to your use. For other uses you must obtain permission from the rights-holder(s) directly, unless additional rights are indicated by a Creative Commons license in the record and/ or on the work itself. This Dissertation has been accepted for inclusion in WVU Graduate Theses, Dissertations, and Problem Reports collection by an authorized administrator of The Research Repository @ WVU.

For more information, please contact researchrepository@mail.wvu.edu. 
EMBODIED REVELATION: THE THREAT OF SUDDEN CARDIAC DEATH FOR IMPLANTABLE CARDIOVERTER DEFIBRILLATOR CANDIDATES

\author{
Vera Barton-Caro \\ Dissertation submitted to the \\ School of Nursing at West Virginia University \\ in partial fulfillment of the requirements for the degree of \\ Doctor of Philosophy \\ In \\ Nursing
}

Alvita Nathaniel, Ph.D., FNP-BC, FAANP, Chair

Roger D. Carpenter, Ph.D., RN

Daniel D. Matlock, MD, MPH

Barbara L. Nunley, Ph.D., RN, GCNS-BC

Mary Jane Smith, PhD., RN

School of Nursing

Morgantown, West Virginia

2013

Keywords: Heart Failure; Implantable Cardioverter Defibrillators; Patient Decision Making 


\begin{abstract}
EMBODIED REVELATION: THE THREAT OF SUDDEN CARDIAC DEATH FOR IMPLANTABLE CARDIOVERTER DEFIBRILLATOR CANDIDATES
\end{abstract}

\title{
Vera Barton-Caro
}

BACKGROUND: Heart failure is a severe, chronic condition characterized by high mortality and high morbidity. Sudden cardiac death is the leading cause of death for people with heart failure as well as the primary cause of death in the United States. Implantable cardioverter defibrillators (ICDs) represent the standard of care as the only effective therapy for primary prevention of sudden cardiac death. However, a significant proportion of qualifying heart failure patients declines this life-saving device. Nurses are charged with advocating for wellinformed patient decisions. Yet, there is little extant literature that addresses the decisionmaking process for patients considering an ICD. PURPOSE: The purpose of this study was to explore the decision-making process heart failure patients experience when considering a primary prevention ICD. METHODS: This classic grounded theory study utilized purposive sampling to recruit 12 heart failure patients who had been offered primary prevention ICD implantation. Data from open-ended interviews were collected and analyzed. RESULTS: The grounded theory of embodied revelation: the threat of sudden cardiac death for ICD candidates describes the decision-making process of heart failure patients considering an ICD. The theory consists of four stages and a critical juncture. The first stage of the theory is living in conscious 
denial in which patients are aware on some level that they have heart failure and that they could die from this condition. Regardless of the degree of understanding, the awareness of true mortality risk is repressed. The stage ends abruptly with the critical juncture of grasping the threat of sudden cardiac death when the patient begins to comprehend the risk of death and the second stage of heightening awareness begins if the condition of valuing longevity is met. This stage is usually precipitated by a significant medical event and newly realized candor displayed by the health care provider concerning the significant death risk and recommendation for an ICD. Patients who declined ICD therapy remain in the first stage. They did not experience the critical juncture and never moved to the second stage of heightening awareness. The third stage of sanctioning ICD therapy begins while the patient is still experiencing some degree of anxiety related to a new understanding of the risk of death and the life-saving capabilities of the ICD. The decision to accept the device occurs rather quickly. At this point, the patient usually takes on a passive role and acquiesces to their provider's recommendation. The final stage of the theory, living in new assurance, describes how the heart failure patient continues to consider and support the decision made often downplaying the rigor of the process. The patient enjoys a more blissful state of assurance fueled by a new sense of security with having an ICD. CONCLUSIONS: Embodied revelation: the threat of sudden cardiac death for ICD candidates explains the complex decision-making process surrounding an invasive life-sustaining therapy. This new grounded theory has profound implications for research, nursing and medical practice, and bioethical considerations. 


\section{AKNOWLEDGEMENTS}

While only my name appears on the title page, I would like to thank some of the many people who contributed to this study, starting with my dissertation committee: Dr. Mary Jane Smith, whose personal guidance inspired this clinician to bravely climb that ladder of abstraction; Dr. Roger Carpenter and Dr. Barbara L. Nunley, who provided me with constructive criticism pushing for clarity and helping with every aspect of format; Dr. Dan Matlock, whose content expertise and thought-provoking comments took this study in directions I would not have considered; Dr. Alvita Nathaniel, my dissertation chair, for her trust, patient guidance, unwavering support and mentorship throughout the dissertation process. I wish to thank the WVU Foundation and School of Nursing without whose financial and meritorious contributions I could not have pursued this doctorate and the doctoral nursing faculty, who, without exception, gave me nurturing support and demonstrated complete faith in my ability to accomplish this goal. I am grateful to my co-workers, who supported my academic pursuits, while at times having to take on some of my workload; my professional colleagues, who have served as mentors, especially Dr. Rick and Jo Terry, without whose caring support I would not have had the opportunity to pursue my dreams; to my personal and virtual friends, whose regular messages of support meant the world to me; to my WVU PhD cohort family: Mariann, Betty, Crystal, and Kristi for invaluable support, feedback, and friendship. I wish to thank my family, in particular my children, Bart and Katie, who offered support and would have accepted nothing short of completion. I am grateful to my soul mate and editor, Butch, who supported me through every dark moment and shared my enthusiasm with each conceptual epiphany. Finally, I am grateful to all the heart failure patients, for whom I have had the honor of caring, and who inspired me through each stage of this process. 


\section{DEDICATION}

I dedicate this dissertation to my dad, the late William R. Barton, MD. By the example of his passion for his profession, Dad served as an inspiration for my commitment to nursing. Asserting that by choosing a career I would love, he showed me that it would never be a job. A man of insatiable intellectual curiosity, Dad passed on to me that academic and professional integrity are paramount, and that education is a life-long pursuit. He always told me I should have been a doctor. Although a PhD is not what he originally had in mind, no one would have been prouder of me than he. 


\title{
TABLE OF CONTENTS
}

\begin{abstract}
V
AKNOWLEDGEMENTS ....................................................................................................................... iv

DEDICATION..................................................................................................................................................... V
\end{abstract}

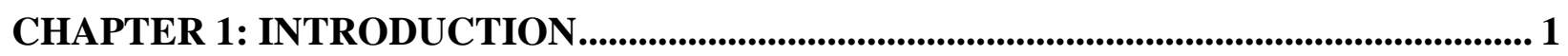

Purpose and Definition of Terms ……………………................................................ 2

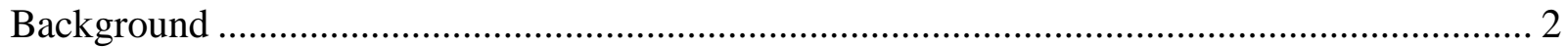

Prevalence

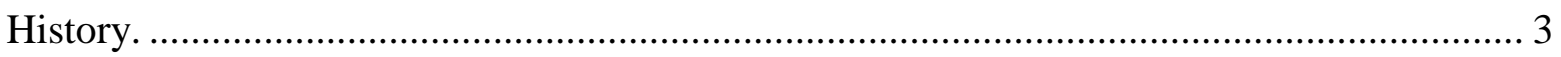

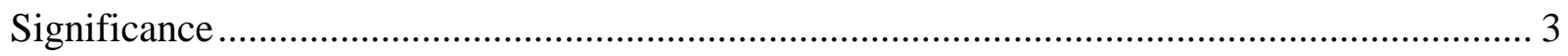

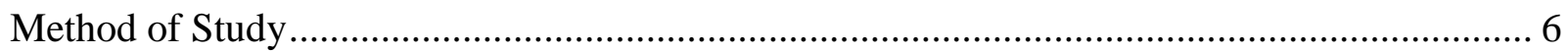

Theoretical Underpinnings ............................................................................................ 6

CHAPTER 2: REVIEW OF THE LITERATURE..........................................................

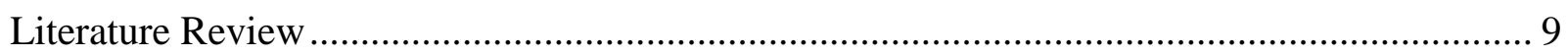

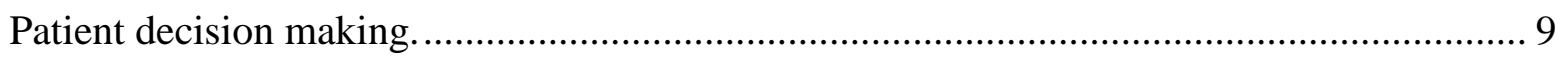

Patient decision making surrounding burdensome therapies. ................................................ 10

Appraisal of treatment burden .................................................................................. 12

Patient age

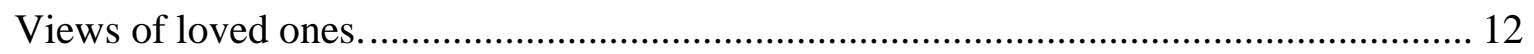


Patient understanding.................................................................................... 13

Physician recommendation ............................................................................... 14

Change in preferences over time........................................................................ 14

Measuring willingness to accept life-sustaining therapy.............................................. 15

Underutilization of internal cardioverter defibrillators. .............................................. 15

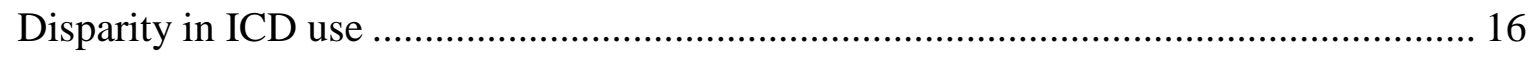

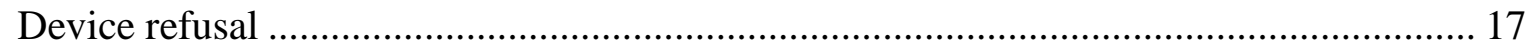

Patient and provider perspectives of implantable cardioverter defibrillator therapy........... 18

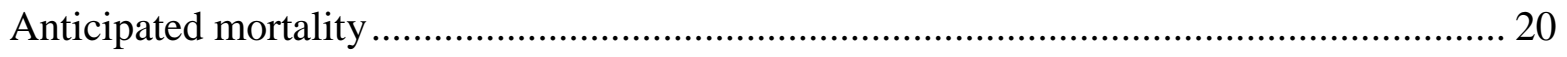

Provider recommendation of ICDs .......................................................................... 21

Heart failure patient decision making surrounding primary prevention implantable

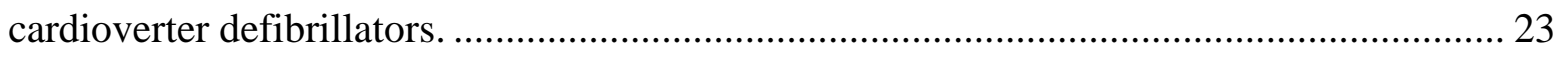

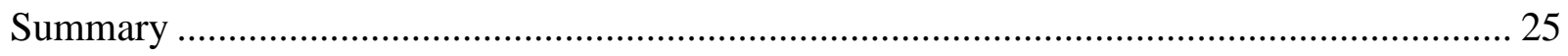

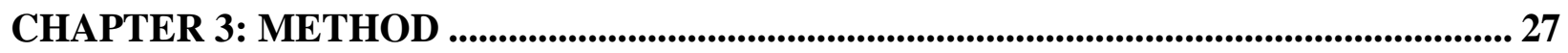

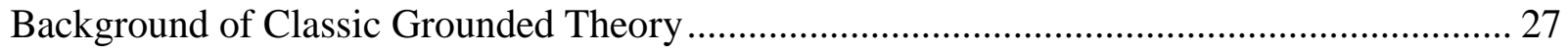

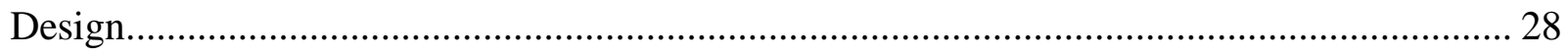

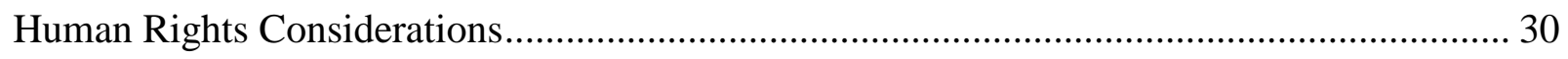

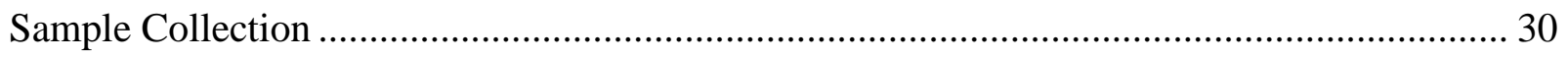

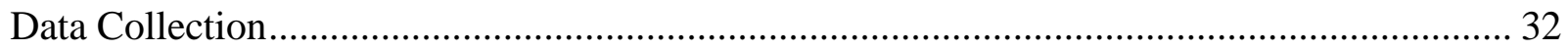

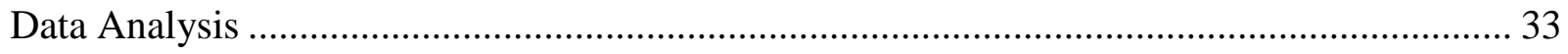


Coding.

Theoretical sampling. 34

Categories 34

Memoing 35

Stages. 35

Theory development. 36

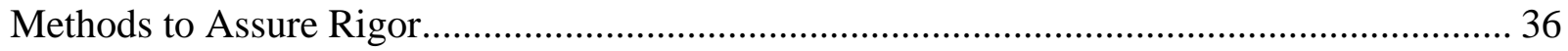

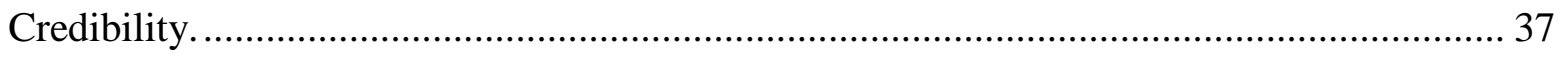

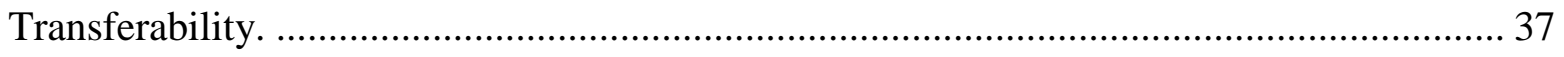

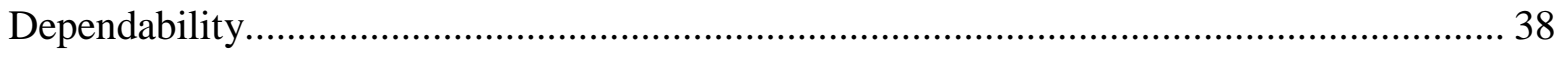

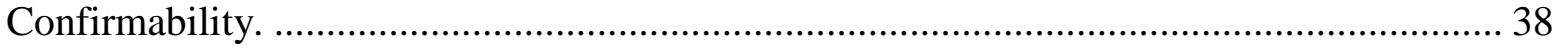

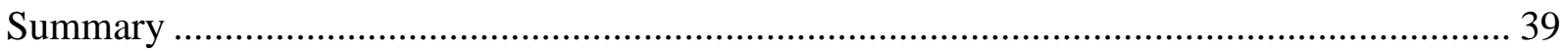

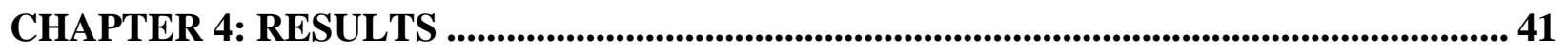

Summary of Embodied Revelation: The Threat of Sudden Cardiac Death for ICD Candidates

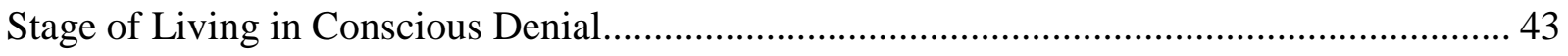

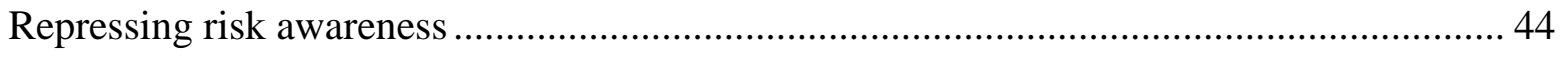

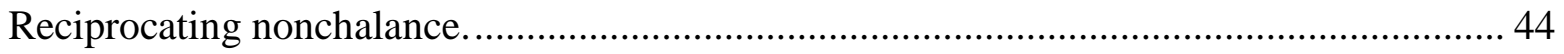

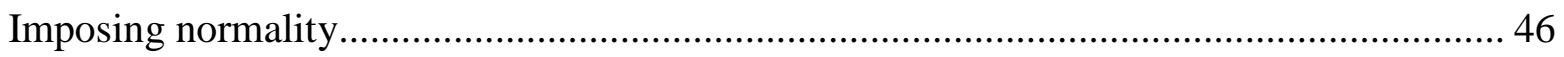

The Critical Juncture of Grasping the Threat of Sudden Cardiac Death ............................... 47 


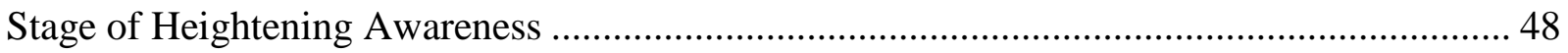

Experiencing a significant medical event ........................................................................... 49

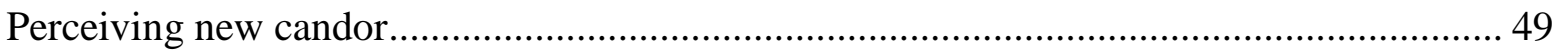

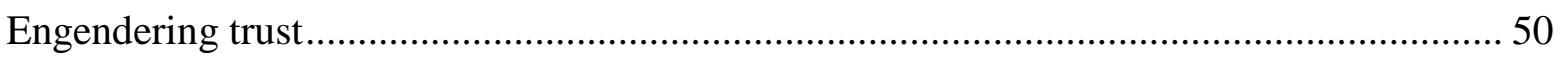

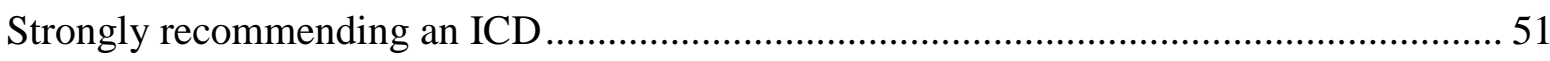

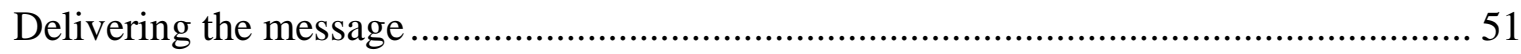

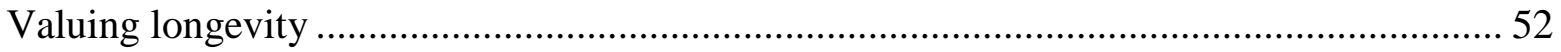

Stage of Sanctioning Implantable Cardioverter Defibrillator Therapy …………..................... 52

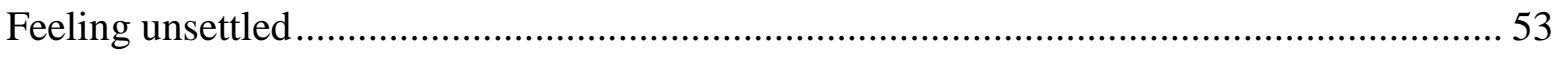

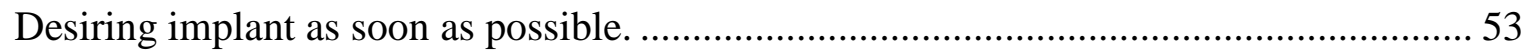

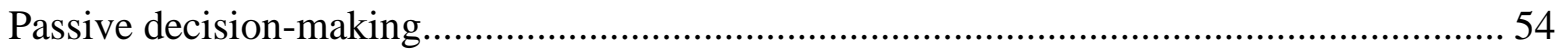

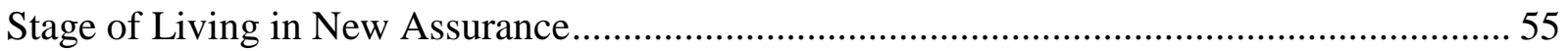

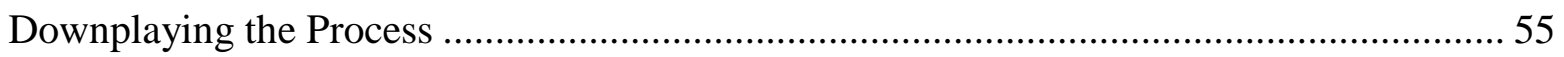

Declining Primary Prevention Implantable Cardioverter Defibrillator Therapy ....................... 57

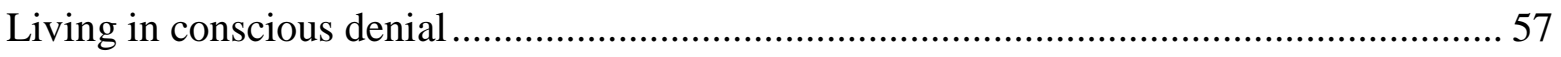

Repressing risk awareness. ....................................................................................... 57

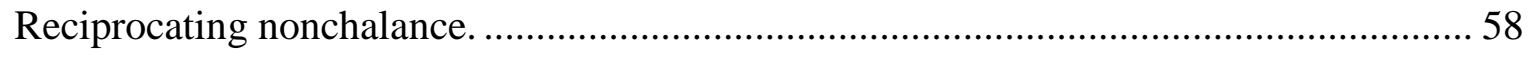

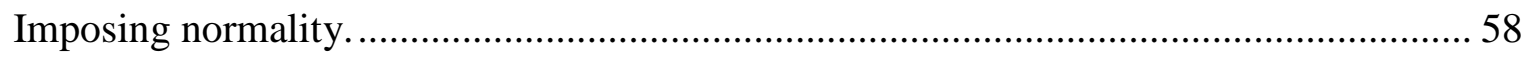

Missing the critical juncture and heightening awareness ................................................. 58

Not valuing longevity ............................................................................................ 58 
Not experiencing a significant medical event. ..................................................... 59

Not perceiving new candor. ........................................................................... 59

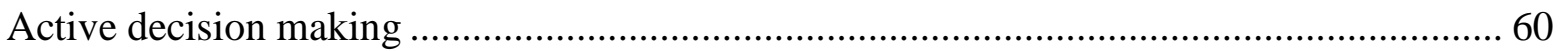

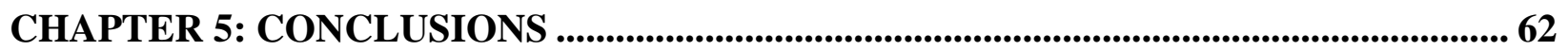

Summary of Embodied Revelation: The Threat of Sudden Cardiac Death for ICD Candidates

Comparison of Embodied Revelation: The Threat of Sudden Cardiac Death for ICD

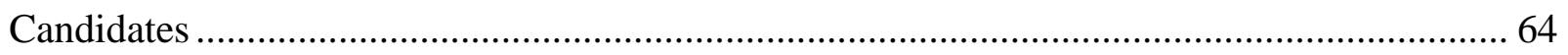

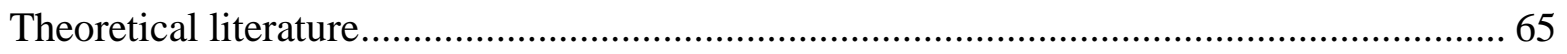

Current concept analyses of patient decision making .......................................... 65

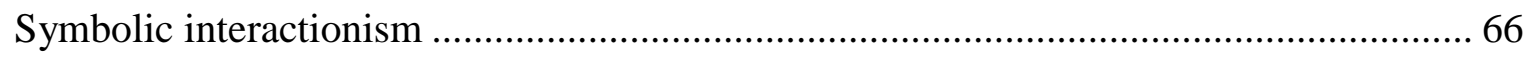

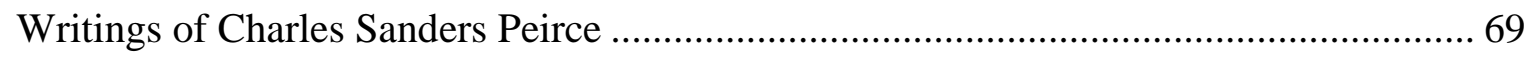

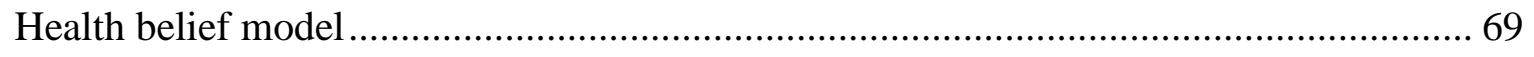

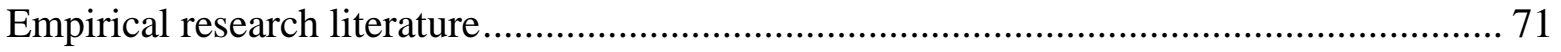

Patient decision making surrounding potentially burdensome life-sustaining therapies ... 72

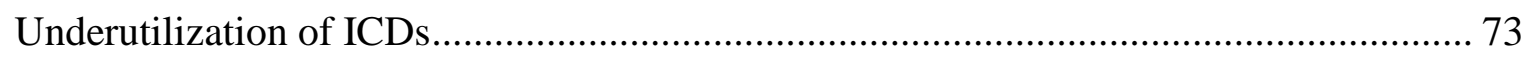

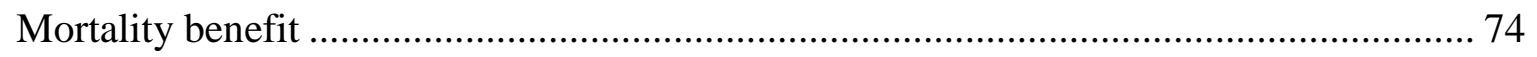

The patient's perspective regarding ICDs........................................................... 74

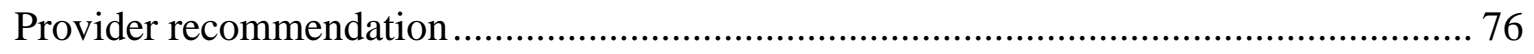

Heart failure patient decision making surrounding primary prevention ICDs. ............... 77 
Critique of the Theory

Credibility. 79

Transferability 80

Dependability 80

Confirmability 81

Limitations of the theory 81

Implications for Research, Nursing Science, Clinical Practice, and Bioethical Considerations

Research 82

The discipline of nursing. 83

Nursing and medical practice 85

Conclusion 90

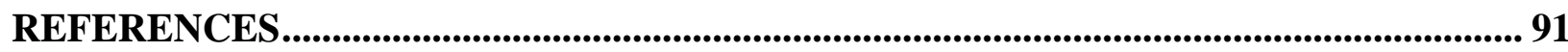

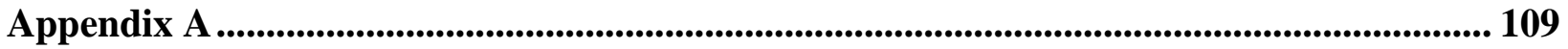

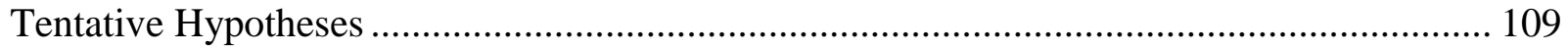

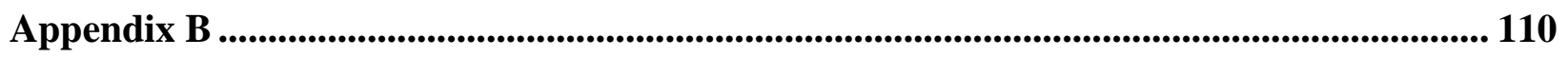

Examples of Field Notes Depicting Concepts and Stages........................................................... 110

Example of Stage I: Conscious Denial with properties: repressing risk awareness, reciprocating nonchalance, and imposing normality 110

Example of the Critical Juncture of Grasping the Threat of Sudden Cardiac Death 111 
Example of Stage II of Heightening Awareness with properties of perceiving new candor and strongly recommending an ICD

Examples of Stage IV: Living in New Assurance with the property of downplaying the process

Appendix C

Appendix D.

Appendix E

Appendix F

Appendix G.

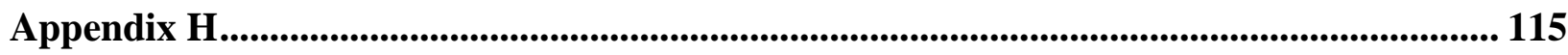

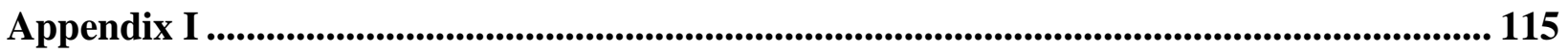

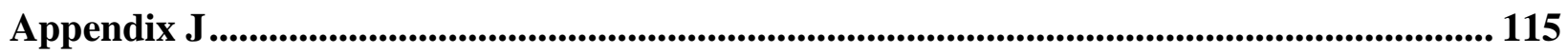




\section{CHAPTER 1: INTRODUCTION}

Heart failure is a severe, chronic condition characterized by high mortality and high morbidity. Sudden cardiac death, the result of a lethal arrhythmia, is the leading cause of death for people with heart failure as well as the primary cause of death in the United States (Roger et al., 2010). Implantable cardioverter defibrillators (ICDs) represent the standard of care for primary prevention of sudden cardiac death in heart failure (Hunt et al., 2005). Primary prevention therapies are those aimed at preventing a first occurrence. Secondary prevention refers to therapies that prevent a disease or event from recurring or exacerbating (vanWelsenes et al., 2011). In the case of ICDs, secondary prevention devices are implanted in patients who have already demonstrated potentially lethal ventricular arrhythmias by surviving a sudden cardiac arrhythmia event or having had inducible ventricular tachycardia or fibrillation demonstrated by an electrophysiologic study. Primary prevention ICDs are implanted prophylactically in patients who have been deemed high risk for lethal ventricular tachyarrhythmias due to their left ventricular dysfunction, but have not yet experienced potentially life-threatening ventricular arrhythmias (Duray, Israel, \& Hohnloser, 2006). The problem that this investigation addressed is that a significant proportion of qualifying heart failure patients who are at risk for lifethreatening arrhythmias decline ICD therapy (Hernandez et al., 2007; Lakshmanadoss et al., 2011; LaPointe et al., 2011; Ruskin, Camm, Zipes, Hallstrom, \& McCrory-Usset, 2002; Thomas et al., 2007). Few studies address the decision-making process for these patients. 


\section{Purpose and Definition of Terms}

The purpose of this classic grounded theory study was to develop a theory explaining the decision-making process heart failure patients experience when considering implantation of a primary prevention ICD. The research question for the investigation was: "What is going on during the decision-making process of heart failure patients considering primary prevention ICD implantation?" For the purposes of this study, the primary research concepts were defined as follows:

-Decision-Making Process: the cognitive process of selecting a choice from available options

-Heart Failure Patient: an adult with systolic heart failure, evidenced by a left ventricular ejection fraction of $35 \%$ or below.

-Implantable Cardioverter Defibrillator: a metallic device similar to a pacemaker, implanted underneath the skin, able to detect lethal tachyarrhythmias and in most cases, emits an electrical shock that aborts the arrhythmia.

\section{Background}

Prevalence. Unlike many other cardiovascular conditions, the incidence of heart failure is increasing, and approximately 5.8 million people in the United States have heart failure (Roger et al., 2010). About 670,000 people are diagnosed with this chronic condition each year, and $50 \%$ of heart failure patients die within five years of the diagnosis (Roger et al.). Evidencebased medications and device therapies have revolutionized the treatment of heart failure in the last two decades, offering patients the potential for improved quality and quantity of life. The 
leading cause of death for people with heart failure is sudden cardiac death (American Heart Association [AHA], 2010). The magnitude of sudden cardiac death exceeds the total number of deaths from AIDS, breast cancer, lung cancer and stroke annually (Myerburg \& Castellanos, 2001).

History. Implanted devices have been recognized as the only effective therapy to prevent sudden cardiac death in recent years (Bardy et al., 2005; Echt et al., 1991; Moss et al., 2002). Prior to 2004, antiarrhythmic drugs were the primary therapy aimed at preventing sudden cardiac death (Bardy et al.). The publication of The Cardiac Arrhythmia Suppression Trial (CAST) highlighted the adverse mortality effects with traditional antiarrhythmic agents (Echt et al., 1991). The ICD was introduced in 1980 to address the problem of sudden cardiac death (Kastor, 1989). Contemporary ICDs, metallic devices similar to pacemakers, are surgically implanted underneath the skin usually in the chest area. These devices aim to detect lethal arrhythmias and emit an electrical shock that aborts the arrhythmia. Prior to 2002, ICDs were implanted only for secondary prevention. Based on landmark trials demonstrating significantly improved survival from sudden cardiac death, these devices now represent a class IA recommendation as primary prevention for all patients with systolic heart failure defined as a left ventricular ejection fraction of $35 \%$ or less on optimal pharmacologic therapy (Bardy et al.; Moss et al.). Data show that these devices are underutilized for reasons that are not completely understood (Lakshamanadoss et al., 2011; McKinney, 2011).

\section{Significance}

There are a few major areas of significance that this study addresses. Sudden cardiac death is the leading cause of death in the United States (AHA, 2010). This condition is 
potentially predictable and preventable, yet many patients decline the life-saving therapy of an ICD (Gravelin et al., 2011; LaPointe et al., 2011). There is a gap in the knowledge related to primary prevention ICDs. Lastly, there is a gap in the knowledge regarding how this situation may correlate to patient decision making surrounding other potentially burdensome, lifesustaining therapies.

Heart failure is on the rise, and this condition is the most expensive health care issue facing our nation today (Roger et al., 2010). This progressive condition carries a high morbidity and mortality rate (AHA, 2010). Primary prevention ICD therapy is the only effective therapy in preventing sudden cardiac death, the primary cause of heart failure mortality (Roger et al., 2010). Yet, growing data show that a significant proportion of qualifying patients declines this lifesaving therapy (Gravelin et al., 2011; LaPointe et al., 2011). Understanding patient decision making surrounding ICDs and other burdensome life-sustaining treatments could hold social significance as policies and standards of care are adopted. Health care providers are obligated to promote evidence-based life-saving therapies, but also respect and facilitate autonomous patient decisions. Patients must understand and be able to weigh the potential risk and benefit issues in order to make well-informed decisions. The new grounded theory generated by this study will be useful to nurses and other health care providers who work with patients at the time they are confronted with the decision surrounding an ICD. An understanding of the patient's perspective in such health care decisions could help clinicians and facilitate development of pre-implant assessment and patient education tools.

Factors influencing patient decision making about primary prevention ICDs could be significantly different than issues involving secondary devices. There is a lack of data regarding 
primary prevention ICDs. Most of the research regarding ICDs has involved secondary prevention devices. The primary prevention indication for ICDs is a more recent guideline as compared to secondary prevention device therapy (Hunt et al., 2005). Those patients offered a secondary prevention ICD have already "survived” sudden cardiac death. Primary prevention ICDs are indicated for heart failure patients who are at significant risk for sudden cardiac death (Hunt et al.). These patients are asked to consider a potentially burdensome, yet life-saving therapy. We have a poor understanding as to why a significant portion of qualifying heart failure patients declines ICD therapy. This investigation added to our understanding of patient decision making surrounding primary prevention devices that can avert the most common cause of death in the United States.

Potential correlation between factors contributing to patient decision making surrounding end-of-life therapies and heart failure patient decision making surrounding primary prevention ICDs have not been explored. Extant literature on patient decision making and refusal of potentially burdensome therapies has involved issues surrounding advanced directives and treatments for people with limited life expectancies. These studies included populations with end-stage cancer, chronic obstructive lung disease, renal failure and heart failure, but without regard to ICD therapy. Primary factors that contributed to decision making under these conditions included: 1) appraised treatment burden (Fried, Bradley, Towle, \& Allore, 2002; van Kleffens, van Baarsen, \& van Leeuwen, 2004; Zikmund-Fisher, Lacy, \& Fagerlin, 2008), 2) patient knowledge and understanding (Fried et al.; Fried, O’Leary, Van Ness, \& Fraenkel, 2007; Verhoeff \& White, 2002), and 3) physician recommendation (Caldwell, Arthurs, \& Demers, 2007; Silvestri, Knittig, Zoller, \& Nietert, 2003; Verhoeff \& White). Further study was needed 
to assess whether these factors influence decision making surrounding ICD therapy in the heart failure population.

\section{Method of Study}

To explore the complex decision-making process of heart failure patients considering primary prevention ICDs, this investigator employed classic grounded theory. Classic grounded theory, founded by Glaser and Strauss (1967), is an inductive methodology that examines processes and focuses on the experiences and perceptions of participants who are attempting to resolve a problem. Classic grounded theory culminates in the emergence of a conceptual theory generated from and grounded in the data. The initial plan was for a quantitative study measuring the influence of various factors in a heart failure patient's decision to accept or decline ICD implantation. After a thorough review of the literature, clearly factors in the decision-making process had not yet been identified. A qualitative study was needed to tease out concepts that are important to heart failure patients as they face this complex decision. The dynamic nature of the complex decision-making process heart failure patients experience when trying to decide whether to accept an ICD was a perfect fit for classic grounded theory. Classic grounded theory methodology will be discussed in detail in chapter three.

\section{Theoretical Underpinnings}

Philosophical foundations provide cohesion when grounding research methodologies. A theoretical framework provides the lens through which data can be explained rather than just described (Aldiabat \& Navenec, 2011). Identifying theoretical underpinnings for a classic grounded theory study can be problematic as Glaser and Strauss (1967) did not identify a theoretical framework for their inductive method (Nathaniel, 2011). A popular notion is that 
symbolic interactionism is a fitting philosophical foundation for classic grounded theory based on Strauss's interactionist and pragmatist connections to the University of Chicago (McCallin, Nathaniel, \& Andrews, 2011). An assumption of symbolic interactionism is that human behavior and decision making are subjective and dynamic social processes. These assumptions can be related to the grounded theory premise that common social processes can be identified in human behavior. People make decisions based on the meaning of different concepts to them in a particular setting. The highly contextual nature of a classic grounded theory investigation appears suitable as an expression of symbolic interactionism.

The subjective meaning of human behavior, social process, and pragmatism were core themes of studies in symbolic interactionism (Mead, 1934). Early work in symbolic interactionism was conducted by German sociologist and economist Max Weber (1864-1920) and American philosopher George H. Mead (1863-1931). Findings of these early works included propositions that: 1) humans continually modify and interpret behavior based on the actions of others, 2) the meaning of action arises from social interaction, and 3) society is constructed through the process of human interpretation (Blumer, 1969). The philosophical school of pragmatism held that all beliefs have practical consequences. The meaning of thought is based on the subsequent actions (Bawden, 1904).

Symbolic interactionism researchers investigate how people create meaning during social interaction, how they present and construct the self or "identity," and how they define situations of co-presence with others (Blumer, 1969). Herbert Blumer, who studied with Mead at the University of Chicago, was responsible for coining the term, "symbolic interactionism," as well as for formulating the most prominent version of the theory (Blumer). Central is the belief that 
people act toward things based on what meaning those things hold. This classic grounded theory investigation was viewed through the lens of symbolic interactionism.

There may be no ideal choice as a theoretical underpinning for this study. The founder of classic grounded theory, Glaser, does not believe symbolic interactionism offers a foundation for grounded theory, but accepts the theory as a choice when choosing a sensitizing concept for classic grounded theory development (Nathaniel, 2011). Implantable cardioverter defibrillators represent a potentially life-saving technology for heart failure patients. However, these devices require an invasive procedure culminating in a potentially burdensome permanent therapy. The decision-making process heart failure patients encounter when faced with an ICD is not well understood. Framed by the contextual lens of symbolic interactionism, a classic grounded theory study was carried out to explore the decision-making process surrounding primary prevention ICDs. 


\section{CHAPTER 2: REVIEW OF THE LITERATURE}

A scant literature base exists for heart failure patient decision making surrounding primary prevention ICDs. A literature search was conducted using CINAHL, Medline, Pubmed, and PsychInfo databases. Inclusion criteria included English language and human, adult subjects. Key search terms included heart failure, decision making, and implantable cardioverter defibrillators. An ideal classic grounded theory review of the literature is only complete following the study, grounded in the data and findings (Guthrie \& Lowe, 2011). In an effort to provide a synopsis of the timely knowledge surrounding this topic, this literature review was ongoing throughout the course of this investigation employing the constant comparative method in comparing findings of the present study. The subsequent review will include the following categories of related literature: 1) patient decision making surrounding potentially burdensome life-sustaining therapies, 2) underutilization of implantable cardioverter defibrillators, 3) patient and provider perspectives of implantable cardioverter defibrillators , and 4) heart failure patient decision making surrounding primary prevention implantable cardioverter defibrillators.

\section{Literature Review}

Patient decision making. Patient decision making has been studied and theories exist in several disciplines. Matteson and Hawkins (1990) produced one of the early concept analyses in nursing literature. Relevant to qualitative research, Cannon-Bowers, Salas, and Pruitt (1996) proposed naturalistic decision-making theory with the assumption that decisions are made in a dynamic, contextual environment. Noone (2002) presented a more recent model of patient decision making with implications for nursing that defined attributes, antecedents, consequences 
and empirical referents illustrated by case studies. Decision making was defined as "the selection of a salient alternative or acceptable solution" (Noone, p. 27). Noone defined attributes of patient decision making as: 1) an intentional choice between two or more discrete options, 2) a decision based on recognition of a stimulus for action, 3) a choice that commits a person to a path of action, and 4) a decision that includes the expectation to accomplish a specific goal or goals. According to Noone, the choice is not limited to the most ideal alternative. Decision making requires a stimulus for action or recognition that a decision needs to be made. The intentional choice commits a person to action in order to achieve a desired outcome. Antecedents are events or behaviors that occur prior to decision making. These include a stimulus for action, appraisal of risks, awareness of options, gathering of information, and evaluation of risks, benefits, and alternatives. Consequences represent the outcomes of the decision-making process and include acceptance of the choice and/or reevaluation of the decision with subsequent actions. Empirical referents are observable outcomes of the decision (Noone). Patient preferences are an example of decision properties that could be measured.

Patient decision making surrounding burdensome therapies. The patient decisionmaking literature was refined to decisions surrounding potentially burdensome, life-sustaining therapies. The origin of the term "burden," as it relates to health care initially appeared in the doctrines of the Roman Catholic Church. These definitions and opinions have long been held as the basis for many health care provider decisions regarding extraordinary care. Pope Pius XII (1957), in response to an anesthetist's question as to when to begin and end use of mechanical respirators, remarked that one should be held to only "ordinary means" defined as not involving any "grave burden". Gillon (1986) described burdensome as disproportionate in relation to the 
expected benefits and the probability of benefit being attained. In more recent years, burden has generally been described in terms of effect on quality of life. For the purposes of this discussion, a treatment was defined as "burdensome" from the individual perspective of the patient. In weighing the merits of a therapy, patients balance the amount of potential pain and suffering (physical, psychological, emotional) with the desired benefit to be gained from the therapy.

Studies examining the patient decision-making process surrounding potentially burdensome life-sustaining therapies have primarily involved end-of-life treatment decisions for the seriously ill. The quantitative studies were exploratory, descriptive or correlational. Some investigations failed to identify methodology (Fried et al., 2007; Silvestri et al.,2003; van den Brink-Muinen et al., 2006; Zikmund-Fisher et al., 2008). Purposive sampling was often used with small samples (Caldwell et al., 2007; Silvestri et al.). Participants in these studies included those with end-stage cancer, chronic obstructive lung diseases, and renal disease often focusing on dialysis and advanced directives. A limited number of these investigations included heart failure patients, but did not include decisions surrounding ICD therapy. Common themes identified as contributing to end-of-life treatment decision making included: appraised treatment burden (Fried et al., 2002; van Kleffens et al., 2004; Zikmund-Fisher et al.), patient age (Rosenfeld, Wenger, \& Kawaga-Singer, 2001; Zikmund-Fisher et al.), views of loved ones (Rosenfeld et al.; Silvestri et al.; Verhoef \& White, 2002; van Kleffens et al., 2004), lack understanding by the patient regarding prognosis and outcomes (Fried et al., 2002; Fried et al.,2007; Verhoef \& White), and physician recommendation (Caldwell et al., 2007; Silvestri et al.; Verhoef \& White). Different levels of autonomy in decision making by patients were 
identified, but this variability did not necessarily relate to the patient's decision regarding lifesustaining therapy (Goldstein et al., 2008; Mueller, Jenkins, Bramstedt, \& Hayes, 2008).

Appraisal of treatment burden. Perceived predicted outcomes and side effects of the life-sustaining therapy appeared to hold significant weight in decisions regarding burdensome treatments (Rosenfeld et al., 2001; Verhoef \& White, 2002; Silvestri et al., 2003). In their phenomenological study examining features of potential life-sustaining therapies at end-of-life, Rosenfeld and colleagues also found that informants described treatments as desirable to the extent they could return patients to their valued life activities. Interestingly, this was one of the only studies that discussed quality of life issues as a determining factor in life-sustaining therapy decisions among the very ill.

Patient age. Patient age contributed to decisions surrounding potentially burdensome life-sustaining therapies. Rosenfeld and colleagues (2001) found that advanced age and the meaning of having lived a "full life" were relevant in the decision-making process. These findings were inconsistent with a study of Caldwell and colleagues (2007) that did not find advancing age to be a predictor of decisions regarding life-sustaining treatments. A related study by Zikmund-Fisher and colleagues (2008) randomly assigned terminally ill cancer patients to the role of patient, physician or "other" and to an age of 25 or 65 prior to reading a scenario about decision making between aggressive chemotherapy that could prolong life by two years or palliative care. In this study, patient age appeared to influence medical decisions made for others but not necessarily decisions made for themselves.

Views of loved ones. Experiences and opinions of family and loved ones held significant weight in decisions regarding life-sustaining therapies. Rosenfeld and colleagues 
(2001) found that decision-making authority actually shifted from the physician to family members as functional status declined. Consistent with those findings, Silvestri and colleagues (2003) reported that family recommendation tied for first place when 100 patients with advanced cancer ranked factors influencing their treatment preferences. Focus groups and in-depth interviews were used to explore the decision-making process of cancer patients considering alternative treatments in favor of burdensome conventional treatments (Verhoef \& White, 2002). A primary factor identified as contributing to treatment decisions was experiences of loved ones with similar treatments. van Kleffens and colleagues (2004) had similar findings. Their study exploring patient autonomy in decision making of 30 cancer patients who had refused lifesustaining therapies found that oncological treatments were primarily influenced by patients' own past experiences and experiences of loved ones.

Patient understanding. The degree of understanding the patient has regarding illness, prognosis and potential treatment outcomes affects decisions regarding life-sustaining therapies in very ill patients (Fried et al., 2002; Verhoef \& White, 2002). Over two hundred patients aged 60 and over with limited life expectancies were asked about treatment preferences. A significant portion of these patients was found not to comprehend the likelihood of adverse outcomes from various treatments. This lack of understanding contributed to acceptance of burdensome therapies (Fried et al.). Similarly, Fried and colleagues studied patients with advanced cancer. They found that the more details the patients understood about their potential disability from treatments, the less likely they were to agree to life-sustaining therapies. Verhoef and White reported poor understanding on the part of cancer patients trying to decide whether to forego conventional treatments for experimental ones. 
Physician recommendation. One of the biggest factors contributing to patient decision making surrounding potentially burdensome life-sustaining therapies appears to be physician recommendation. One hundred participants with newly diagnosed advanced lung cancer ranked, in order of importance, factors influencing their treatment decisions (Silvetsri et al., 2003). In this study, oncologist and family physician recommendation ranked first. Patients expressed supreme confidence in their physician's power to control the health of the patients. Similarly, Verhoef and White (2002) found communication with the physician to be a main contributing factor to treatment decisions of cancer patients. These patients also expressed the need for physicians to initiate discussion, truthful disclosure of all prognostic and treatment possibilities and a balanced expression of hope and truth. Consistent with these findings, Caldwell and colleagues (2007) reported that advanced heart failure patients viewed physician communication including truthful discussions about prognosis as important to their decisionmaking process.

Change in preferences over time. Patients are often asked to make major decisions regarding end-of-life care far in advance of imminent death. Van den Brink-Muinen and colleagues (2006) examined how patients' involvement in decision making therapies changed over time by comparing data from cross-sectional studies in 1987 and 2001 . Informed decision making with active patient participation improved over time, but primarily when younger patients were involved. Another observational cohort study examined whether willingness to receive life-sustaining treatments changed over time (Fried et al., 2007). In this study, heart failure patients were represented in a sample of elderly patients that included patients with advanced cancer and chronic obstructive lung disease. Thirty five percent had an inconsistent 
preference trajectory. This proportion rose to $48 \%$ when the decision involved risking physical or cognitive disability to avoid death. In other words, health status in the participants varied over the two year period, but the inconsistency in preferences over time occurred even in those participants with stable health status. In another study, patients admitted the potential for different preferences over time by expressing a need for prognosis discussions to take place during time of their optimal cognitive function (Caldwell et al., 2007).

Measuring willingness to accept life-sustaining therapy. Patient decision making has been measured in chronically ill patients considering life-sustaining, burdensome treatments. Fried and colleagues (2002) developed the Willingness to Accept Life-Sustaining Treatment (WALT) instrument to assess treatment preferences through appraisal of trade-offs involved in life-sustaining therapy. The instrument consists of six scenarios in which respondents weigh treatment decisions in four domains of importance to patients: 1) treatment burden, 2) treatment outcomes, 3) likelihood of the outcome, and 4) length of life following the treatment. Significantly higher WALT scores (indicating greater willingness to undergo burdensome treatment) correlated with those who ranked survival highest as compared to comfort or activity level. Rather than asking about specific treatment interventions, the WALT examined more global attitudes toward treatment burden.

Underutilization of internal cardioverter defibrillators. Despite robust data on improved survival, the preponderance of literature reveals that primary prevention ICDs for eligible heart failure patients are underutilized ( Hernandez et al., 2007; Lakshmanadoss et al., 2011; LaPointe et al., 2011; Ruskin et al., 2002; Thomas et al., 2007). The reasons for underutilization of these devices appear to be multifactorial including patient refusal to some 
degree. An analysis of the American Heart Association Get With the Guidelines heart failure database revealed that less than $40 \%$ of heart failure patients with a Class I indication for primary prevention ICD therapy had a device implanted (Hernandez et al.). The results of a retrospective chart review evaluating overall use of primary prevention ICDs in outpatient cardiology practices was published in 2011(Lakshmanadoses et al.). Of the 275 heart failure patients eligible for ICDs in that study, $43 \%$ had the devices implanted. Based on discharge diagnoses of eligible heart failure patients, an observational study by Ruskin and colleagues suggested that many patients who could have benefited from an ICD were not receiving the therapy. LaPointe and colleagues used hospital claims and registry data to identify patients hospitalized for heart failure with left ventricular ejection fractions of $\leq 30 \%$ for an eight-month period in 2007. Medical records were examined for ICD implantation. Underutilization of ICDs was confirmed with $13 \%$ of eligible patients not receiving a device.

Disparity in ICD use. The ICD underutilization literature suggests gender and racial disparities regarding ICD usage (Al-Khatib et al., 2012; Brown, Croft, Greenlund, Mensah, \& Giles, 2008; Curtis et al., 2007; Davis et al., 2006; Gauri, Davis, Hong, Burke, \& Knight, 2006; Groenveld, Heidenreich, \& Garber, 2005; Hernandez et al.,2007; LaPointe et al., 2011; Thomas et al., 2007). Several studies identified significantly fewer ICD implants among eligible women as compared to men (Al-Khatib et al.; Brown et al.; LaPointe et al.). Using data from The National Hospital Discharge Summary, trends in ICD implantation were tracked between 1990 and 2005 including the primary and secondary prevention indications. During the 15-year time span, the rate of ICD procedures was significantly greater in men than in women (Brown et al.). An analysis of the Duke University Hospital database eligible for an ICD revealed that of the 542 
patients eligible for an ICD $41 \%$ received the device. Implant rates were lowest among females (LaPointe et al.). A recent study that assessed the Get with the Guidelines Heart Failure Improvement Program found a significant improvement in ICD use over time in all gender and race groups as compared to early studies. Racial disparities had all but disappeared, but ICD use with women was still significantly lower than with men (Al-Khatib et al.). Women were also found to be less accepting of ICDs after implant (Spindler, Johansen, Anderson, Mortensen, \& Pedersen, 2004; Walker et al., 2004). Women continue to be under represented in all studies. Future investigations examining all aspects of heart failure, ICDs, patient perceptions and decision making ought to include more women.

Extant literature revealed racial disparity in ICD use among eligible patients (Groenveld et al., 2005; Hernandez et al., 2007; Thomas et al., 2007). An analysis of discharge records of elderly black and white Medicare beneficiaries between the years of 1990 and 2000 revealed significant disparity in ICD implants among blacks. However, equality rates of ICD use improved toward the end of the decade (Groenveld et al.). Data from the National Registry to Advance Heart Health were examined to determine which eligible patients received ICDs. Blacks were significantly less likely (30\% vs $41 \%$ ) to receive the device than were whites (Thomas et al.). Hernandez and colleagues found ICD implant rates lowest among black women (28.2\%), but only slightly better than implant rates among white women (29.8\%). The ICD usage rate for black men was $33.4 \%$ and $43.6 \%$ for white men. Equality rates in ICD use appear to be improving, but clearly, disparity still exists.

Device refusal. There is limited information on how many qualifying heart failure patients are offered therapy and refuse implantation. The success of a screening tool in 
identifying heart failure patients meeting the ICD indications was evaluated (Gravelin et al., 2011). That study reported that two-thirds of the patients offered ICD therapy refused implantation. Despite the small sample size of 17 , the number of refusals was surprisingly high. The LaPointe et al. (2011) study revealed a 17\% patient refusal rate among those who qualified for an ICD. Reasons for patient refusal of ICD therapy have not been established. Al-Khatib and colleagues (2008) organized a think tank of experts in cardiology, electrophysiology and government health agencies in part, to discuss possible reasons for patient refusal of ICDs. The expert consensus was that the patient's inability to grasp their risk for sudden cardiac death, fear of the implant procedure, and quality of life implications had the most impact on patient refusals.

\section{Patient and provider perspectives of implantable cardioverter defibrillator therapy.}

Patient understanding of life-sustaining treatment options and possible outcomes contributed to decision-making of seriously ill patients considering burdensome therapies (Fried et al., 2002; Fried et al., 2007; Verhoef \& White, 2002). Physician recommendation was a strong contributing factor to patient decision-making surrounding life-sustaining therapies for patients with advanced illness (Caldwell et al., 2007; Silvestri et al.,2003; Verhoef \& White). Based on research one can reason that patient and provider perceptions surrounding ICD therapy could have a profound impact on the patient decision-making process regarding whether to accept or decline primary prevention therapy. . Rodriguez and Young (2005) used a cross sectional design and held in-depth interviews with 30 pairs of patients and providers from a large outpatient clinic to explore concepts surrounding life-sustaining therapies. Patients and providers tended to view life-sustaining therapies in terms of four end-of-life goals: 1) extending life, 2) improving quality of life, 3) maintaining or improving certain biological functions, and 4) assisting the body for a 
temporary period of time. In the Rodriguez and Young study, patients believed that providers were more concerned with extending life as opposed to improving quality of life. Providers admitted struggling with conflicting quality-based and physiological patient needs.

Since patients view provider recommendation as an important factor in decision making about life-sustaining therapies, meaningful communication between patient and provider is vital (Caldwell et al., 2007; Silvetsri et al., 2003; Verhoef \& White, 2002). In a pilot study, interviews were administered to 22 physicians and 71 of their patients to explore the effectiveness of their communication regarding end-of-life treatment decisions (Desharnais, Carter, Hennessy, Kurent, \& Carter, 2007). Paired responses were used to identify communication problems with the hopes of designing interventions to improve physician-patient conversations. Concordance or similar response scores were low with the lowest concordance identified between patients with less formal education and physicians. In another study, 15 community-dwelling heart failure patients with ICDs were asked about potential barriers to communication with providers regarding end-of-life deactivation of the device (Goldstein et al., 2008). None of the participants in that study knew that deactivating the device was an option. All participants denied having an understanding about device deactivation.

Recently, Matlock and colleagues (2012) reported decision-making experiences of 295 patients with ICDs in a poster presented at Quality of Care and Outcomes Research in Cardiovascular Disease and Stroke 2012. Results of mailed surveys revealed that $19 \%$ of respondents did not want the device at the time of implant. Those who reported not wanting the device despite having it implanted tended to be younger, reported less participation in the decision-making process, and had higher decision regret. Hauptman, Chibnall, Guild, and 
Armbrecht (2013) explored patient and physician communication regarding ICDs through patient focus groups and recorded patient-physician discussions. Physicians failed to provide complete information to patients. Nearly all of the patients expressed learning more about the risks and benefits of ICDs after implant.

Specialty physician recommendation was found to be vital in patients' agreeing to ICD therapy in a recent study by Matlock, Nowels et al. (2011). Cardiologist and patient perspectives surrounding decision making and ICDs were explored through semi-structured interviews using a constant comparative method for data analysis. Cardiologists desired to adhere to the published guidelines and emphasized the benefits of therapy to their patients. Many patients who chose to receive an ICD reported that they simply followed their physician's advice. Patients who declined ICD therapy expressed concern over the necessity of the device. A great deal of variability was identified surrounding level of communication between patients and physicians regarding the ICD issue. A recent study produced sobering results regarding physician decision-making regarding ICD recommendations (Caverly, Al-Khatib, Kutner, Massoudi, \& Matlock, 2012). Surveys evaluated factors affecting cardiologist decisions to implant primary prevention ICDs and cardiologist feelings regarding ICD benefits. Only $38 \%$ of the cardiologists reported that patient preference mattered "a great deal" and $12 \%$ said that patient preference mattered "very little" or "not at all" when considering who should receive a device. For the physicians in the Matlock et al. study, mortality benefit and adherence to guidelines were paramount.

Anticipated mortality. Estimation of mortality could influence decisions regarding burdensome life-sustaining therapies. A study by Allen and colleagues (2008) compared heart 
failure patient and model predicted life expectancy. The Seattle Heart Failure Model was used to estimate life expectancy and a de novo questionnaire was constructed to examine perceptions of heart failure patients. Actual survival over 2.8 years was determined from the Social Security Death Index. The majority of heart failure patients overestimated their life expectancy by approximately $40 \%$. Those who were younger, less educated, and more symptomatic overestimated their life expectancy. Actual survival data demonstrated no relationship between the patient's level of optimism and estimated survival. The Seattle Heart Failure Model is a wellvalidated tool, but validation has not included racially diverse populations or those represented by substantial use of evidence-based medications and devices.

Anticipated mortality benefits of ICDs framed decisions made by 105 heart failure patients (Stewart et al., 2010). Survival expectations, device benefits and issues regarding deactivation of ICDs were explored. Sixty five percent of the participants surveyed already had primary prevention ICDs. Of those without an ICD, 47\% had previously discussed the device with their physician. The majority of the 105 heart failure patients eligible for primary prevention devices anticipated longevity of life, overestimated the survival benefits of the ICD and indicated reluctance to have the device deactivated even in the face of end-stage disease. The presence of a device did not change the overly optimistic perceptions of life expectancy or lives saved by the ICD.

Provider recommendation of ICDs. Provider recommendation and how treatment options are framed play a profound role in patient decision making (Caldwell et al., 2007; Silvestri et al., 2003; Strachan, Carroll, deLatt, Schwartz, \& Arthur, 2011). The provider's perspective when considering whether to recommend primary prevention ICD therapy could 
influence the patient's decision. Providers must assure well-informed patient decisions regarding potentially burdensome therapies. Most studies exploring attitudes of providers have been qualitative in nature and/or involved deactivation of ICDs at end-of-life. Physicians have expressed a general uncertainty and discomfort with end-of-life care and treatment options (Goldstein et al., 2008; Hauptmen, Swindle, Hussain, Biener, \& Burroughs, 2008; Mueller et al., 2008; Rodriguez \& Young, 2005; Sola \& Bostwick, 2005). To better understand physician decision making involving end stage heart failure patients, cardiologists, geriatricians and internists were surveyed regarding their perceptions (Hauptman et al.). Considerable gaps in knowledge and confidence regarding management options, hospice referral and ICD deactivation were found in this study. A great deal of uncertainty about clinical trajectory reflected the variability in clinical status of end-stage heart failure patients. Most physicians did not formally measure quality of life. A web-based survey was provided to physician members of The Heart Rhythm Society and to representatives from two device companies to describe attitudes and practices regarding deactivation of devices at end-of-life (Mueller et al.). Perceptions and practice differed significantly for pacemaker and ICD deactivation.

Perceptions regarding implantable cardiac devices among physicians appear to vary according to the physician specialty (Al-Khatib et al., 2011). A random sample of members of The American College of Cardiology was surveyed Al-Khatib and colleagues. Compared with non-electrophysiologists, electrophysiologists were significantly more likely to recommend a primary prevention ICD. Physicians surveyed were less likely to offer ICD therapy to an eligible elderly patient. In addition, the use of ICDs varied among regions in the United States. This regional variance in ICD use was further explored with focus on physician attitudes and 
recommendations surrounding ICD implantation (Matlock et al., 2011). Interestingly, physician recommendations were not found to differ significantly between areas of high and low ICD use. However, increasing trends towards variation in recommendations to frail patients and those with a limited life expectancy were identified. Further study is needed to identify interventions to enhance provider self-examination of values and beliefs in preparation for discussions with patients surrounding potentially burdensome life-sustaining therapies including ICDs for heart failure patients.

\section{Heart failure patient decision making surrounding primary prevention implantable} cardioverter defibrillators. There are scant data available on heart failure patients' decisionmaking process surrounding primary prevention ICD therapy. Once implanted, ICDs are generally well accepted by patients (Groeneveld, Matta, Suh, Yang, \& Shea, 2007; May, Smith, Murdock, \& Davis, 1995; Sola \& Bostwick, 2005). However, the decision-making process to accept or decline a device could be difficult for the patient. Twenty- two patients with symptomatic heart failure were interviewed to explore patient perceptions surrounding difficult decisions (Matlock, Nowels, \& Bekelman, 2010). A descriptive theme analysis identified active and passive decision-making styles. Active decision makers identified ICD implantation as one of the most difficult decisions they faced. The patients recognized potential side effects, family and quality of life concerns as concepts they weighed prior to their decisions. Passive decision makers did not identify decisions as difficult. Rather, they described trust in God, trust in their physician and the physician's power as determinants for their passive decision-making style.

The earliest publication detailing the exact process of a heart failure patient's decision to accept or decline a primary prevention was a case study presented by Dr. Peter Zimetbaum 
(2007) that told the story of a 59- year-old heart failure patient who ultimately declined ICD implantation. No conclusions were given, but the problem was introduced and contributing factors were identified. Factors influencing that patient's decision to decline an ICD included fear of a surgical procedure, uncertainty as to the "necessity" of the procedure or how many extra years the procedure would "buy". The patient also expressed concern regarding possible financial incentives for implanting physicians. A follow-up interview with the same patient was conducted two years after the original case study (Mattson-Dicecca \& Reynolds, 2009). The patient revealed that the transpired time had actually strengthened his decision to decline ICD therapy. The patient further shared doing well and not discovering a compelling reason to undergo this surgical procedure. In addition, recent device recalls were concerning to the patient.

Two studies, to date, have explored the specific process of heart failure patients' decision making surrounding primary prevention ICDs (Carroll, Strachan, deLatt, Schwartz, \& Arthur, 2011; Yuhas et al., 2012) . Both of these studies were qualitative in nature using grounded theory methodology. Even though both studies stopped short of theory development, each identified core themes from analyzed interview transcripts. In the first such study from Canada (Carroll et al.), physician recommendation and new awareness of the risk of SCD were motivators for patients to accept an ICD. Decision making preferences fell along a continuum of active to passive. Decision-making approaches were influenced by trust, social influence, and health state. Active decision makers asked questions and carefully appraised the information. Passive decision makers did not see the decision as theirs to make and tended to minimize their personal risk or expressed disinterest in comprehending the risks. In general, participants who 
accepted ICDs did not consider their advanced age or comorbid conditions as factors. However, those who declined an ICD tended to consider these factors into their decision. Of the 44 heart failure patients in the study, 23\% declined ICD implantation, but all had agreed to an ICD consultation.

In the second recent study exploring heart failure patients' attitudes about ICDs after being offered therapy but prior to ICD implant (Yuhas et al., 2012) echoed some of the findings of Carroll and colleagues (2011). Data were collected on 25 patients through phone interviews. Prior to the interviews, 13 had declined ICD therapy. No data were available on whether the interviews changed the minds of any patients. Five major themes emerged from the data demonstrating some striking consistency with the findings of the Carroll study: 1) Patients who refused ICD referral demonstrated a lack of full comprehension as to their personal risk of SCD, 2) Many who accepted ICD implant perceived the clinician as strongly recommending the procedure, 3) Both groups had concerns regarding device recalls and malfunctions, 4) Many participants demonstrated inaccurate beliefs regarding risks and lifestyle changes secondary to ICD implant, and 5) Those who refused ICDs had strong views regarding the appropriateness of invasive life-prolonging interventions. Both of these grounded theory studies were flawed in that they did not culminate with substantive theories. However, important and mostly consistent knowledge were gained regarding the decision to accept or decline primary prevention ICD therapy.

\section{Summary}

Limitations exist in extant literature. There is scant literature exploring heart failure patients' decision making surrounding primary prevention ICD therapy. The two grounded 
theory investigations identified similar themes surrounding heart failure patient decision-making regarding ICDs, but stopped short of formulating a substantive theory (Carrol et al., 2011; Yuhas et al., 2012). Glaser (1998) recognizes the tendency to selectively apply discrete aspects of grounded theory methodology to qualitative research, but contends that this practice is not compatible with the requirements of classic grounded theory. There is a broad literature base for patient decision making regarding potentially burdensome therapies, but most involve chronically ill patients appraising life-sustaining therapies and few include the heart failure population. The majority of studies surrounding ICDs have involved secondary prevention participants. These patients represent a different demographic in that their decision to accept or decline ICD implantation occurred after experiencing a life-threatening cardiac arrhythmia. The complex decision-making process a heart failure patient faces while appraising primary prevention ICD therapy has not previously been adequately studied. The investigation that will be detailed in chapter three further explores this dynamic decision-making process resulting in a new grounded theory. 


\section{CHAPTER 3: METHOD}

To explore the decision-making process and dilemmas heart failure patients experience when faced with prophylactic ICD implantation, the methodology for this study was classic grounded theory. Initially, a quantitative study that would measure the influence of specific factors in a heart failure patient's decision as to whether to accept or decline ICD implantation was planned. After a thorough review of the literature, factors in the decision- making process had not yet been identified. Prior to two recent grounded theory studies (Carroll et al., 2011; Yuhas et al., 2012) there had been no literature base for this topic. Initial studies should be qualitative in nature in order to tease out concepts that are important to heart failure patients during their decision-making process. Unlike previously discussed grounded theory inquiries, this investigation culminated in a substantive theory generated from and grounded in the data.

\section{Background of Classic Grounded Theory}

Classic grounded theory has been used as a qualitative research approach by health and social science investigators for decades to generate substantive theories that conceptually explain problems about which little is known (Field \& Morse, 1985). The grounded theory assumption of the contextual nature of data gathered to formulate new knowledge has appealed to nurse researchers (Field \& Morse). Grounded theorists hold that truth is subjective and relative involving the participant's perceptions of reality (McCallin et al., 2011). Theory emergence presumes uniformity and patterns in human behavior (Glaser, 1978). Therefore, data are contextual and dynamic, yet behaviors predictably occur in patterns. Concepts described as assumptions of classic grounded theory include: 1) multiple, complex realities must be viewed as a whole, 2) the investigator interacts with the participant rather than as an objective bystander, 3) 
humans act in a state of flux, and thus, cause and effect are not determinable, 4) the goal of inquiry is development of new knowledge, and 5) values are inherent to qualitative research (Lincoln \& Guba, 1985).

Grounded theory was developed by Glaser and Strauss (1965) through their research on hospitalized dying patients. The roots of this research technique are in the sociology methodologies of the 1960s. As opposed to the deductive methodology that prevailed at that time, classic grounded theory began with inductive logic viewing social reality as consisting of processes (Tarozzi, 2011). The methodology grew from a merging of Glaser's schooling in mathematical quantitative research and theory generation at Columbia University and Strauss's background in qualitative methodology and symbolic interactionism at The University of Chicago (Glaser, 1998). This novel methodology served to assign new scientific rigor to qualitative research. Strauss later joined Corbin (Strauss \& Corbin, 1990) in developing a somewhat different approach to grounded theory. This dissertation study followed a classic Glaserian methodology.

\section{Design}

According to Glaser (1978), classic grounded theory is an inductive method that looks at processes and focuses on the experiences and perceptions of participants who are attempting to resolve conflict. Classic grounded theory emerges based on the experiences of real people facing real problems (Nathaniel \& Andrews, 2007). The method culminates in the emergence of a conceptual theory generated from and grounded in the data (Glaser \& Strauss, 1967). Classic grounded theory investigations begin with broad research questions. Further inquiry is aimed at 
expanding on and clarification of data collected. This method ideally reveals categories that emerge from interview data that can be elucidated through further research (Glaser).

Theory is generated from the data without preconceived hypotheses (Glaser \& Strauus, 1967). Rather, grounded theory generates hypotheses from the data that can be further examined through future research. An incident is the unit of analysis, moving from data collection to conceptual theory with constant re-evaluation and modification (Glaser, 1978). The elements of classic grounded theory that will be explained in this chapter are: 1) substantive area of interest, 2) data collection, 3) open coding of transcripts of field notes, 4) constant comparison, 5) memoing, and 6) selective coding (Glaser, 1978).

The purpose of this classic grounded theory study was to explore and generate an explanatory theory based on data from heart failure patients who made the decision to accept or decline a primary prevention ICD. The substantive area of interest was heart failure patient decision making surrounding primary prevention ICDs. The study began with the research question: "What is going on during the decision-making process of heart failure patients considering primary prevention ICD implantation?" Sampling, data collection, data analysis and interpretation occurred iteratively. This researcher ultimately reviewed the data to illustrate the resultant theory. An ongoing review of the literature was not completed until after the conceptual theory had been generated. The relevance of existing literature cannot be understood until the main concerns of the participants are discovered through grounded theory (Glaser, 1998). This comparative literature review integrated existing works with the new conceptual theory. Areas in need of further research were identified. Human rights considerations, sampling, data collection, analysis, and theory formation will be detailed. 


\section{Human Rights Considerations}

Research ethics codes demand consideration of human rights when research is conducted on human subjects. To ensure protection of human rights, the proposal for this research was approved by the Institutional Review Board for the Protection of Human Subjects at West Virginia University. As participants were interviewed, information was collected from individuals as a part of this study. Minimal risk to participants was expected. Because the study was comprised of an interview only, the IRB deemed this an exempt study. A consent form was not required of the participants. Instead, a cover letter with a full explanation of the study was provided to participants (See Appendix C for cover letter). Interviews were conducted in a private area convenient to the subjects. Participants were identified by an assigned number only. All participant demographics (see Appendix D for demographic data collection form) and records pertaining to the study were kept under lock and key in a separate location-the private office of the researcher.

\section{Sample Collection}

Due to the narrow population of interest, people with heart failure who had been offered a primary prevention ICD, nonprobability sampling was employed. There was no randomization. The purpose of nonprobability sampling is to obtain an accurate representation of the population from which the sample was drawn so that accurate inferences can be made. Purposive sampling is one form of nonprobability sampling (Polit \& Beck, 2008). In purposive sampling, the sample is chosen based on characteristics of the group. Heart failure patients facing the decision as to whether to accept or decline primary prevention ICD therapy live a unique experience. Sampling for this study was purposive in that participants were referred to the investigator when 
identified as meeting study criteria. So as not to influence the decision, patients were interviewed after the decision to accept or decline ICD therapy had already been made.

The sample came from four separate cardiology practices (see Appendix E, F, G, and H for agency agreement letters). Three sites were relatively rural and a fourth site was more urban. Every effort was made to include equal numbers of males and females and acceptors and decliners of ICD therapy. Inclusion criteria consisted of: English-speaking, adult (age eighteen or older), and systolic heart failure for whom a primary prevention ICD was indicated and had been offered. Cardiology providers identified potential participants who met the inclusion criteria. A handout, prepared by this investigator, was available to these clinicians to give to potential participants at the end of an encounter. These handouts were written in lay terms and described the study as well as gave the contact information for this investigator and the dissertation faculty mentor. Potential participants were instructed by the clinician to contact the investigator by phone or email for more information if he or she was interested in participating (see Appendix I and $\mathrm{J}$ for handouts). Details regarding the study and procedures were outlined for the potential participant once contact with this investigator was made. If the patient wished to participate, a place and time was chosen for the interview that was convenient for the participant and provided necessary comfort and privacy for the interviews.

Sampling continued until saturation of the data had been reached and no new concepts were emerging. This investigation ended with a sample of 12 heart failure patients (see Appendix D for demographic information collected). Three of the 12 participants had declined ICD implantation. Females made up $25 \%$ of the sample. The challenge of recruiting females and ICD decliners was consistent with prior research. More than half of the participants had 
some college education. The participants represented a wide variety of ages. The youngest participant was 33 years old, and the oldest was 82 years of age. As a part of the demographic data, participants were asked what type of provider first recommended primary prevention ICD therapy. Half were first approached by a physician. The other $50 \%$ of the participants first received an ICD recommendation from an advanced practice or registered nurse. These data hold implications for nurses who are in a position to recommend burdensome, life-sustaining therapies.

\section{Data Collection}

The simultaneous generating and analyzing of data of a classic grounded theory study demand that the researcher collect his or her own data (Gynnild, 2011). The investigation began with a single, loosely structured, in-depth interview of each participant. Glaser (1998) defined the interview in its broadest sense as a conversation between equal participants, led by the subject. All device recipients were interviewed at least nine months after implant. Those who declined ICD therapy were interviewed at least one year after refusal.

Interviews took place in a casual setting to promote openness. The researcher's goal was to create an environment in which the participant felt comfortable enough to open up about what mattered most to him or her; instilling the spill (Glaser, 1998). The conversation began with a broad open-ended question to start the flow of conversation. The participant was encouraged to talk and allow the story to flow. The investigator then remained attentive (Nathaniel, 2008).

Data were recorded in the form of field notes immediately following each interview. As advised by Glaser (1998), interviews were not tape recorded. This allowed for more openness by the participant and more attentiveness by the researcher (Glaser). Glaser proposed that 
informants feel "safer" with disclosing meaningful and potentially sensitive information without recording. In the spirit of conversation, concentration remained on the original experience that was relevant to the participant rather than concentrating on audio or written notes (Sandelowski, 1995). Transcribing from every word would have gone against Glaser's (1998) basic principle of delimiting data through constant comparison and subsequent theoretical sampling. Transcription of field notes following the interview provided for efficient and meaningful data collection.

The process of classic grounded theory is guided by what is emerging from the data (Guthrie \& Lowe, 2011). Follow-up questions were based on what data had been discovered already, what appeared to hold importance to the participants, and what ideas required further description. Data collection ended when saturation of concepts had been observed.

\section{Data Analysis}

Classic grounded theory requires systematic analysis of large amounts of data. Field notes were transcribed immediately following interviews. Examples of field notes can be found in Appendix B. The researcher identified participant behavioral patterns in the data, gave names to concepts that best explained what was emerging, and ultimately generated a theory that accounted for the patterns of behavior found to be relevant to the participants (Glaser, 1978). Using constant comparison, data were analyzed, coded, and organized into concepts and categories.

Coding. Coding is an important aspect in the generation of a classic grounded theory and continues throughout the study. Concepts are the meaningful names chosen to best capture an emergent social pattern grounded in the data (Glaser, 2002). Open coding begins immediately 
after field notes are written. The field notes are then reviewed to identify key points as codes. Numerous codes were recorded in the margins of the field notes. Grounded theory uncovers patterns of behavior that participants may not understand or even be aware of (Glaser). Relationships between concepts were discovered. Grounded theory seeks to describe core processes rather than the entire incident (Glaser). This assumption provides for natural delimiting of reams of data. As a core category or the main concern of the participants emerges, coding becomes more selective around that core category as a natural way of delimiting the data. Theoretical coding begins the process of conceptualizing the codes for fit into an eventual theory (Glaser, 1978). The investigator begins to write conceptually instead of descriptively to lay the groundwork for the emerging theory.

Theoretical sampling. Theoretical sampling is the process by which the researcher decides, based on constant comparative analysis, what data would be most helpful to collect next (Glaser, 1978). The idea is to further develop the emerging categories that represent what is most important to the participants. Ultimately, code saturation was achieved when no new codes were emerging. So, the emerging theory was guiding future sampling and data collection.

Categories. Categories are groups of concepts brought together as themes that give a sense of what the participants are saying and expressing (Glaser, 1978). Categories emerge contextually. A core category(s) surfaces as one that resolves the problem for the participant (Glaser, 1978). This category relates to all other concepts and explains the behavior the study is investigating. The emergence of the core category was based on the assumption that each study participant had one main concern and one natural process for resolving the concern (Glaser, 1998). The core category accounts for most of the variability in behavior (Glaser, 1978). 
Memoing. Memoing represents the investigator's reflections on data and theoretical relationships among codes. In this way, the codes are raised to a conceptual level (Glaser, 1998). This process occurred throughout data collection and analysis. Ideas and possible hypotheses about connections between codes and categories came to mind at any time of the day or night. The researcher was driven to write up these memos immediately as they come to mind. Memos were recorded on separate pieces of paper and stored in a memo fund. Glaser emphasized the importance of memos being sortable. From the memo fund, memos were literally sorted and arranged by trial and error. Memos were sorted according to theoretical fit without any preconceived outlines. The use of computer software to force sorting into categories would negate the assumed need for researcher conceptualization (Glaser, 2002). Sorting and resorting of ever-emerging memos ultimately served to stage a grounded theory that accurately explained the process being studied.

Stages. Grounded theories that describe processes are generally comprised of stages (Glaser, 1978). These stages must account for variations in the problematic patterns of behavior. The stages in this study became evident as memos of core concepts and categories were sorted to explain the process. Properties were identified as characteristics that were common to all concepts in a particular stage (Goede \& Villiers, 2003). Sub-properties were also identified as attributes of properties. Properties and sub-properties add richness and meaning to categories and stages (Strauss \& Corbin, 1998). Conditions emerged and can be defined as factors that lead to or are necessary for an occurrence of phenomenon or transition from one stage to the next (Strauss \& Corbin). Transition from the first to second stage was contingent on a critical juncture that brought about a change in behavior. Critical junctures can be perceived or not 
perceived by the participant. But they determine whether or not the next stage of the process will be entered or if the participant will remain in the present stage (Glaser, 1978). Stages, conditions, properties, and sub properties were identified to enrich this theory that explains the decision-making process of heart failure patients considering primary prevention ICDs. Classic grounded theory does not prescribe the types, patterns, or numbers of concepts necessary for theory formation. Rather, all emerge from the grounded data.

Theory development. A grounded theory emerged as if taking on a life of its own. Sorting of memos led to staging of the new theory, and writing began. The theory developed around the core category. The theory accounted for the discovered patterns of behavior which were relevant and problematic for those who experienced the process.

\section{Methods to Assure Rigor}

An assumption of grounded theory is that science must be true to its subject matter (Martin \& Gynnild, 2011). Classic grounded theory was originally formulated to minimize preconceptions and thus ensure that the theory arises directly from the data (Simmons, 2011). Emerging concepts come directly from the data to ensure fit, relevance and workability. This methodology is much different from the way most grand theories are founded in conjectured concepts with forced fit and relevance (Glaser, 2002). Classic grounded theory assumes that the investigator has the ability to conceptualize. Classic grounded theory's underlying assumptions, based on "qualitative mathematics" present the opportunity for highly rigorous analysis (Gynnild, 2011). In order to assure rigor in this research proposal, Lincoln and Guba's (1985) criteria to assure qualitative research rigor, internal and external validity, reliability, and objectivity were addressed in terms of credibility, transferability, dependability, and 
confirmability as they apply to classic grounded theory and Glaser's (1978) criteria of fit, work, relevance, and modifiability. A general description of these criteria is provided. The criteria will be applied to data specific to this study in later chapters.

Credibility. Credibility is described as the subject-oriented truth value of the findings or how well the findings represent the realities of the participants (Lincoln \& Guba, 1985). The reality as interpreted by the investigator must represent truthfully the lived and expressed reality of the participants. Glaser's (1978) “grab” is reported in Lincoln and Guba's terms as an element being easily recognizable to others who have lived a similar experience. In Glaser's terms, the data must "fit" the ultimate findings. Credibility was achieved in this study by the constant comparative method of classic grounded theory. New data were compared to previous data. Sufficient time was required with subjects to build trust and glean rich data that were meaningful to that subject. Classic grounded theory's dependence on long, open interviews is consistent with this requirement. Furthermore, potential misinformation was guarded against by the constant comparative method (Glaser, 1978).

Additionally, Glaser's criteria of work and relevance (1978) provide for credibility. Glaser demands that the ensuing theory works insofar as the theory accurately explains the data as expressed by the participants. This is in contrast to a deductive method that strives to assure fit of data to a preconceived hypothesis. The findings and ultimate theory were relevant in that they truthfully represented the core concepts involved in the process being studied.

Transferability. To assure credibility the findings of classic grounded theory need to be modifiable or "transferable" beyond the scope of the proposed study. The conceptualization demanded of grounded theorists ensures transcendence beyond descriptive methods. Concepts 
last forever (Glaser, 2002). Glaser (1978) proposed that the findings of classic grounded theory were meant to serve future investigators as groundwork for transferable judgments. Transferability was confirmed using Glaser's (1978) hypotheses to assure truth by “correcting" data. The constant comparative method corrected any preconceptions or biases. Modification in classic grounded theory occurred in two ways. The findings were constantly being modified as new data emerged that presented new concepts. Secondly, theoretical sampling was employed to refine concepts as new concepts emerged. Speaking to transferability, the findings, due to the conceptual nature, can ideally be modified for use in other human processes that embody similar complexities and distress. The findings are transferable if they can be conveyed and relevant outside the current study (Guba \& Lincoln, 1981). Subsequent studies should modify the theory moving toward a final consensus (McCallen et al.,2011).

Dependability. To assure that the findings are dependable, classic grounded theorists examine the data, findings and interpretations by way of an audit. Audit techniques are advised by Lincoln and Guba (1985) as a way to examine all processes of the investigation. Findings of a grounded theory investigation are dependable because they were grounded in the data. Findings were constantly checked for supporting data. Since the reader does not have access to the data, the goal is to achieve a good fit between the patterns that have been labeled and words or phrases selected to represent that label (Martin \& Gynnild, 2011). All processes can be deconstructed back to the data.

Confirmability. Glaser (1998) proposed the "audit trail" as the main instrument to confirm the findings. The findings must be confirmed by way of an audit trail in the field notes, memos, codes and categories. A notebook was maintained of all participant data that could be 
constantly cross checked with emerging findings. Participants, interviews and memos were labeled for ease of identification in order to track notations. The ultimate test of confirmability in classic grounded theory is the emergence of a working theory that fits and explains the data.

\section{Summary}

Classic grounded theory as developed by Glaser and Strauss (1967) represents the method of inquiry for this study to explore heart failure patient decision making surrounding primary prevention ICD therapy. The study design was detailed and protection of human subject rights was assured. Sampling, data collection and analysis have been described. Methods to assure rigor have been expressed in terms of credibility, transferability, dependability, and confirmability.

The ultimate purpose of classic grounded theory research was generation of a theory to explain emergent patterns of behavior with the focus on the individual experiences of the participants. This methodology is most useful when the phenomenon of inquiry is a complex social process holding great meaning to the subjects. The decision to accept or decline an ICD, a life -saving yet potentially burdensome therapy emerges after a decision-making process. Heart failure patients face a dilemma when considering prophylactic implantation of an ICD. They must weigh the potential risks and benefits. Primary prevention ICDs now represent the standard of care for eligible heart failure patients offering a significant survival benefit from sudden cardiac death (Hunt et al., 2005). However, ICD implantation is an invasive procedure culminating in a potentially burdensome permanent therapy. This dilemma was particularly suited to classic grounded theory because of the importance of meaning and context in the decision-making process. A review of the literature revealed that concepts surrounding the 
decision-making process of heart failure patients considering primary prevention ICD therapy had only recently begun to be identified. The new grounded theory that will be discussed in the next chapter holds great implications for nursing and medical clinicians who strive for evidencebased, optimal patient outcomes while advocating for well-informed patient decisions. 


\section{CHAPTER 4: RESULTS}

This chapter presents a grounded theory of embodied revelation: the threat of sudden cardiac death for ICD candidates. The theory emerged from interview data collected and analyzed from heart failure patients who had experienced the decision-making process surrounding a primary prevention ICD. Analysis of in-depth interview data employed classic grounded theory methodology as detailed in Chapter 3. This new grounded theory describes the decision-making process heart failure patients experience when considering implantation of a primary prevention ICD. The study sample of 12 heart failure patients included three who declined a primary prevention ICD. These participants appeared to share the first stage in common with those who accepted an ICD. The two groups diverged following the first stage. Those who accepted ICD therapy experienced a revelation about his or her personal risk of sudden cardiac death. This revelation was embodied in two ways. The revelation came from the body in that the realization was contextually rich, based on feelings, beliefs, and values. Secondly, the revelation was embodied in that the decision to accept or decline a life-sustaining device represented a tangible expression of the revelation of personal risk. The declining group did not describe experiencing the critical juncture of grasping the risk of sudden cardiac death and therefore, did not move on through the process of accepting a primary prevention ICD. Those in the decliner group offered different perspectives on their decision-making process. Results of data from the decliner group will be discussed separately at the end of this chapter. 


\section{Summary of Embodied Revelation: The Threat of Sudden Cardiac Death for ICD}

\section{Candidates}

Figure 1. The Grounded theory of Embodied Revelation: The Threat of Sudden Cardiac Death

\section{For ICD Candidates}

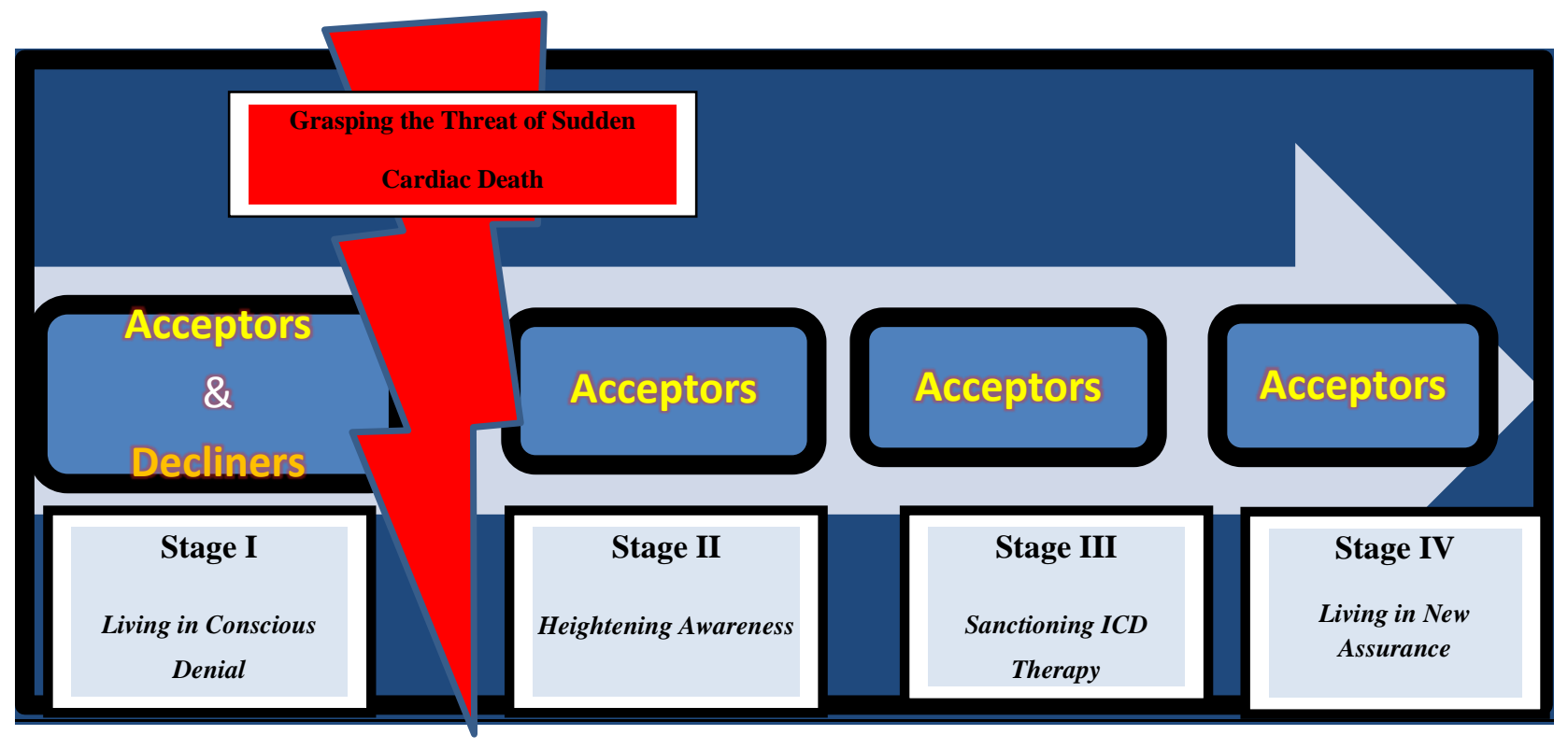

The grounded theory of embodied revelation: the threat of sudden cardiac death for ICD

candidates includes four stages and a critical juncture. Figure 1 depicts a model representing the new grounded theory. Major tentative hypotheses are summarized in Appendix A. Classic grounded theory demands that the researcher formulate his or her own concepts in generating theory rather than forcing data into the concepts of others (Glaser, 2002). This "conceptual license" (Glaser, 1998) transcends other descriptive qualitative methods by explaining the behavior of the participants rather than simply recounting the behavior. As a novice grounded theorist, through the constant comparative method, this researcher trusted the emerging theory and strove to formulate concepts that best described the main concerns of the participants. The first stage of the theory is living in conscious denial in which participants were aware on some 
level that they had heart failure and that they could die from this condition. The property of repressing risk awareness explains how mortality risk was either not completely comprehended and/or repressed. For those who ultimately accepted primary prevention ICD therapy, this first stage ended with the critical juncture of grasping the real threat of sudden cardiac death. A second brief stage of heightening awareness found the participant in the early stages of realizing the threat of his or her serious condition including the potential for sudden cardiac death as long as the condition of valuing longevity is met. The third stage of sanctioning ICD therapy occurred rather quickly as the patient who is feeling unsettled about their newly discovered risk agreed to have an ICD implanted sooner than later.

The final stage of living in new assurance occurs after ICD implantation and continues indefinitely. This stage describes how the heart failure patient continues to consider and support the decision made while often downplaying the rigor of the process. The patient is enjoying a more blissful state of assurance fueled by a new sense of security with having an ICD.

\section{Stage of Living in Conscious Denial}

Figure 2. Stage I of Living in Conscious Denial

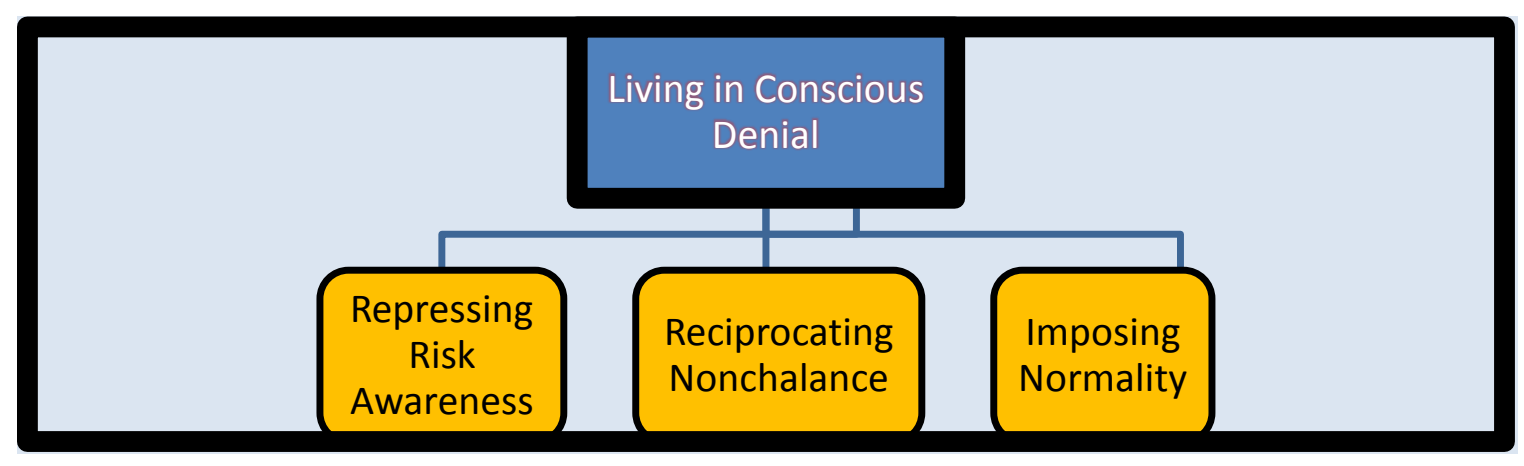


The first stage of living in conscious denial, depicted in Figure 2, includes three properties of repressing risk awareness, reciprocating nonchalance, and imposing normality. This stage embodies a continuum of patient comprehension of what it means to have heart failure. Participants maintain a low level of realizing threat. This is a stage of relative ease as long as the underlying awareness of mortality is not realized. The stage of living in conscious denial may last days to years and ends with the critical juncture of grasping the real threat of sudden cardiac death which sends the participant into the second stage of heightening of awareness.

Repressing risk awareness. Participants in the first stage of living in conscious denial are repressing risk awareness as they have some general knowledge of the risk for sudden cardiac death while not completely appreciating or validating their own personal risk. The ICD is viewed by the participants as an option. They do not recall being given any compelling reason to proceed with the implantation procedure. Agreeing to an ICD requires awareness of personal risk of sudden cardiac death AND the life-saving capability of an ICD. While repressing awareness, the patient does not believe he or she needs an ICD. One participant described this stage as "living in denial". Another participant explained that he wanted to deny that there was a real problem. An elderly gentleman admitted that he did not want to believe how serious his condition was. Participants try not to think about the significance of their condition or the risk of death. In most cases the idea of an ICD had been broached by a health care provider more than once, but was perceived by the participant as a casual reference.

Reciprocating nonchalance. The property of reciprocating nonchalance explains how participants and health care providers share a casual attitude about the risk of sudden cardiac 
death that is mutually self- perpetuating. The heart failure patient, during conscious denial, does not dwell on topics of sudden cardiac death or ICDs. Discussions initiated by clinicians on these topics are perceived as being nonchalant. This perceived casual attitude on the part of the health care professional perpetuates the patient's conscious denial and nonchalance regarding issues surrounding sudden cardiac death and ICDs which in turn facilitates further nonchalance on the part of the clinician. Participants implied during interviews that clinicians may have delivered the message casually in an effort not to alarm the patient and engender hope. Implantable cardioverter defibrillators were perceived as an option. Casual discussions with health care providers about heart failure, sudden cardiac death, and ICDs actually reinforce the first stage of living in conscious denial for the patient. The casual nature of conversations about an ICD affirms the perception that the patient is not seriously ill and the ICD is not really needed. During this first stage of relative ease, participants do not ask many questions or prolong ICD discussions. These conversations are avoided and/or cut short by both the participant and the health care provider. Realizing any real threat would likely bring about some level of anxiety.

Repressing risk awareness and reciprocating nonchalance offer a comfort level to both participants and providers. Participants explained the casual nature of discussions with providers by talking about how busy clinical staff members were. One patient remarked "they never took the time to really explain things". Participants seemed to equate the time and care taken with explanations with the amount of importance the provider attached to a topic. Participants said of physicians "He didn't explain things right", "He said that we should probably do this at some point", "It didn't sound like a big deal", "They just sort of mentioned it in passing". In turn, the casual response by the patient appeared to affirm the casual nature taken by the provider as if to 
say that the patient was not "ready" for such discussions. One male participant explained “Another cardiologist had brought it (the ICD) up earlier. I didn't take it seriously. They were always really busy, never spent much time".

Imposing normality. Imposing normality represents another property of living in conscious denial. While they are repressing risk awareness, participants demonstrate the need to prove to themselves that their risk is not only low, but that they are "normal" or "okay. In an effort to keep the reality of a life-threatening condition repressed, the participants concentrate on more mundane life issues or how much worse off others are. In some cases, they test themselves physically to prove fitness. One high school music teacher explained that he was commonly up all night worrying about music, but admitted to giving little thought to his serious medical condition. A few participants talked about how they kept from worrying about themselves by thinking about others with "worse EFs (ejection fractions)". In some cases imposing normality was manifested as participants felt the need to prove how well they were by testing their hearts with extreme physical activities. Upon being discharged after a silent myocardial infarction, one male participant decided to immediately walk five miles. "I just wanted to see if I could do it". Another gentleman explained how he felt great after his bypass surgery and did things he probably should not have done. A female participant prided herself in not missing exercise sessions regardless of her symptom level on any particular day. 


\section{The Critical Juncture of Grasping the Threat of Sudden Cardiac Death}

For acceptors of primary prevention ICD therapy, the first stage of living in conscious denial ended with the critical juncture of grasping the threat of sudden cardiac death. Decliners of primary prevention ICD therapy either did not experience the critical juncture or did not render the risk of sudden cardiac death important enough to warrant an invasive prophylactic device. Therefore, decliners remain in the first stage without progressing to the next stage. The heart failure patients who ultimately accepted primary prevention ICD therapy suddenly comprehended the reality of their personal risk for sudden cardiac death as the second stage of heightening awareness began. Participants could no longer take comfort in repressing their risk awareness: "I realized I wasn't getting better. They told me I needed it (the ICD). I needed it", "Once they explained it to me, I knew I had to have it", "Suddenly they say I'm in bad shape", "I didn't want to be dead", "It's a life-saving thing. My heart is really THAT bad. The hard part was accepting how bad my heart was". The critical juncture represents a time of epiphany and heightening anxiety over the newly realized threat of sudden cardiac death without the lifesaving device implanted. 


\section{Stage of Heightening Awareness}

Figure 3. Stage II of Heightening Awareness

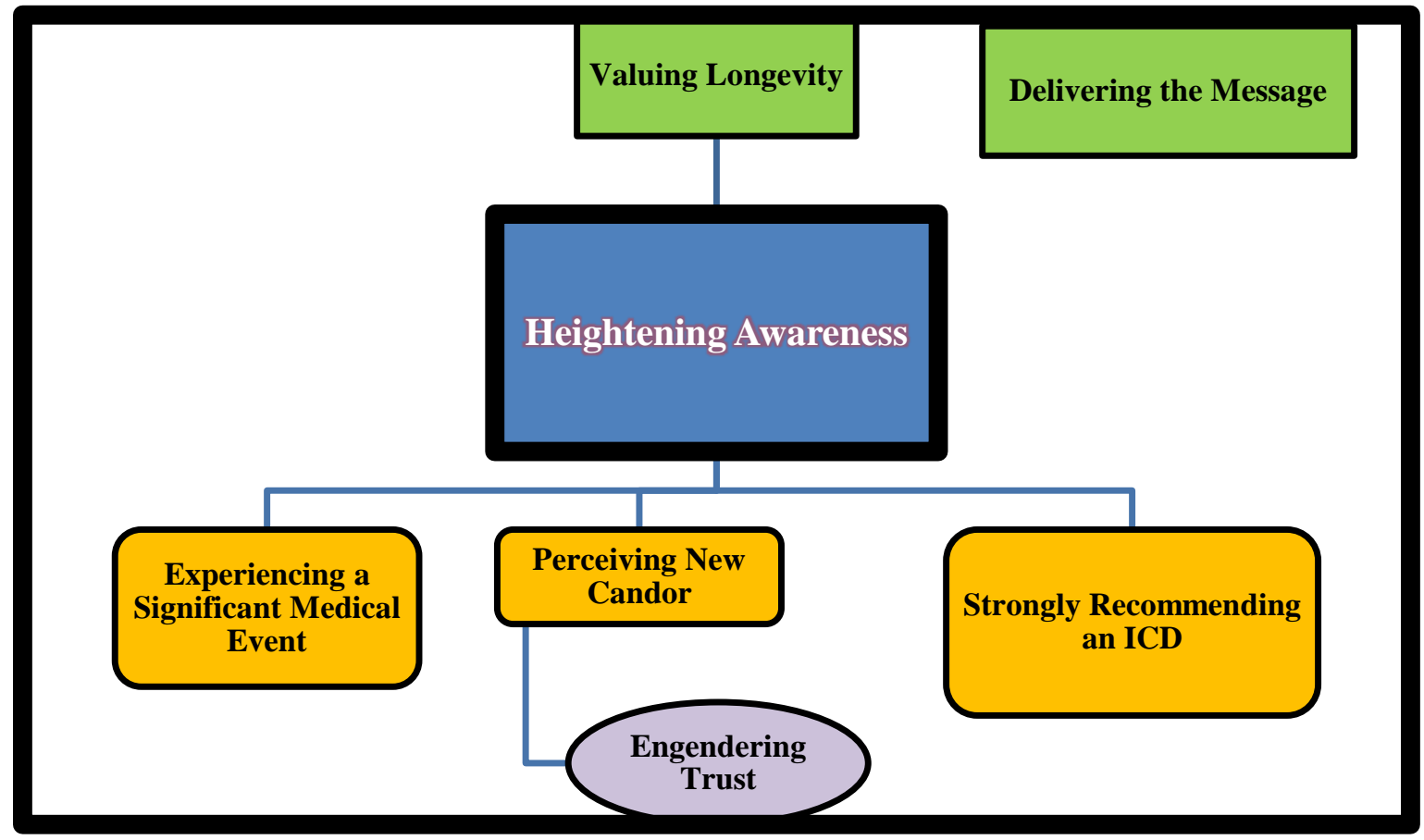

The second stage of heightening awareness, depicted in Figure 3, includes one condition of valuing longevity, two properties of experiencing a significant medical event and perceiving new candor and two sub-properties of engendering trust and delivering the message. This stage begins with the critical juncture of grasping the real threat of sudden cardiac death. Only those participants who ultimately accepted ICD therapy experienced the critical juncture while moving on to heightening awareness. Decliners of ICD remain in the first stage of conscious denial.

They did not experience the critical juncture in the same way acceptors of ICDs did and therefore, never moved onto this second stage. Yuhas and colleagues (2012) who used grounded theory methodology to collect and analyze data also concluded that decliners of primary 
prevention ICD lacked full comprehension of their risk of sudden cardiac death. For acceptors of ICD therapy, the state of relative ease of the first stage disappears as mild anxiety begins to crescendo with heightening awareness.

Experiencing a significant medical event. The heightening of awareness of personal risk of death often follows a significant medical event. The medical event served to frighten the patient and uncover the reality of the severity of his or her condition. The medical events that participants experienced were not arrhythmic in nature. In other words, they had not experienced a life-threatening arrhythmia that would have deemed ICD therapy a secondary prevention. Examples of significant medical events that triggered heightening awareness included hospitalizations for acute congestive heart failure and cardiac testing that reconfirmed the weak condition of their heart muscle. One participant described a hospitalization as a "wake-up call from God". Two participants were hospitalized for second myocardial infarctions. Upon hearing results of a cardiac testing one female participant recalled thinking “suddenly I'm in bad shape". Another participant explained how he "blew the front part of my heart out" with another heart attack. Two patients talked about new and bothersome symptoms that confirmed their condition. "After being in the hospital, I could no longer make my bed without getting tired. I knew I wasn't getting any better".

Perceiving new candor. In all cases heightening of awareness is precipitated by newly perceived candor displayed by the health care provider. Following a significant medical event, discussions surrounding sudden cardiac death and ICDs suddenly took on a much more serious tone. The patient perceived new candor as the clinician used simple language in delivering the message. The provider was now frank with the heart failure patient about the significant risk of 
sudden cardiac death and the life-saving capabilities of an ICD. One participant described being told he had "sudden cardiac death syndrome". Another patient recalled being told that he would have an episode and either he would have the device that would likely save his life or he would not have the device and die". Participants described the property of perceiving new candor as "they were straight up with me", "I could die. That got my attention". At some point during candid discussions, the provider strongly recommended a primary prevention ICD. This recommendation was usually also precipitated by a significant medical event. Also noteworthy, this suddenly perceived provider candor initiated a property of engendering trust from the patient that ultimately strengthened the decision to follow the provider's advice to get an ICD. Participants in Carroll and colleagues' (2011) grounded theory study also reported new awareness of sudden cardiac death risk and physician recommendation as motivators to accept ICD therapy.

Engendering trust. Engendering trust represented a sub-property of perceiving new candor. In some cases, the patient was experiencing a first encounter with this specific clinician who strongly recommended an ICD. In other cases, their known health care provider displayed a new frankness regarding sudden cardiac death and an ICD engendering a heightened trust on the part of the heart failure patient. Almost all the participants discussed how much they trusted the provider who recommended the ICD. Patients talked about the time the provider took in explaining things. Quality time spent between patient and provider took on a new significance. The trusted clinicians spent time explaining things frankly but completely. Patients described the clinician who strongly recommended the ICD in the following ways: "He makes you feel like you're his only patient", "I trust the doctor and his staff to know what they're doing", "I knew he 
was a good doctor. He really explained everything", "He even drew diagrams so I could understand", "They were straight up with me so I trusted them". The enhanced trust in the candid provider further strengthened the grasp of sudden cardiac death risk. The patients could no longer deny an understanding of the real chance of death as the risk had been carefully and clearly explained by a trusted provider. This concept of trust in the provider also emerged from the Yuhas et al. (2012) grounded theory study as contributing to the decision to accept a primary prevention ICD.

Strongly recommending an ICD. As the heart failure patient gains heightening awareness and begins to grasp the threat of sudden cardiac death, the clinician strongly recommends an ICD. The previously perceived option of a device is now perceived as being strongly advised. The strong recommendation for an ICD is vital to the critical juncture of grasping the threat of sudden cardiac death. The stronger the awareness of sudden cardiac death risk is, the stronger the recommendation for an ICD is perceived. How the message recommending the ICD is delivered determined how strongly the recommendation was perceived.

Delivering the message. Delivering the message represents a condition of strongly recommending an ICD. The provider who, in many cases, formerly presented a primary prevention ICD as an option is now perceived as strongly recommending the device. Participants explain the recommendation as "He just told me I needed to have this done", "I was told I had no option", "Would I rather be working or be dead ?". The stage of heightening awareness will crescendo with the critical juncture of grasping the threat of sudden cardiac death only if the condition of valuing longevity is present. 
Valuing longevity. Valuing longevity is a condition of heightening awareness. Those patients who agreed to a primary prevention ICD described placing a high value on living longer. Decliners of ICD therapy expressed a more deterministic view that events are fixed in advance and that we have little power to change the basic course of life events. The declining group did not embody the condition of valuing longevity. Participants who agreed to an ICD discussed the importance of sustaining life to them: "They told me it (ICD) saves lives, and I was interested in living", "I wanted to live longer", "Life is worth living", "I wanted to be around for my grandbabies." "I could die. That got my attention".

\section{Stage of Sanctioning Implantable Cardioverter Defibrillator Therapy}

Figure 4. Stage III of Sanctioning ICD Therapy

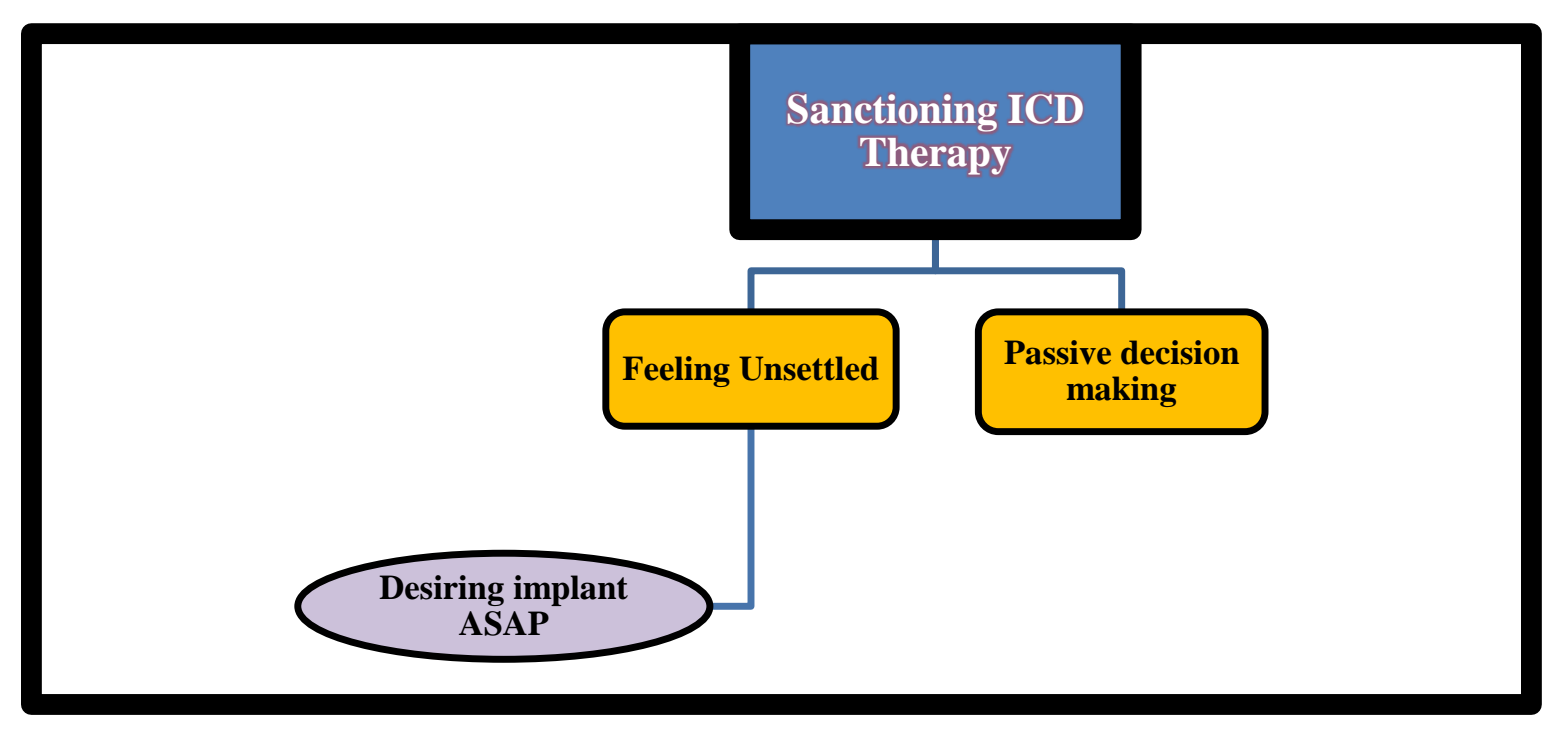

The third stage of sanctioning ICD therapy, depicted in Figure 4, includes two properties of feeling unsettled and passive decision making, and a sub-property of desiring implant as soon 
as possible. The stage begins after experiencing the critical juncture of grasping the threat of sudden cardiac death through the heightening awareness of stage two. The heart failure patient is experiencing some degree of anxiety related to the unearthed understanding regarding the risk of sudden cardiac death and the life-saving capabilities of an ICD. The decision to accept the device occurs quickly as the patient takes on a passive role and acquiesces to the provider's recommendation. Although numerous interviewees expressed their desire to be active participants in their health care decisions, they exhibited relative ease in agreeing to the device their trusted health care professional had recommended. Participants described the decision to accept an ICD as "I didn't want it to be my decision", "The doctors know a lot more than I do", "When they tell me I need something for my heart, I listen". The participants not only promptly agreed to a primary prevention ICD, they requested the device to be implanted as soon as possible.

Feeling unsettled. Participants in the third stage of sanctioning ICD therapy experience anxiety over being vulnerable to sudden cardiac death without the benefit of an ICD. The comfort of conscious denial is gone. The statements of participants quoted above during the critical juncture reflected an unsettled feeling; a feeling of urgency until they had the device implanted. Now that they understood the risk, they not only agreed to an ICD, but requested the procedure immediately. The unsettled feeling remains until the device is implanted and a sense of reassurance returns.

Desiring implant as soon as possible. A sub-property of feeling unsettled is the heart failure patient's desiring implant as soon as possible. Fueled by anxiety surrounding sudden cardiac death, the life-saving capabilities of an ICD, valuing longevity, and the provider's strong 
recommendation for the device, the patient now requests the ICD be implanted as soon as possible. Participants described this property as: "My only question was when.", "It was now or never.", "I just wanted to get it done”. One patient explained how agonizing the eight-week waiting period of optimizing medical therapy prior to implant was for him. He wore an external "life vest" defibrillator prior to the ICD procedure being approved by his insurance company.

Passive decision-making. Participants who accepted primary prevention ICD therapy were generally found to be passive decision makers. Those who accepted the device appeared to gladly agree to the device their trusted provider had strongly recommended. Participants explained how they preferred not to be expected to make such an important decision. They preferred leaving the decision up to the provider and or family members: "They know what's best for me", "I liked when my family stepped in. I didn't want to be the one to make that decision". Accepting patients talked about their lack of qualifications to make such a big health care decision: "I'm not smart enough. They (the doctors) know a lot more than me". In fact, clinicians who promoted autonomous patient decision making regarding an ICD were not trusted as much. In describing one such provider an ICD-accepting patient remarked "How could he expect me to make that decision? He's supposed to know a lot more than me. I want him to tell me what to do". 


\section{Stage of Living in New Assurance}

Figure 5. Stage IV of Living in New Assurance

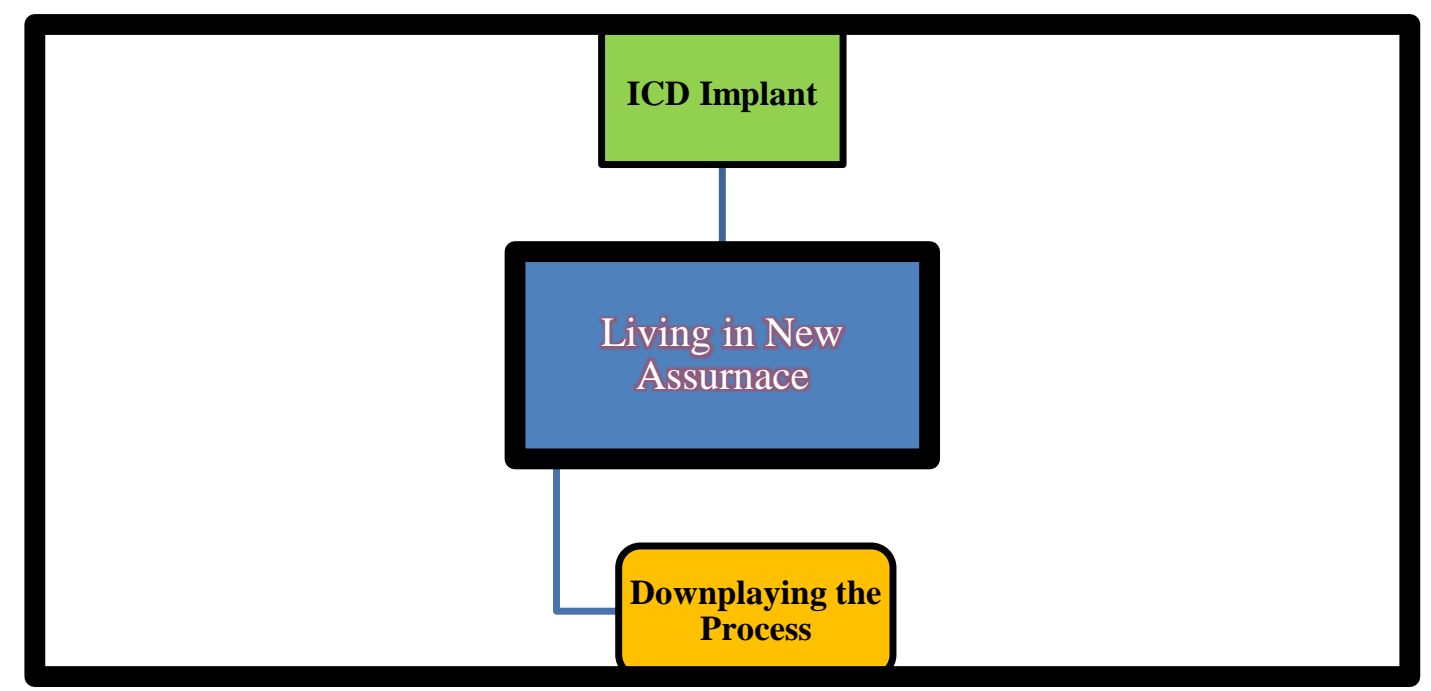

The investigator includes a final stage, stage IV, of living in new assurance because, for acceptors of ICD therapy, the decision-making process surrounding the ICD continues in the sense that the heart failure patient continues to consider, verbalize about, and support the decision made. This stage has one condition and one property (see Figure 5) and is preceded by the condition of the ICD implant. Decliners of ICD therapy also appear to live at peace with their decision not to have the implant procedure, remaining in the first stage of conscious denial. But that property for decliners does not constitute a new assurance which only comes after the patient has a life-saving device implanted. A property of living in new assurance is downplaying the process which explains how participants, now relaxing into a new reassurance, downplay the implant procedure and in some cases, the entire decision-making process.

Downplaying the Process. During the final stage of living in new assurance, the participants uniformly described the ICD procedure and recovery period including the present as 
something on the lines of "no big deal". Those who had an ICD implanted downplayed the rigor of the decision-making process and once again appeared to repress the seriousness of their condition. This stage is embodied by a sense of nonchalance and ease similar to what was expressed in the first stage of conscious denial. However, the new ease is now fueled by a sense of reassurance that the patient is no longer vulnerable to sudden cardiac death. One participant remarked that "I'd rather have this done than go to the dentist". Another gentleman downplayed the procedure by saying “I don't even remember the surgery. It was no big deal. They just put it in". Another participant diminished the decision by saying "I know I'll probably never even need it (the ICD)". As in the first stage, participants often "test" themselves in an attempt to return to normality. One female participant explained that she still had her bucket list that she planned to get to. Participants expressed no regret concerning their decision to accept a device. They were at peace with their decision. They often spoke of counseling others regarding the inconsequential ICD procedure. One female participant went into great detail about why she advised a friend of hers to get an ICD. Another patient described his decision to accept the device as an easy one by recounting all the medical details of his condition.

During this final stage, acceptors had the need to reiterate their trust in the health care professional who recommended the ICD by detailing the provider's professional attributes. Heart failure patients who almost unanimously made the abrupt decision to accept the ICD solely on the recommendation of their provider, now expressed the importance of considering loved ones when deciding to have the ICD implanted. Participants, in support of their decision, discussed how the decision impacted their loved ones. They often spoke of wanting to live for 
specific family members and viewed the decision to have the ICD implanted as relatively selfless. All of these feelings appear to contribute to living in new assurance.

\section{Declining Primary Prevention Implantable Cardioverter Defibrillator Therapy}

The heart failure patients who declined a primary prevention ICD were forthcoming about their reasons for not accepting device therapy. The decliner participants share the first stage of living in conscious denial with those who accepted ICD therapy. All three decliners remain at peace with their decision.

Living in conscious denial. The participants who declined primary prevention ICD therapy remain in the first stage of living in conscious denial. There was no apparent epiphany as to personal risk of sudden cardiac death or there was no validation that the risk was critical enough to them to accept an invasive prophylactic device implant. Therefore, decliners did not move on to the second stage of heightening awareness. They expressed no regrets about their decision to decline ICD therapy.

Repressing risk awareness. The decliner participants, remaining in conscious denial, maintained various degrees of understanding as to their personal risk of sudden cardiac death. This group did not appear to grasp the fact that symptom level or how one feels with heart failure has little to nothing to do with the risk of sudden cardiac death. Declining participants downplayed their heart failure condition and the ICD issue. One patient preferred to talk about other people he knows with "much worse" medical problems as compared to his medical issues. He described his heart failure as a "silly problem" that "no one wanted to hear about" as compared to the more serious health conditions of others. He also remarked that "ICDs are for very sick people". He did not view himself as such a person. Another decliner expressed pride 
in his decision to decline an ICD. He explained that he never felt his condition "warranted" such an invasive procedure as an ICD.

Reciprocating nonchalance. The property of reciprocating nonchalance also emerged from the decliner data. One participant was approached only once about an ICD. The situation was presented to him as "a little heart problem". He was told that he "probably needs a defibrillator". Another participant explained that his doctor did tell him about sudden cardiac and the ICD, but when the patient was not interested, the subject was dropped so the participant did not perceive the issue as a vital one. Since that time, the ICD had been brought up in a similarly casual nature. Declining participants discussed ICDs and sudden cardiac death in casual terms similar to how they described discussions with health care providers.

Imposing normality. There was evidence of the property of imposing normality among the declining group. These participants talked about their good quality of life that they treasured. One gentleman explained how he makes sure he is very physically active and remains able to "everything" he wants to do. Another patient actually described ICD therapy as "stepping out of normality" which is something he never wished to do.

Missing the critical juncture and heightening awareness. The declining group did not experience the critical juncture of grasping the threat of sudden cardiac death. The second stage of heightening awareness was never entered and the condition of valuing longevity and properties of that stage were not observed in the decliner group.

Not valuing longevity. Not valuing longevity emerged as a property in the decliner group instead of the property of valuing longevity for the ICD accepting group. Not valuing longevity describes the decliners' somewhat deterministic view of life and death. They did not 
describe a high personal value for sustaining life. Rather, they spoke in terms of the course of one's life and timing of death being predetermined. In speaking of his heart attack 10 years ago, one gentleman said "Maybe I should have died back then". He went on to explain "My life hasn't been easy. I'm not too keen on life". In talking about death, another declining patient explained 'I'm not big on insurance policies. What happens happens. You can't fight it". Another decliner described living "day by day" and "not worrying about tomorrow". He remarked that "we're all going to die". What is not clear is whether or not the decliners who lacked high esteem for longevity would have considered primary prevention ICD therapy if they had experienced a significant medical event, perceived new candor, and perceived a strong ICD recommendation. One participant appeared to try and answer that question with the remark "I don't think anyone could have ever talked me into it (the ICD)".

Not experiencing a significant medical event. None of the three patients who declined primary prevention ICD therapy had experienced what they considered to be a significant medical event. One participant explained that he has "felt fine", "It (heart failure) doesn't affect me". He was not "convinced" that his condition warranted such an invasive procedure. Another patient explained that he had not had any hospitalizations in years. He commented "If it ain't broke.....". The third decliner remarked that he felt "the same as when my EF was $45 \%$ ".

Not perceiving new candor. Perceiving new candor was lacking in the ICD decliner group. These participants did not feel they were ever given a good enough reason to accept the device. They spoke about heart failure and sudden cardiac death with relative nonchalance as the accepting group did while in the first stage of conscious denial. None of the decliners described any kind of candor expressed by providers regarding the risk of sudden cardiac death of ICD 
therapy. Acceptors of ICD therapy not only perceived new candor from the clinician, but this candor enhanced the trust the patient had in the provider. Those in the decliner group did not express remarkable trust in their health care providers. To the contrary, the decliners recounted stories expressing lack of trust in providers. One decliner, in reference to the clinician who presented the ICD, remarked "I just don't trust people. I question everything". The two other decliners recounted stories about how they had been wrongly advised by a medical professional and were relieved they had not followed the advice. One decliner described how he felt providers were "too eager" to recommend procedures "without looking at all the aspects". That participant felt that patients should better educate themselves to be prepared for difficult medical decisions. No one in the decliner group perceived new candor or receiving a strong recommendation for an ICD from a provider. How the message was delivered did not precipitate any in the declining group to accept a primary prevention ICD.

Active decision making. An unexpected divergent finding between the two groups of participants was that acceptors and decliners of ICD therapy exhibited differing decision-making styles. As the acceptors of primary prevention ICDs displayed a preference for passive decision making, the decliners all expressed qualities of active decision-making. To clarify, acceptors of ICDs exhibited a preference for passive decision making in that they generally desired not to make the decision alone. But, they actively expressed a preference to have the decision made for them by their trusted provider. On the other hand, decliners of ICDs preferred more autonomy in their resolution. One decliner explained medical decision making as: "It's a very personal decision. Everyone needs to make his or her own". Another decliner spoke about a friend of his 
who had received an ICD saying "They talked him into it". Another decliner remarked that he "would never blindly follow orders".

This chapter has presented a new grounded theory of embodied revelation: the threat of sudden cardiac death for ICD candidates. The theory, grounded in participant interview data, explains the decision-making process heart failure patients face when presented with ICD therapy. Stages, conditions, properties, sub-properties, and a critical juncture emerged and were detailed. The same theory was discussed in terms of those who declined ICD therapy. Although the first stage of the theory was shared between the accepting and declining groups, the divergence of the declining group was described. A summary of the theory, comparisons with extant theory and literature, limitations of the study, and implications for practice and further research will be discussed in chapter five. 


\section{CHAPTER 5: CONCLUSIONS}

This chapter presents discussion surrounding the new grounded theory of embodied revelation: the threat of sudden cardiac death for ICD candidates. The theory describes the decision-making process of heart failure patients considering primary prevention ICD therapy. The concept of embodied revelation encompasses the core concept for both acceptors and decliners of primary prevention ICD therapy. The threat of sudden cardiac death was realized on some level by all participants. For some, the risk was always understood to varying degrees. For others, the enlightenment regarding personal risk of sudden cardiac death was exposed suddenly following a significant medical event and/or a strong recommendation from a provider. Embodied, as used in the title of this dissertation, is defined as made concrete or perceptible (Mirriam-Webster, 2013). The decision to accept or decline a life-sustaining device is an embodiment or a tangible expression of what sudden cardiac death, the ICD and desire for longevity mean to a particular heart failure patient. In this way, meaning is a revelation that comes as a result of the individual's interpretation of thoughts and feelings about issues surrounding ICD therapy. The investigator addresses the following in this final chapter: 1) a summary of the theory, 2) comparison of theory with extant literature, 3) critique of the theory, 4) implications for future research, 5) implications for clinical practice, and 6) bioethical considerations. 


\section{Summary of Embodied Revelation: The Threat of Sudden Cardiac Death for ICD Candidates}

The theory of embodied revelation: the threat of sudden cardiac death for ICD candidates consists of four stages and a critical juncture. The first stage of living in conscious denial describes patients as aware on some level that they have heart failure and that they could die from the condition. Participants enjoy a relative ease during this state as they are repressing risk awareness with regard to sudden cardiac death. Conscious denial is partially maintained by the property of reciprocating nonchalance. Participants and their providers converse regarding serious issues such as sudden cardiac death using a casual tone that perpetuates the nonchalance. Participants convince themselves and others that they are not the victims of a serious condition as they concentrate on mundane issues and try to live like healthy people through imposing normality. This investigator would be remiss if she did not acknowledge that a nearly identical concept was defined by Charmaz (1991) as supernormalizing. In her description of people attempting to return to routines following heart attacks, Charmaz describes how a person, despite having a serious medical condition, attempts to withhold, recapture or achieve his or her identity as "normal". This is viewed as a way to avoid being identified as a "victim".

The stage of conscious denial ends with the critical juncture of grasping the real threat of sudden cardiac death when the patient experiences the second stage of heightening awareness of the personal risk of sudden cardiac death and the life-saving capability of an ICD. Those participants who ultimately declined primary prevention ICD therapy did not experience the critical juncture and remain in the first stage of conscious denial. As explained in chapter four, decliners did not move through the subsequent stages. For those who ultimately accept primary 
prevention ICD therapy, the heightening awareness of mortality risk is dependent on the condition of valuing longevity. Properties of heightening awareness include experiencing a significant medical event and realizing new candor. A medical event triggers sudden candor on the part of the provider regarding risk. The provider, in turn, engenders trust from the patient by delivering the message in a clear and concise manner, and strongly recommending an ICD. The third stage of sanctioning ICD therapy occurs quickly after heightening awareness as the patient passively agrees with his or her provider's recommendation for an ICD and requests the procedure as soon as possible. This is a stage of increasing anxiety for the patient as he or she is feeling unsettled until the device is finally implanted. The final stage of living in new assurance occurs after ICD implantation. This stage describes how the heart failure patient continues to consider and support the decision made often downplaying the process. The patient is enjoying a more blissful state of assurance fueled by a new sense of security with having an ICD.

\section{Comparison of Embodied Revelation: The Threat of Sudden Cardiac Death for ICD}

\section{Candidates}

There was little existing literature for heart failure patient decision making surrounding primary prevention ICD therapy. The literature review in chapter two was originally formulated prior to the grounded theory data collection and analysis of the present study. In the spirit of emerging grounded data and the constant comparative method, a literature search was ongoing throughout the course of this investigation. In particular, examination of theoretical literature following theory development brought to light new relationships between existing models and the new grounded theory that emerged from this investigation. Current literature surrounding 
patient and provider perspectives of ICD decision making was also added as these studies support the knowledge base and support the implications of this new grounded theory. A comparison of the new grounded theory embodied revelation: the threat of sudden cardiac death for ICD candidates with extant literature will be presented in these related categories: 1) theoretical literature, and 2) empirical research literature including the following categories: a) patient decision making surrounding potentially burdensome life-sustaining therapies, b) underutilization of ICDs, c) patient and provider perspectives of ICDs, and d) heart failure patient decision making surrounding primary prevention ICDs.

Theoretical literature. The new grounded theory, embodied revelation: the threat of sudden cardiac death for ICD candidates will be evaluated for consistencies and inconsistencies with symbolic interactionism, the conceptual lens through which this study was viewed, writings of Charles Sanders Peirce, and the health belief model. First, a brief discussion follows surrounding two of the most current patient decision-making analyses that were presented in chapter two.

Current concept analyses of patient decision making. Current patient decision-making research supports the grounded theory Embodied revelation: the threat of sudden cardiac death for ICD candidates in its recognition of the growing difficulties patients face concerning modern health care technologies. The naturalistic decision-making movement attempts to define the nature of difficult decisions. Classic grounded theory presents a methodology to analyze such decisions. Grounded theory is rigorous, yet permits the flexibility needed for socially relevant, complex decisions (Glaser \& Strauss, 1967). In their analysis, Cannon-Bowers and colleagues (1996) examined and expanded the conceptualization of naturalistic decision making. Their 
conclusions supported the assumptions of the new grounded theory that difficult patient decisions are dynamic and contextual in nature. Noone's (2002) concept analysis of patient decision making produced a nursing model that identified attributes, antecedents, and consequences of patient decisions. These properties support stages and properties that emerged during the decision-making process surrounding ICDs. Noone concluded that patient decisions are based on recognition of a stimulus for action. The critical juncture of grasping mortality risk represents such an antecedent. Noone's model also includes patient expectations to accomplish goals and a commitment by the patient to a path of action. In the case of the ICD decision, that goal would be to sustain life. The commitment by the patient to a path of action is represented by the third stage of sanctioning ICD therapy with the property of requesting an implant as soon as possible. Noone also included consequences of decision making that included acceptance or resolution of the decision. This part of the model is represented by the new grounded theory's last stage of living in new assurance that describes the patient continuing to consider and support the decision made to accept a primary prevention ICD.

Symbolic interactionism. For reasons discussed in chapter one of this dissertation, symbolic interactionism was chosen as the theoretical framework for this study prior to data collection and analysis. The founders of classic grounded theory did not subscribe to any particular philosophical framework to underpin their work. To the contrary, they objected to the notion. However, the basic goals of social interactionism and grounded theory are compatible. At the most basic level, the grounded theory assumptions regarding the social construction of realities and meanings as manmade (Glaser, 1998) are congruent with the assumptions of symbolic interactionism. 
Grounded theorists seek to discover basic human social processes that can be explained by theory. Social interactionism can provide a framework to collect meaningful, contextual data to explain behavior (Charon, 1979). This grounded theory study revealed the type of contextual, dynamic social process celebrated by symbolic interactionism. The decision to accept or decline a primary prevention ICD occurred during a decision-making process. An assumption of symbolic interactions is that human behavior is a subjective and dynamic social process (Blumer, 1969). Grounded theorists collect and analyze data on the premise that common social processes can be identified in human behavior (Glaser, 1979). As expected of the methodology, behavioral patterns emerged laying the groundwork for this new grounded theory. This theory will be discussed in terms of the core principles of symbolic interactionism.

The concepts of meaning, language, and thought (Blumer, 1969) make up a human's selfidentity and influence behavior according to the symbolic interactionism school of thought. The assumption that people behave based on the meanings various aspects of an action or decision supports findings of the new grounded theory. Participants made the decision to accept or decline ICD therapy based on what sudden cardiac death meant to them and if and how they understood this potential mode of death to apply to them. If participants did not understand or until they understood their personal risk of sudden cardiac death, they did not agree to a primary prevention ICD. In order for the device to be accepted, the ICD had to hold meaning as a lifesaving therapy to the individual. Assuming the patient attributed appropriate meaning to sudden cardiac death and an ICD, the decision to accept the device was further contingent on their personal meaning of life. Holding a high value on longevity was necessary to accept ICD therapy. 
Symbolic interactionism supports the grounded theory view that meanings arise from social interaction and humans identify meaning in the speech of others. "Self" is a core concept in social interactionism. Behaviors manifest based on a continual inner dialogue between the "I" who acts and the "me" who interprets the self that is reflected by others (Mead, 1934). In other words, humans react to the attitudes of others. This notion was manifested in communication between heart failure patients and their health care providers who discussed ICD therapy with them. The critical juncture of grasping the threat of sudden cardiac death was dependent on the patient's perception of provider candor regarding the risk of sudden cardiac death and the lifesaving capability of the ICD. How these concepts were communicated by the provider was vital to the decision to accept or decline a device. Furthermore, a strong recommendation from a clinician strengthened the patient's grasp of mortality risk, enhanced trust in that provider and led to their acceptance of the ICD.

To social interactionists, thought embodies the mental conversation that can modify an individual's interpretation of language (Blumer, 1969). With roots in the philosophical school of pragmatism, grounded theory describes that the meaning of thoughts are based on subsequent action or "practical consequences" (Bawden, 1904). In the decision-making process surrounding ICD therapy, patients mentally wrestle with different points of view, pros and cons of the device. This dilemma can explain the patient's need for suddenly perceived candor by the provider in order to "tip the scales" towards an accepting position. The degree of meaning the risk of sudden cardiac death and an ICD hold are ultimately judged by the participant's accepting or declining the device. 
Writings of Charles Sanders Peirce. Charles Sanders Peirce (1839-1914), the father of pragmatism, was never mentioned by the founders of classic grounded theory as an influence of their work. However, many of the assumptions of grounded theory are compatible with the writings of Peirce, and Peirce is known to have influenced mentors of Glaser and Strauss (Nathaniel, 2011). Peirce's writings are compatible with the grounded theory assumption of an objective reality separate from the researcher, towards which inquiry and discovery move (Glaser, 1978). Peirce espoused that the meaning of concepts was based on practical consequences and that meaning could be recognized by meaningful observation (Peirce, 1955). The meaning of concepts such as sudden cardiac death and ICDs was reflected in the dynamic decision-making process that emerged during the data collection and analysis of this grounded theory study. Peirce characterized inquiry as the struggle to rid ourselves of the "irritant" of doubt and achieve a state of belief (Peirce, 1877). His proclaimed assumption was that humans prefer contentment to truth and will actually avoid doubt if they are content. This premise is congruent with the properties that emerged as the first stage of conscious denial in this grounded theory study. During this stage, participants live in relative contentment as long as any doubt as to their risk of sudden cardiac death is repressed. As soon as heightening awareness of risk eats away at the comfortable state of conscious denial, irritation and anxiety ensue.

Health belief model. The health belief model was chosen to compare with embodied revelation: the threat of sudden cardiac death for ICD candidates because the model is one of the most widely used conceptual frameworks in nursing research when attempting to predict patient preventive and compliant behavior. Emerging concepts of the new grounded theory invoked similarities with the well-known health belief model. The original model was designed 
in the 1950s to explain and predict responses to therapies by seriously ill patients. Three social psychologists working with the United States Public Health Services sought to explain the behaviors of patients with tuberculosis who failed to engage in a free health screening program (Rosenstock, 1966). The theoretical framework was originally grounded in interview data of 1200 randomly selected respondents who were asked about their attitudes and perceptions surrounding diagnostic x-rays (Hochbaum, 1956). The health belief model articulates concepts that were found to be predictive of preventive health behavior rather than a formal theory. Similar to findings of the new grounded theory, the health belief model focuses on the relationships between patient attitudes and beliefs and patient behaviors. The personal threat posed by and the expected effectiveness of a treatment predict patient behavior in a given situation. The health belief model supports the new grounded theory in terms of the model's four basic concepts. A person will take action/make a decision based upon: 1) perceived susceptibility, 2) perceived severity, 3) perceived benefit, and 4) perceived barriers (Rosenstock, 1974). Perceived susceptibility is embodied in the critical juncture of grasping the threat of sudden cardiac death. Perceived severity speaks to the heart failure patient's understanding of the seriousness of sudden cardiac death. Additionally, "trigger factors" in leading an individual to perceive severity can be linked to the condition of experiencing a significant medical event in the new grounded theory. Perceived benefit refers to the belief in the life-saving capability of an ICD.

The fourth health belief model concept of perceived barriers does not correlate as well with data that emerged during embodied revelation: the threat of sudden cardiac death for ICD candidates. Perceived barriers refer to the patient's opinions regarding potential risks. These 
risks could be physical, psychological, and/or emotional. Fear of negative outcomes from ICD therapy did not emerge as a significant property in the decision-making process of patients considering primary prevention ICD therapy.

The health belief model could be helpful in considering strategies to prepare patients for major health decisions and therapies. However, the model appears to lack any role for emotional issues such as fear or denial which seem to play a part in embodied revelation: the threat of sudden cardiac death for ICD candidates. Last of all, this model focuses only on the individual's beliefs and neglects the potential role of social factors. The new grounded theory clearly highlights the importance of the social interaction between the patient and the health care provider. On the contrary, the health belief model could be viewed as holding the patient solely responsible for his or her health care decisions and actions. This removes the responsibility of the provider to completely explain procedures and recommendations to the patient in the spirit of an informed decision. The grounded theory of embodied revelation: the threat of sudden cardiac death for ICD candidates more fully explains the decision-making process unique to the patient population studied.

Empirical research literature. In general, extant literature supports the findings that emerged from this investigation. Glaser (2002) emphasizes that the chosen methodology should be based on the needs of the research. The qualitative literature surrounding aspects of patient decision making was often descriptive while failing to produce theoretical explanation of the concept. The grounded theory of embodied revelation: the threat of sudden cardiac death for ICD candidates explains in conceptual terms what is going on as heart failure patients grapple with the issues surrounding a primary prevention ICD as a potentially burdensome yet life- 
saving therapy. A comparative review of the extant empirical literature presented in chapter two and this grounded theory study will follow. Findings regarding the following major categories will be discussed: 1) patient decision making surrounding potentially burdensome life-sustaining therapies, 2) underutilization of ICDs, 3) mortality benefit, 4) patient perspectives surrounding ICDs, 5) provider perspectives surrounding ICDs, and 6) heart failure patient decision making surrounding primary prevention ICDs.

\section{Patient decision making surrounding potentially burdensome life-sustaining therapies.}

Existing literature examining patient decision making surrounding burdensome, life-sustaining therapies mainly included participants who were seriously ill and facing end-of-life quandaries. Two themes identified as contributing to end-of-life treatment decisions are similar to concepts that emerged in the grounded theory study. In most cases, dying patients considered physician recommendation when deciding the merit of a treatment (Caldwell et al., 2007; Silvestri et al., 2003; Verhoef \& White, 2002) and many terminal patients lacked complete comprehension of their prognosis and potential treatment outcomes (Fried et al., 2002, 2008; Verhoef \& White). A strong recommendation for an ICD emerged as a property of the second stage of heightening awareness in the grounded theory study. This recommendation was a key factor in participants' agreeing to ICD therapy. These same participants and decliners in the study revealed varying levels of comprehension regarding heart failure, sudden cardiac death, and ICD therapy. Various levels of autonomy were observed in dying patients who were making decisions regarding lifesustaining therapies. Inconsistent with the findings of the present grounded theory study, the level of autonomy for other groups of patients considering life-sustaining therapies did not appear to correlate to the ultimate treatment decisions made (Goldstein et al., 2008; Mueller et 
al., 2008). Participants who accepted primary prevention ICD therapy in the grounded theory study were more likely to be passive decision makers than those who declined the device.

In the extant literature, appraised treatment burden, patient age, and views of loved ones were all found to influence end-of-life treatment decisions (Caldwell et al., 2006; Rosenfeld et al., 2001; Silvestri et al.,2003; van Kleffens et al., 2004; Verhoef \& White, 2002; ZikmundFisher et al., 2008). These factors did not emerge as significantly contributing to heart failure patient decision making regarding primary prevention ICDs in the newly presented grounded theory. In existing literature, terminally ill patients were found to have inconsistent preferences regarding treatments over time (Caldwell et al., 2007; Fried et al., 2007; Van den Brink-Muinen et al., 2006). In contrast, decisions about ICD therapy appeared to remain constant over time in the grounded theory study. Both acceptors and decliners reconsidered and appeared to strengthen their decisions as time went on. However, a longitudinal study with many more participants would be necessary to properly evaluate this concept of ICD preferences over time.

Fried et al. (2002) developed an instrument to measure willingness to accept lifesustaining treatment (WALT). Consistent with the grounded theory study, participants using WALT ranked survival highest in their decision to accept life-sustaining therapy. Valuing longevity emerged as a condition for accepting primary prevention ICD therapy.

Underutilization of ICDs. Literature review revealed that primary prevention ICD use for qualifying patients was underutilized (Hernandez et al., 2007; Lakshmanadoss et al., 2011; LaPointe et al., 2011; Ruskin et al., 2002; Thomas et al., 2007). Underutilization of devices would be difficult to make a claim about based on the data of twelve heart failure patients. However, the grounded theory study revealed a decliner rate of 3 of 12 . Disparity of use would 
also be difficult to assess with such a small sample, although consistent with existing literature on ICDs, women were under represented in the grounded theory study.

Mortality benefit. Estimation of mortality could frame decisions to accept or decline ICDs. Heart failure patients were found to be overly optimistic about their life expectancy (Allen et al., 2008). Survival data revealed no relationship between patient's level of optimism regarding longevity and estimated survival. Stewart et al. (2010) found that most heart failure patients overestimated their own life expectancy and the survival benefits of an ICD regardless if the patient had an ICD or not. Participants in the grounded theory study were not questioned about their anticipated mortality. Grounded theory depends on what data emerge from participants as most important to them. Discussions surrounding expected life expectancy did not surface. However, acceptors of ICD therapy strongly believe, based mostly on provider recommendation, in the life-saving capability of the device and clearly valued life as a condition of accepting the device.

The patient's perspective regarding ICDs. The theory embodied revelation: the threat of sudden cardiac death for ICD candidates is grounded in data of heart failure patients considering ICD therapy. This new theory is entirely grounded in stories told from the participants' perspectives. The extant literature surrounding patient decision making regarding life-sustaining therapies often contrasts the patient and provider points of view. The literature review was limited to patient perspectives prior to ICD implant. With regards to therapies being considered, patients felt that providers were most interested in extending life (Rodriguez \& Young, 2005). Regarding discussions with physicians about life-sustaining therapies, patients reported ineffective communication resulting in lack of understanding (Desharnais et al., 2007; 
Goldstein et al., 2008). A recently published study by Hauptman et al. (2013) explored patient and physician communication regarding ICDs through patient focus groups and recorded patientphysician discussions. Physicians failed to provide complete information to patients. Nearly all of the patients expressed learning more about the risks and benefits of ICDs after implant as compared to prior agreeing to the device.

Participants in the grounded theory study expressed different levels and quality of communication with their providers. Those who accepted ICD therapy generally felt that they were given enough information to make their decision and expressed trust in their providers. However, conversations with providers in the first stage of conscious denial were described as casual. Decliners of ICD therapy were more critical of provider communications in general, but deemed themselves informed enough to make a decision regarding ICD therapy.

A recent study specifically evaluated patient experiences surrounding primary prevention ICDs. In a poster presented at Quality of Care and Outcomes Research in Cardiovascular Disease and Stroke 2012 Scientific Sessions, Matlock and colleagues reported on the decision-making experiences of 295 patients with implanted ICDs. Results of mailed surveys revealed the surprising fact that $19 \%$ of respondents did not want the device at the time of implant. Those who reported not wanting the device despite having the ICD implanted tended to be younger, reported less participation in the decision-making process, and had higher decision regret. The concept of a good decision will be explored in the bioethical section of this chapter.

Generally, acceptors of primary prevention ICDs in the grounded theory study appeared to give little thought to ICDs prior to the critical juncture of grasping the threat of sudden cardiac death. The perception of the device then changed for acceptors to a life-saving therapy 
that they desired. None of the participants volunteered that they were sorry they had the ICD implanted or that they really did not want the device at the time of implant. For decliners who remain in the first stage of denial, ICDs continue to be viewed primarily as invasive therapies that they do not need.

Provider recommendation. Existing literature strongly supports the grounded theory findings that provider recommendation is a prime motivator for accepting primary prevention ICD therapy. Physician recommendation was vital to patient decision-making surrounding lifesustaining therapies for patients with advanced illness (Caldwell et al., 2007; Silvestri et al.,2003; Verhoef \& White, 2002). Congruent with the grounded theory findings, recent data report provider recommendation as key in motivating patients to accept primary prevention ICD therapy (Carroll et al., 2011; Matlock et al., 2011; Yuhas et al., 2012). Although the grounded theory reflects only the patient's perspective, the provider's perspective could have significant implications since their recommendation impels patients to have ICDs implanted. In the Matlock et al. study, cardiologists reported wanting to adhere to published guidelines when recommending ICD therapy. Many patients reported simply following physician recommendation when deciding to have the device implanted. A recently published study produced sobering results regarding physician decision-making regarding ICD recommendations (Caverly et al., 2012). Surveys evaluated factors affecting cardiologist decisions to implant primary prevention ICDs and cardiologist feelings regarding ICD benefits. Only $38 \%$ of the cardiologists reported that patient preference mattered "a great deal" and $12 \%$ said that patient preference mattered "very little" or "not at all" when considering who should receive a device. 
For the physicians in the Matlock et al. study, mortality benefit and adherence to guidelines were paramount.

Heart failure patient decision making surrounding primary prevention ICDs. The scant literature available on heart failure patient decision making surrounding primary prevention ICDs revealed both consistencies and inconsistencies with the data that emerged from the grounded theory study. The theme analysis of Matlock et al. (2010) explored active and passive decision makers. Similar to the participants in the present study, passive decision makers in that study did not characterize their decision regarding an ICD as difficult. Acceptors of the device in the grounded theory study were generally passive about their decision which was strongly based on provider recommendation. Once the patients grasped their mortality risk and a strong recommendation for the device, their decision to accept the device was quick and easy. Active decision makers in the Matlock et al. study described their ICD decision as one of the most difficult they had to make. Decliners in the grounded theory study tended to be more active in the decision-making process. They asked more questions and did more personal research, but did not characterize their decision-making process as difficult.

Limited data on ICD decliners support findings of the new grounded theory study embodied revelation: the threat of sudden cardiac death for ICD candidates. The first two publications on the topic detailed a case study about a primary prevention device decliner (Mattson-Dicecca \& Reynolds, 2009; Zimetbaum, 2007). A primary factor in the patient's refusal was his questioning of the "necessity" of the device. The patient discussed how well he felt and lack of a compelling reason to accept implantation. Similarly, grounded theory decliners never experienced the critical juncture of grasping the risk of sudden cardiac death. They 
remained in the first stage of conscious denial without full realization of their mortality risk and the life-saving capability of an ICD.

Findings of two other existing studies exploring heart failure patient decision making surrounding primary prevention ICDs supported the new grounded theory. Both of these studies also used grounded theory methodology to collect and analyze data, but each failed to produce a substantive theory that articulates the process of decision making surrounding primary prevention ICDs. Some of the concepts that were identified as contributing to decision making were identical to those concepts and properties that emerged in embodied revelation: the threat of sudden cardiac death for ICD candidates. Carroll et al. (2011) found that passive decision makers did not view the decision regarding an ICD as theirs to make. Rather, like the participants in the present study, they preferred to rely on the recommendation of their trusted clinician. Inconsistent with data that emerged from the present grounded theory study, decliners in the Carroll et al. study considered advanced age and comorbid conditions in their decision. However, determinations regarding the potential meanings these concepts hold to the decisionmaking process cannot be discerned since no theory emerged.

A recent study by Yuhas et al. (2012) produced themes with striking similarities to the present study. Heart failure patients who declined ICD therapy were interviewed by telephone. The participants demonstrated a lack of understanding as to their personal risk of sudden cardiac death and questioned the appropriateness of such an invasive procedure. As in the grounded theory study, acceptors of the device perceived strong recommendations from their provider. Inconsistent with findings of the new grounded theory study, Yuhas et al. participants voiced concerns over device recalls and malfunctions. Whether this topic was raised by the investigator 
or freely emerged from data was unclear. These concerns did not surface as a main concern of participants during the open-ended interviews of this investigator's grounded theory study.

In contrast to these two recent studies exploring heart failure patient decision-making surrounding primary prevention ICDs, embodied revelation: the threat of sudden cardiac death for ICD candidates represents an original substantive theory. The other two recent studies present data that appear to contribute to the decision participants ultimately make. However, the contributing components were not conceptualized. Relationships between the concepts were not explored, analyzed, and hypothesized. Therefore, meaning cannot be assigned to the data. The new grounded theory presented in this paper is the first theory to this investigator's knowledge to fully explain this decision-making process. The theory accounts for all variations in the data and explains how the participants solve their main concern.

\section{Critique of the Theory}

The new grounded theory embodied revelation: the threat of sudden cardiac death for ICD candidates will be evaluated in terms of Lincoln and Guba's (1985) criteria to assure qualitative research rigor followed by a discussion of the limitations of the study. Validity, reliability, and objectivity will be addressed as credibility, transferability, dependability, and confirmability as described in chapter three.

Credibility. Credibility refers to how well the findings of the study represent the actual experiences of the participants (Lincoln \& Guba, 1985). Credibility was achieved by the constant comparative method as new data was compared to previously discovered data. This theory emerged directly from participant data. The study began without hypotheses or any preconceived ideas that the researcher hoped to support. The investigator began with one open- 
ended question similar to: "Tell me about what was going on as you came to the decision to accept (or decline) an implantable defibrillator". The participants started talking from that point. Any follow-up questions from the investigator were derived from data already shared for purposes of clarification or expansion of concepts. The categories, properties and stages resulted from analyzing and conceptualizing the stories patients told about the decision to accept or decline a primary prevention ICD. All concepts included in the theory can be traced back to participant data. Therefore, the theory meets the criteria for credibility.

Transferability. This theory fits the criteria of transferability in that the theory can be modified beyond the scope of the present study. Grounded theory studies do not rely on description of participant experiences, but rather conceptualization by the researcher (Glaser, 2002). This conceptualization transcends specific experiences. Concepts were constantly modified as new data emerged. The findings of this study are viewed as a ground work for future investigations that will add to the data and knowledge. The stages of this theory should be able to be transferred to explain other decision-making processes involving complex and/or troubling issues.

Dependability. The theory was found to be dependable based on auditing of the data, findings, interpretations, and concepts. Audit techniques are advised to examine all processes of the study (Lincoln \& Guba, 1985). The audit ensures that the concepts represent appropriate and accurate labels for the data (Martin \& Gynnild, 2011). Although interviews were not audio recorded as per classic grounded theory methodology, direct quotes from participants were jotted down throughout the interviews to enrich the data. Field notes were transcribed immediately 
following each interview, numbered and dated according to participant. All concepts, properties, and stages are able to be traced back to the data.

Confirmability. Once again, an audit trail as advised by Glaser (1998) confirmed the findings of this theory. As new data and concepts emerged, findings were constantly cross checked with recorded data and memos. After constantly comparing new with existing data and analyzing and reanalyzing, this theory truly does explain what was going on during the decisionmaking process to accept or decline a primary prevention ICD.

Limitations of the theory. This investigator recognizes several limitations to this study. The sample size was small at 12 participants. Data saturation was met rather early in data collection despite including only three ICD decliners. Consistent with extant data, patients who have declined primary prevention ICDs are difficult to recruit. This researcher cannot say with certainty that decliner data were saturated. The three decliners interviewed were volunteer participants. Unheard data from ICD decliners who are unwilling to be interviewed could modify the theory.

Many participants discussed the first and subsequent times primary prevention ICDs were recommended to them. Participants did not offer specific knowledge nor did they likely know exactly how long they had qualified for a primary prevention device. The knowledge of how long a patient had been known to have a very low ejection fraction and thus be at significant risk for sudden cardiac death could have framed the provider's recommendation message.

Finally, the classic grounded theory demand for the researcher to collect, analyze, and conceptualize the data can pose challenges with regards to subjectivity. Glaser (2002) described grounded theory as a "perspective-based" methodology. Despite the investigator's best efforts to 
remain objective, what stands out in the data to the researcher can reflect, partially, the researcher's own understandings and perceptions. This researcher is also a clinician and in a few cases, participants were former patients of the researcher. Participants were given clear explanations as to the unique role of the researcher as opposed to that of a clinician. However, the possibility of bias must be acknowledged. Separating research and clinical ethical standards was, in some cases, challenging when participants clearly expressed misinformation or misunderstanding of issues surrounding sudden cardiac death and ICDs. This novice researcher did her best not to intercede with corrective explanations. Additionally, for the participants who had been former patients of the researcher, the potential for a Hawthorne-like effect bias existed whereby participants could have modified their responses based on the knowledge that they were being studied (Gillespie, 1991). These participants had enjoyed a positive and trusting relationship with a clinician who was now interviewing them about a health care decision. The participants could have downplayed any negative aspects regarding specific providers and information received.

\section{Implications for Research, Nursing Science, Clinical Practice, and Bioethical}

\section{Considerations}

The new grounded theory of embodied revelation: the threat of sudden cardiac death for ICD candidates has potential implications for nursing research, nursing and medical clinical practice, and bioethical considerations. Potential implications for each of these areas will be discussed.

Research. The findings of this study provide the framework for further research. A goal of a grounded theory study is to present a set of tentative theoretical hypothesis that invites 
ongoing study to add to the knowledge. The literature review and findings of the study exposed gaps in knowledge regarding all aspects of primary prevention ICDs. Although there has been a recent influx of primary prevention studies, the preponderance of data remains on secondary devices. Specifically, studies including more participants who declined primary prevention devices are needed. Decliners are more difficult to recruit, but data from decliner volunteers may not represent decliners who are not willing to be interviewed. Additionally, further study on provider perspectives surrounding primary prevention devices would be helpful. The data revealed that providers who are in a position to discuss and recommend ICDs hold enormous power with regard to the decision-making process of the patient. How the primary prevention ICD issue is discussed and how the message and/or recommendation are delivered to the patient has significant ramifications as to whether the patient accepts or declines the device. How this discussion is framed could be at least partially dependent on the provider's personal views and values surrounding device therapy. Recent findings that a significant portion of providers view patient preference as relatively unimportant to the decision to implant an ICD are concerning and represent a step backwards to the days of paternalistic medical decision making. A better understanding of the provider perspective could facilitate tools to help providers evaluate themselves and facilitate informed patient decisions.

The discipline of nursing. The new grounded theory of embodied revelation: the threat of sudden cardiac death for ICD candidates contributes to the discipline of nursing as described by Reed (1995) and Newman, Sime, and Corcoran (1991). Reed and Newman et al. proposed paradigms to provide the perspective from which phenomena are viewed and new nursing knowledge is sought and accepted. Margaret Newman and colleagues submitted caring in the 
human health experience as a focus for the study of nursing. Embodied revelation is a human health experience. In this unitary-transformative abstract worldview, objects of inquiry are recognized as contextually dynamic involving high levels of mutuality. The knowledge gained from the new grounded theory resulted from high levels of trust between the nurse researcher and participant. The interviews changed and grew in response to gathered data. The theory that emerged was grounded in patient orientation and highly contextual in its embrace of values, meanings, roles of others, choices, and purpose as they applied to the patient's decision.

Similar to Newman et al. (1991), Reed (1995) suggests that new nursing knowledge be patient oriented, context sensitive, pattern focused and participatory. Reed further proposed a metanarrative of human developmental potential and transcendent capacity for health and healing as a framework for nursing research. The merit of nursing research is examined in terms of its relevance to nursing practice. The research problem of heart failure patient decision making surrounding primary prevention ICDs was born from a caring nurse's practice story. The theory that emerged explains a contextually dynamic decision-making process that, for acceptors of ICD therapy, involves stages involving powerful circumstances. The knowledge gained from this theory will help nurses foster and respect well-informed patient decisions at various levels of autonomy as prescribed by the patient. A classic grounded theory demands a level of transcendence as data are conceptualized rather than reported as experiences. This new theory has potential nursing science implications beyond the scope of heart failure patients and ICDs. The findings should be studied as they relate to other complex decision-making processes involving burdensome therapeutic options. 
Nursing and medical practice. This grounded theory holds implications for clinical practice. This section would normally speak only to nursing practice ramifications. However, data reveal that in many if not most cases, physicians discuss and recommend primary prevention device therapy to patients. For half of the participants in this study, nurses or advanced practice nurses first discussed the ICD topic with patients. Even if not in a position to recommend life-sustaining therapies, nurses have an inherent obligation to facilitate wellinformed patient decisions. Understanding the issues involved in the decision-making process of patients considering primary prevention ICD therapy is important to all nurses caring for heart failure patients.

Clinicians need to examine their own perceptions surrounding primary prevention ICD therapy prior to discussing or recommending the device to patients. Care needs to be taken in how the message is delivered in order for the true intent of the clinician to be perceived by the patient. This study revealed that patients respond best to providers who have engendered trust. Frank discussions containing expert information are expected and admired by patients. Data revealed that patients held significant misinformation surrounding issues of sudden cardiac death and primary prevention ICDs. Clinicians need to ensure that they are imparting accurate information and check that the patient has received the intended message.

The study implies the potential for decision-making instruments throughout the process. Decision aides could be helpful during all stages of the theory. Ensuring accurate and frank information is vital during the first stage of conscious denial. In their attempts to define "good" decisions, Elwynn and Miron-Shatz (2009) emphasize that information does not equate to understanding. This study highlighted the need for improved discourse between patients and 
providers. Elwyn and Miron-Shatz propose prerequisites for effective deliberation processes for patients considering potentially burdensome therapies. Patients must be made aware that options exist, and all aspects of these options need to be discussed, understood, and considered. Options should be presented and received in accessible formats such as characteristics of the options, potential outcomes, probabilities of outcomes, and imagining counterfactual or what if scenarios. Potential risks should be conveyed as to maximize understanding. Patients should be queried about their perceptions of the decision-making process as to the relevance and sufficiency of the information and understanding in making a resolution.

The participants described the anxiety they experienced during the second stage of heightening awareness. Patients, at this stage, had experienced an epiphany with regard to their personal risk of sudden cardiac death. They were troubled and impatient until they had the ICD implanted. Clinician measures to ease the anxiety of patients during this stage would be beneficial.

Clinician interventions could be helpful after ICD implantation. Participants expressed a willingness to talk about their decision to accept an ICD and their experiences with the device during the last stage of new assurance. Participants indicated the need to validate their decision. A systematic review of 45 studies with more than 5000 patients revealed significant depression and anxiety in ICD recipients (Magyar-Russell et al., 2011). Most of these studies involved secondary prevention device recipients, and evidence was inconsistent as to rates of depression and anxiety among patients with primary prevention devices. The participants in the grounded theory study did not discuss feelings of depression or anxiety. However, all these patients were interviewed at least one year after device implant. There is evidence that ICD-related anxiety 
improves after the first year following implant (Kapa et al., 2010). There is some evidence that support groups for patients with ICDs are helpful to device recipients (Dickerson \& Posluszay, 2000; Verhoef \& White, 2002). Again, most studies looking at support group benefit involved secondary prevention ICD recipients. There are many support group options for patients with ICDs. Many hospitals, health plans, and heart failure clinics offer such programs. Online support groups and chat rooms are also available for patients that clinicians feel could benefit.

Bioethical implications. The new grounded theory presented harbors bioethical implications surrounding the decision-making process of heart failure patients considering primary prevention ICD therapy. Ethical obligations are inherent to nursing. Decision making surrounding ICDs is a good example of how complex heath care decisions have become for patients. The choices are not always clear. Beauchamp and Childress (2012) provided ethical principles to serve as a moral compass in helping health care providers advocate for patient rights. Respect for patient autonomy is one of those principles that guides nursing analysis and resolution of health care decision dilemmas. In the name of respect for autonomy, the patient's role in the decision-making process has progressed from a passive stance in which decision making was relinquished to providers to active participation in major health decisions. Respect for autonomy recognizes the right of the individual to decide for him or herself based on personal values, beliefs, and projected lifespan stemming from the person's life experience (Ridley, 1998). The obligation to facilitate active patient participation in health care decisions presumes that autonomy is what the patient desires. A growing literature suggests that a significant number of patients do not seek the level of involvement the bioethics literature proposes they should (Deber, Kraetschemer, Urowitz, \& Sharpe, 2007). The majority of patients facing major 
medical decisions prefer a shared decision making relationship with their provider and/or family members (Deber, 1994; Deber et al. ; Elwyn, Edwards, \& Kinnersley, 1999; Matlock et al., 2010; Sudore \& Fried, 2010). Respect for autonomy must include recognition of the patient as a societal being. Decisions are made in the context of community (Burkhardt \& Nathaniel, 2008).

This researcher proposes that an implication of this study is the need for an expanded view of patient autonomy and further investigation regarding the measure of good decisionmaking processes. Participants who accepted ICDs in this study generally preferred a more passive role in decision making. In fact, they preferred to be told what was best for them by their trusted provider. This presents a dilemma for providers. Patients count on their provider to share their expertise and knowledge to help the patient make a decision. Providers may be reluctant to engage in too much discussion surrounding proposed therapies for fear of unduly influencing the patient's decision. Patients in the first stage of the theory described their providers as avoiding much serious discussion regarding risk of sudden cardiac death and ICDs. Perhaps fear of perpetuating paternalistic attitudes in favor of facilitating patient autonomy contributed to lack of meaningful information provided. An autonomous patient also has the right to refuse treatment or active participation in his or her own care. Facilitating autonomous patient choices must include respect for the option to include healthcare providers, family, and loved ones in the decision making process, and the realization that patient preferences may not always be clear, may fluctuate over time, and may include refusal of care or participation in healthcare decisions.

Nurses and all providers who are in a position to present major therapeutic decisions to patients ought to be mainly concerned with an informed, "good" decision by the patient rather 
than any "right" decision. Elwyn and Miron-Shatz (2009) examined approaches to measuring the concept of a good decision. They propose that decisions should not be evaluated by reference to their outcomes, but rather, they emphasize focus on the deliberation process which includes a pre-decisional deliberation process, the act of determination, and post-decisional outcomes. These periods mirror the stages embodied revelation: the threat of sudden cardiac death for ICD candidates. Bioethicists and clinicians often refer to patient preferences as a criterion for good decisions. Lichtenstein and Slovic (2006) make the important distinction between preferences that are revealed which is the way they are often understood and preferences that are constructed based on knowledge. Sepucha et al. (2007), in a pilot study exploring the quality of therapeutic decisions made by patients with breast cancer, proposed that context and decision-specific knowledge and concordance between patient values and the decision made were feasible measures of quality decisions. Clinicians ought to embrace the fact that the information imparted to and understood by the patient partially creates the patient preference that respect for autonomy strives for.

Facilitating informed, good decisions involves more than the informed consent procedure. Unfortunately, supporting patient autonomy for many providers basically consists of "you have the right to refuse". A patient who shows lack of enthusiasm for a therapeutic option is often described as "refusing" therapy. The assumption is that the decision has already been made and that there is little need for further explanation or discussion. Patients who are chronically or critically ill are often ill equipped to make rationale, informed decisions. Respect for patient autonomy in the course of decisions regarding life-sustaining therapies can be challenging. As such, clinicians need to give the time and effort required to fully explain options 
and promote useful dialogue with the patient regarding their main concerns. Contrary to the traditional interpretation of respect for patient autonomy, providers need to become more comfortable assuming a more active role in the actual health care decision if this is what the patient chooses.

\section{Conclusion}

Embodied revelation: the threat of sudden cardiac death for ICD candidates represents a new substantive theory that explains the decision of heart failure patients considering primary prevention ICD therapy. The decision to accept or decline this invasive, life-sustaining device occurs after a decision making process. The decision is a result of the revelation of his or her personal risk of sudden cardiac death and embodies what that risk means to him or her. This revelation of risk embodies personal beliefs, feelings, and values. The actual decision to accept or decline the device represents a tangible expression of the value the risk of sudden cardiac death holds with the individual. This theory helps fill the existing gap in knowledge surrounding a patient's decision to accept or decline the only effective therapy to prevent the leading cause of mortality in the United States. Classic grounded theory methodology is not meant to verify existing theories or produce conclusions. Rather, grounded theory generates major hypotheses that provide a framework for ongoing study. The theory holds implications for research, nursing science, practice, and bioethical considerations. 


\section{REFERENCES}

Aldiabat, K.M., \& Navenec, C.L. (2011). Philosophical roots of classic grounded theory: Its foundations in symbolic interactionism. The Qualitative Report, 16 (4), 1063-1080.

Al-Khatib, S.A., Sanders, G.D., O’Brien, S.M., Matlock, D., Zimmer, L.O., Masoudi, F.A., \& Peterson, E. (2011). Do physicians' attitudes toward implantable cardioverter defibrillator therapy vary by patient age, gender, or race? Annals of Noninvasive Electrocardiology, 16 (1), 77-84.

Al-Khatib, S.M., Sanders, G.D., Carlson, M., Cicic, A., Curtis, A., Fonarow, G.C.,...Zipes, D. (2008). Preventing tomorrow's sudden cardiac death: dissemination of effective therapies for sudden cardiac death prevention. American Heart Journal, 156, 613-804.

Allen, L.A., Yager, J.E., Funk, M.J., Levy, W.C., Tulsky, J.A., Bowers, M.T.,... Felker, G.M. (2008). Discordance between patient-predicted and model-predicted life expectancy among ambulatory patients with heart failure. Journal of the American Medical Association, 299 (21), 2522-2542.

American Heart Association. (2010). Heart disease and stroke statistics 2009 update. Dallas, TX: American Heart Association.

Bardy, G.H., Lee, K.L., Poole, J.E., Packer, D.L., Boineau, R., Domanski, M.,... Ip, J.H. for the Sudden Cardiac Death in Heart Failure Trial (SCD-HeFT). (2005). 
Amiodarone or an implantable cardioverter-defibrillator for congestive heart failure. New England Journal of Medicine, 352 (3), 225-237.

Bawden, H.H. (1904). What is pragmatism? The Journal of Philosophy, Psychology, and Scientific Methods, 1(16), 421-427.

Beauchamp, T.L., \& Childress, J.(2012). Principles of biomedical ethics. New York: Oxford University Press.

Blumer, H. (1969). Symbolic interactionism: Perspective and method. Englewood Cliffs, NJ: Prentice Hall.

Brown, D.W., Croft, J.B., Greenlund, K.J., Mensah, G.A., \& Giles, W.H. (2008). Trends in hospitalization for implantation of cardioverter-defibrillators in the United States, 1990-2005. (2008). American Journal of Cardiology, 101 (12), 1753-1755.

Burkhardt, M., \& Nathaniel, A.K. (2008). Ethics \& issues in contemporary nursing, ( $3^{\text {rd }}$ ed.) Clifton Park, NY: Delmar Thompson Learning.

Caldwell, P.H., Arthur, H.M. \& Demers, C. (2007). Preferences of patients with heart failure for prognosis communication. Canadian Journal of Cardiology, 23 (10), $791-796$.

Cannon-Bowers, J.A., Salas, E., \& Pruitt, J.S. (1996). Establishing the boundaries of paradigm for 
decision-making research. Human Factors, 38, 193-205.

Carroll, S.L., Strachan, P.H., de Laat, S., Schwartz, L., \& Arthur, H.M. (2011). Patients' decisions to accept or decline an implantable cardioverter defibrillator. Health Expectations, 1369-7625.

Caverly, T.J., Al-Khatib, S.M., Kutner, J.S., Massoudi, F.A., \& Matlock, D.D. (2012). Patient preferences in the placement of implantable cardioverter defibrillators. Archives of Internal Medicine, 172, (14), 1104-1107. doi: 10.1001/archinternmed.2012.2177.

Charmaz, K. (1991). Good days, bad days: The self in chronic illness and time. CT: Rutgers University Press.

Charon, J. (1979). Symbolic Interactionism: An introduction, interpretation, and integration. Englewood Cliffs, NJ: Prentice Hall.

Curtis, L.H., Al-Khatib, S.M., Shea, A.M., Hammill, B.G., Hernandez, A.F., \& Schulman, K.A. (2007). Sex differences in the use of implantable cardioverter defibrillators for primary and secondary prevention of sudden cardiac death. Journal of the American Medical Association, 298, 1517-1524.

Davis, D.R., Tang, A.S., Lemey, R., Green, M.S., Gollob, M.H., \& Birnie, D.H. (2006). Influence of gender on implantable cardioverter defibrillator implantation for primary and secondary prevention of sudden cardiac death. Europace, 8, 1054-1056. 
Deber, R.B. (1994). Physicians in health care management: The patient-physician partnership: changing roles, and the desire for information. The Canadian Medical Association Journal, 151, 171-176.

Deber, R.B., Kraetschemer, N., Urowitz, S., \& Sharpe, N. (2007). Do people want to be autonomous patients? Preferred roles in treatment decision-making in several patient populations. Health Expectations, 10, 248-258.

Desharnais, S.,Carter, R., Hennessy, W., Kurent, J., \& Carter, C. (2007). Lack of concordance between physician and patient: Reports of end-of-life care decisions. Journal of Palliative Medicine, 10 (3), 728-740.

Dickerson, S., \& Posluszay, M. (2000). Help seeking in a support group for recipients of Implantable cardioverter defibrillators and their support person. Heart \& Lung, 29 (2), 87-91.

Duray, G., Israel, C.W., \& Hohnloser, S.H. (2006). Recent primary prevention implantable cardioverter defibrillator trials. Current Opinion in Cardiology, 21(1), 9-15.

Echt, D.S., Liebson, P.R., Mitchell, L.B., Peters, R.W., Obias-Manno, D.,...Greene, H.L. (1991). Mortality and morbidity in patients receiving encainide, flecainide, or placebo. The cardiac arrhythmia suppression trial. The New England Journal of Medicine, 324 (12), 781-788. 
Elwyn, G., Edwards, A., \& Kinnersley, P. (1999). Shared decision-making in primary care: The neglected second half of the consultation. British Journal of General Practice, 49, 477-482.

Elwyn, G. \& Miron-Satz, T. (2009). Deliberation before determination: The definition and Evaluation of good decision making. Health Expectation, 13, 139-147.

Embodied [Def. 2]. (n.d.) In Merriam Webster online, Retrieved April 15, 2013 from www.merriam-webster.com/dictionary/embody.

Field, P., \& Morse, J.M. (Eds.). (1985). Nursing research: The application of qualitative approaches. London: Chapman and Hall.

Fried, T.R., Bradley, E.H., Towle, V.R., \& Allore, H. (2002). Understanding the treatment preferences of seriously ill patients. New England Journal of Medicine, 346, 1061-1066.

Fried, T.R., O’Leary, J., Van Ness, P., \& Fraenkel, L. (2007). Inconsistency over time in the preferences of older persons with advanced illness for life-sustaining treatment. Journal of the American Geriatric Society, 55, 1007-1014.

Gauri, A.J., Davis, A., Hong, T., Burke, M.C., \& Knight, B.P. (2006). Disparities in the use of primary prevention and defibrillator therapy among blacks and women. The American Journal of Medicine, 119 (2), e17-e21. 
Gillespie, R. (1991). Manufacturing knowledge: A history of the hawthorne experiments. Cambridge: Cambridge University Press.

Gillon, R. (1986). Ordinary and extraordinary means. British Medical Journal, 292, 259-261.

Glaser, B.G. (1978). Theoretical sensitivity: Advances in the methodology of grounded theory. Mill Valley, CA: Sociology Press.

Glaser, B.G. (1998). Doing grounded theory: Issues \& discussions. Mill Valley, CA: Sociology Press.

Glaser, B.G. (2002). Conceptualization: On theory and theorizing using grounded theory. International Journal of Qualitative Methods, 1 (2), 1-31.

Glaser, B., \& Strauss, A.L. (1965). Awareness of dying. Chicago: Aldine Publishing Company.

Glaser, B., \& Strauss, A. (1967). The discovery of grounded theory: Strategies for qualitative research. Chicago: Aldine Publishing Company.

Goede, R., \& DeVilliers, C. (2003). The application of grounded theory as methodology in studies on the use of methodology in IS practices. Proceedings of SAICSIT, 217, 208-217. 
Goldstein, N.E., Mehta, D., Siddiqui, S., Teitelbaum, E., Zeidman, J., Singson, M.,...Morrison, R.S. (2008). 'It's like an act of suicide" Patients' attitudes toward deactivation of implantable defibrillators. Journal of General Internal Medicine, 23 (1), 7-12

Gravelin, L.M., Yuhas, J., Remetz, M., Radford, M., Foley, J. \& Lampert, R. (2011). Use of a screening tool improves appropriate referral to an Electrophysiologist for implantable cardioverter-defibrillators for primary prevention of sudden cardiac death. Circulation, 4, 152-156.

Groeneveld, P.W., Heidenreich, P.A., \& Garber, A.M. (2005). Trends in implantable cardioverter defibrillator racial disparity: The importance of geography. Journal of the American College of Cardiology, 45 (1), 72-78.

Groeneveld, P.W., Matta, M.A., Suh, J.J., Yang, F., \& Shea, J.A. (2007). Quality of life among implantable cardioverter-defibrillator recipients in the primary prevention therapeutic era. Pacing Clinical Electrophysiology, 30 (4), 463-471.

Guba, E.G., \& Lincoln, Y.S. (1981). Effective evaluation: Improving the usefulness of evaluation results through responsive and naturalistic approaches. San Francisco: Jossey-Bass.

Guthrie, W., \& Lowe, A. (2011). Getting through the PhD process using Grounded Theory: 
a supervisor-researcher perspective. In V.B. Martin \& A. Gynnild (Eds.), Grounded theory, the philosophy, method, and work of Barney Glaser (pp. 51-68). Boca Raton, FL: Brown Walker Press.

Gynnild, A. (2011). Atmosphering the conceptual discovery. In V.B. Martin \& A. Gynnild (Eds.), Grounded theory, the philosophy, method, and work of Barney Glaser. (pp. 31-49). Boca Raton, FL: Brown Walker Press.

Hauptman, P.J., Chibnall, J.T., Guild, C., \& Armbrecht, E.S (2013). Patients perceptions, physician communication, and the implantable cardioverter defibrillator. Journal of the American Medical Association, Internal Medicine, 18, 1-7. Advance online publication. doi: 10.1001/jamainternmed.2013.3171

Hauptman, P.J., Swindle, J., Hussain, Z., Biener, L., \& Burroughs, T.E. (2008). Physician attitudes towards end-stage heart failure: A national survey. American Journal of Medicine, 121 (2), 127-135.

Hernandez, A.F., Fonarow, G.C., Liang, L., Al-Khatib, S.M., Curtis, L.H., LaBresh, K.A., ... Peterson, E.D. (2007). Sex and racial differences in the use of implantable cardioverter defibrillators among patients hospitalized with heart failure. Journal of the American Medical Association, 298 (13), 1525-1531.

Hochbaum, G. (1956). Why people seek diagnostic x-rays. Public Health Reports, 71 
377-380.

Hunt, S.A., Abraham, W.T., Chin, M.H., Feldman, A.M., Francis, G.S., Ganiats, T. G.,... Riegel, B. (2005). ACC/AHA 2005 guidelines update for the diagnosis and management of chronic heart failure in the adult. A report of the American College of Cardiology/ The American Heart Association task force on practice guidelines (writing committee to update the 2001 guidelines for the evaluation and management of heart failure).

Circulation, 112, e154-e235.

Kapa, S., Rotundi-Trevisano, D., Mariano, Z., Aves, T., Irvine, J., Dovian, P., \& Hayes, D.L. (2010). Psychopathology in patients with ICDs over time: Results of a prospective study. Pacing Clinical Electrophysiology, 33 (2), 198-200.

Kastor, J.A. (1989). Michel Mirowski and the automatic implantable defibrillator. American Journal of Cardiology, 63, 977-982.

Lakshamanadoss, U.,Sherazi, S. , Aggarwal, A., His, D., Aktor, M.K., Daubert, J.P., \& Shah, A.H. (2011). Underutilization of cardioverter defibrillators in primary prevention of sudden cardiac death. Cardiology Research, 2 (1), 1-6. Doi: 10.4021/cr13w

LaPointe, N.M., Al-Khatib, S.M., Piccini, J.P., Atwater, B.D., Honeycutt, E., Thomas, K.,... 
Peterson, E.D. (2011). Extent of and reasons for nonuse of implantable cardioverter defibrillator devices in clinical practice among eligible patients with left ventricular systolic dysfunction. Circulation: Cardiovascular Quality \& Outcomes, 4 (2), 146151.

Lichtenstein, S., \& Slovic, P. (2006). The construction of preference. Cambridge: Cambridge University Press.

Lincoln, Y., \& Guba, E. (1985). Naturalistic inquiry. London: SAGE.

Magyar-Russell, G., Thomas, B.D., Cai, J.X., Baveja, T., Kuhl, E.A., Singh, P.P.,... Ziegelstein, R.C. (2011). The prevalence of anxiety and depression in adults with implantable cardioverter defibrillators: a systematic review. The Journal of Psychosomatic Research,71 (4), 223-231.

Martin, V.B., \& Gynnild, A. (Eds.). (2011). Grounded theory-the philosophy, method, and work of Barney Glaser. Boca Raton, FL: Brown Walker Press.

Matlock, D.D., Jenkins, A.R., Masoudi, F.A., Magid, D.J., Sepucha, K.A., \& Kutner, J.F. (2012). Decision making experiences of patients with implantable cardioverter defibrillators. Poster presented at the meeting of Quality of Care and Outcomes Research in cardiovascular disease and stroke 2012 scientific sessions. Atlanta, Georgia.

Matlock, D.D., Kutner, J.S., Emersmann, C.B., Al-Khatib, S.M., Sanders, G.D., Dickinson, M., 
..., Masoudi, F.A. (2011). Regional variations in physicians' attitudes and recommenddations surrounding implantable cardioverter-defibrillators. Journal of Cardiac

Failure, 17 (4), 318-324.

Matlock, D.D., Nowels, C.T., \& Bekelman, D.B. (2010). Patient perspectives on decision making in heart failure. Journal of Cardiac Failure, 16 (10), 823-826.

Matlock, D.D., Nowels, C.T., Masoudi, F.A., Sauer, W.H., Bekelman, D.B., Main, D.S., \& Kutner, J.S. (2011). Patient and cardiologist perceptions on decision making for implanatable cardioverter-defibrillators: A qualitative study. Pace, 34 (12), 1633 1644.

Matteson, P., \& Hawkins, J.W. (1990). Concept analysis of decision making. Nursing Forum, 25 (2), 4-10.

Mattson-Dicecca, A.A., \& Reynolds, E. (2009). Update: A 59-year-old man considering implanttation of a cardiac defibrillator. Journal of the American Medical Association, 302 (1), 81 .

May, C.D., Smith, P.R., Murdock, C.J., \& Davis, M.J. (1995). The impact of the implantable cardioverter defibrillator on quality-of-life. Pacing Clinical Electrophysiology, 18, (7), 1411-1418.

McCallin, A., Nathanial, A., \& Andrews, T. (2011). Learning methodology minus mentorship. 
In V.B. Martin and A. Gynnild (Eds.), Grounded theory- the philosophy, method and work of Barney Glaser (pp. 69-84). Boca Raton, FL: Brown Walker Press.

McKinney, M. (2011). Irregular practices: Wide variations in use of heart implants. Modern Healthcare, 41 (2), 10-11.

Mead, G.H (1934). Mind, self, and society. Chicago: University of Chicago Press.

Moss, A.J., Zaraba, W., Jackson, W., Klein, H., Wilberg, D.J., Cannon, D.S.,...Andrews, B.B. for the Multicenter Automatic Defibrillator Implantation Trial II investigators. (2002). Prophylactic implantation of a defibrillator in patients with myocardial infarction and reduced ejection fraction. New England Journal of Medicine, 346, 877-883.

Mueller, P.S., Jenkins, S.M., Bramstedt, K.A., \& Hayes, D.C. (2008). Deactivating implanted cardiac devices in terminally ill patients: Practices and attitudes. Pacing and Clinical Electrophysiology, 31 (5), 560-568.

Myerburg, R.J., \& Castellanos, A. (2001). Cardiac arrest in sudden cardiac death. In E. Braunwald, D.P. Zipes , \& P. Libby (Eds.), Heart disease: A textbook of cardiovascular medicine, (6th ed.), (pp. 890-931). Philadelphia: WB Saunders.

Nathaniel, A.K. (2008). Eliciting spill: A methodological note. The Grounded Theory Review, 7 (1), 59-63.

Nathaniel, A. K. (2011). An integrated philosophical framework that fits grounded 
theory. In V.B. Martin \& A. Gynnild (Eds.), Grounded theory: The philosophy, method, and work of Barney Glaser (pp. 187-200). Boca Raton, FL: Brown Walker Press.

Nathaniel, A.K., \& Andrews, T. (2007). How Grounded Theory can improve nursing care quality. Journal of Healthcare Quality, 22 (4), 350-357.

Newman, M.A., Sime, A.M., \& Corcoran-Perry, S.A. (1991). The focus of the discipline of nursing. Advances in Nursing Science, 14, 1-6.

Noone, J. (2002). Concept analysis of decision making. Nursing Forum, 37 (3), 21-32.

Peirce, C.S. (1877). The fixation of belief. Popular Science Monthly, 12, 1-15.

Peirce, C.S. (1953). Philosophical Writings of Peirce. Mineola, NY: Dover Publications.

Polit, D. F., \& Beck. (2008). Nursing research: Generating and assessing evidence for nursing practice. $\left(8^{\text {th }}\right.$ ed.). Philadelphia, PA: Lippincott Williams \& Wilkins.

Pope Pius XII. (1957). The prolongation of life. In S.J. Reiser, A.J. Dyck,\& W.J. Curran (Eds.), Ethics in medicine-historical perspectives and contemporary concern (pp. 501-504). Cambridge, MA: MIT Press.

Reed, P.G. (1995). A treatise on nursing knowledge development for the $21^{\text {st }}$ century: 
Beyond postmodernism. Advances in Nursing Science, 17, 70-84.

Ridley, A. (1998). Beginning bioethics. New York: St. Martin's Press.

Rodriguez, K. C., \& Young, A.J. (2005). Patients' and healthcare providers' understandings of

life-sustaining treatment: Are perceptions of goals shared or divergent? Social Science \& Medicine, 62 (1), 125-133.

Roger, V.L., Go, A.S., Lloyd-James, D.M., Adams, R.J., Berry, J.D., Carnethon, M.R.,...WylieRosett, J. (2010). Heart disease and stroke statistics-2011 update: A report from the American Heart Association. Circulation, 123, e18-e209. doi: 10.1161/CIR.0b01 3e 3182009701.

Rosenfeld, K.E., Wenger, N.S., \& Kagawa-Singer, M. (2001). End-of-life decision making. Journal of Geriatric Internal Medicine, 15, 620-625.

Rosenstock, I.M. (1966). Why people use health services. Millbank Memorial Fund Quarterly, 44 (3), 99-127.

Rosenstock, I.M. (1974). Historical origins of health belief model. Health Education Monographs, 2 (4).

Ruskin, J.N., Camm, A.J., Zipes, D.P., Hallstrom, A.P., \& McGrory-Usset, M.E. (2002). Implantable cardioverter defibrillator utilization based on discharge diagnoses from 
medicare and managed care patients. Journal of Cardiovascular Electrophysiology, 13 (1), 38-43.

Sandelowski, M. (1995). Qualitative analysis: What it is and how to begin. Research in Nursing \& Health, $18(4), 371-375$.

Sepucha, K., Ozanne, E., Silvia, K., Partridge, A., \& Mulley, A.G. (2007). An approach to measuring the quality of breast cancer decisions. Patient Education and Counselling, 65, 261-269.

Silvestri, G.A., Knittig, S., Zoller, J.S., \& Nietert, P.J. (2003). Importance of faith on medical decisions regarding cancer care. Journal of Clinical Oncology, 21 (7), 1379-1382.

Simmons, O.E. (2011). Why classic grounded theory? In V.B. Martin \& A. Gynnild (Eds.), Grounded Theory-The philosophy, method, and work of Barney Glaser (pp. 15-30). Boca Raton, Florida: Brown Walker Press.

Sola, C.L., \& Bostwick, J.M ( 2005). Implantable cardioverter-defibrillators, induced anxiety, and quality of life. Mayo Clinic Proceedings, 80 (2), 232-237.

Spindler, H., Johansen, J.B., Anderson, K., Mortensen, P., \& Perersen, S. S. (2004). Gender differences in anxiety and concerns about the cardioverter defibrillator. PACE, 32, 614-621. 
Stewart, G.C., Weintraub, J.R., Pratibhu, P.P., Semigran, M.J., Camuso, J.M., Brooks, K.,...

Stevenson, L.W. (2010). Patient expectations from implantable defibrillators to prevent death in heart failure. Journal of Cardiac Failure, 16 (2), 106-113.

Strachan, P.H., Carroll, S.L., deLatt, S., Schwartz, L., \& Arthur, H.M. (2011). Patients' perspectives on end-of-life issues and implantable cardioverter defibrillators. The Journal of Palliative Care, 27 (1), 6-11.

Strauss, A., \& Corbin, J. (1990). Basics of qualitative research: Grounded theory procedures and techniques. New York: Sage Press.

Strauss, A., \& Corbin, J. (1998). Basics of qualitative research: Techniques and procedures for Developing grounded theory ( $2^{\text {nd }}$ ed.). New York: Sage Press.

Sudore, R.L., \& Fried, T.R. (2010). Redefining the "planning" in advance care planning: Preparing for end-of-life decision making. Annals of Internal Medicine, 153 (4), 256-261.

Tarozzi, M. (2011). On translating grounded theory when translating is doing. In V.B. Martin \& A. Gynnild (Eds.), Grounded theory, the philosophy, method. And work of Barney 
Glaser (pp. 161-174). Boca Rotan, FL: Brown Walker Press.

Thomas, K.L., Al-Khatib, S.M., Kelsey, R.L., Bush, H., Brosius, L., Velazquez, E.J.,...

Gilliam, F.R. (2007). Racial disparity in the utilization of implantable-cardioverter defibrillators among patients with prior myocardial infarction and an ejection fraction $\leq 35 \%$. American Journal of Cardiology, 16 (1), 77-84.

Van den Brink-Muinen, A., van Dulmer, S.M., de Haes, H.C., Visser, A.P., Schellevis, F.G., \& Bensing, J.M. (2006). Has patients' involvement in the decision-making process changed over time? Health Expectations, 9 (4), 333-342.

van Kleffens, T., van Baaresn, B., \& van Leeuwen, E.(2004). The medical practice of patient autonomy and cancer treatment refusals: a patient's and physician's perspective. Social Science Medicine, 58, 2325-2336.

Van Welsenes, G.H., van Ries, J.B., Borleffs, C.J., Cannegieter, S.C., Bax, J.J., van Ewen, L., ...Schalji, M. J. (2011). Long-term follow-up of primary and secondary prevention Implantable cardioverter defibrillator patients. Europace, 13 (3), 389-394.

Verhoef, M.J., \& White, M.A. (2002). Factors in making the decision to forgo conventional cancer treatment. Cancer Practice, 10 (4), 201-207. 
Walker, R.L., Campbell, K.A., Sears, S.F., Glenn, B.A., Sotile, R., Curtis, A.B.,...Conti, J.B. (2004). Women and the implantable cardioverter defibrillator: a lifespan perspective on key psychological issues. Clinical Cardiology, 27 (10), 243-246.

Yuhas, J., Mattocks, K., Gravelin, L., Remetz, M., Foley, J., Fazio, R., \& Lampert, R. (2012). Patients' attitudes and perceptions of implantable cardioverter-defibrillators: Potential barriers to appropriate primary prophylaxis. PACE, 35, 1179-1187.

Zikmund-Fisher, B.J., Lacey, H.P., \& Fagerlin, A. (2008). The potential impact of decision role and patient age on end-of-life treatment decision making. Journal of Medical Ethics, 34 (5), 327-331.

Zimetbaum, P. (2007). A 59-year-old man considering implantation of a cardiac defibrillator. Journal of the American Medical Association, 297 (17), 1909-1916. 


\section{Appendix A}

\section{Tentative Hypotheses}

- There is a relationship between experiencing a significant medical event, a strong recommendation from a provider and a valuing longevity for acceptors of primary prevention ICDs.

- For acceptors of primary prevention ICDs, stage I living in conscious denial, ends with the critical juncture of grasping the threat of risk of sudden cardiac death.

- For acceptors of primary prevention ICDs, stage II, heightening awareness, begins following the critical juncture of grasping the threat of sudden cardiac death.

- For acceptors of primary prevention ICD therapy, stage III, sanctioning an ICD, follows stage II, heightening awareness.

- Stage IV, living in new assurance, occurs after stage III, sanctioning an ICD, and is the final stage of embodied revelation: the threat of sudden cardiac death for ICD candidates.

- There is a relationship between not perceiving a strong recommendation from a provider, not trusting providers, and not valuing longevity for decliners of primary prevention ICDs. 


\section{Appendix B}

\section{Examples of Field Notes Depicting Concepts and Stages}

Example of Stage I: Conscious Denial with properties: repressing risk awareness, reciprocating nonchalance, and imposing normality

\section{D.S. $10 / 30 / 12$}

\section{* 1}

"Tell me about how you arrived at the decision to have a defibrillator implanted"

D.S. declined an ICD for 3 years before he agreed to the implant.

DS: The conversation came up after I had been in the hospital in 2003. Dr.---said that "we should probably do this". I put him off for 3 years. I kept putting him off for 3 years. They kept giving him literature about ICDs. ineverread any of the literature. He thought "I"l just live in denial yeah, I read it". Fwanted to deny there was an actual problem. This was no big deal."

I would think about it for the first few days after the appointment, and then l'd forget about it.

I think I was "thinking like a 20-year-old".

I never worried about it. I only worry about things that are important to me. They would tell me "you have a heart problem", yeah whatever." I would lie awake at night thinking and worrying about music. 
Example of the Critical Juncture of Grasping the Threat of Sudden Cardiac Death

\section{\#8- R.B.}

V: So, I know that coming to the decision to have an ICD (implantable defibrillator) can be rather difficult. Tell me about how your arrived at the decision to have one implanted.

R.B.: "They told me I had no option". I blew that front part of my heart out. It was dead. I was afraid l'd have another heart attack if I exerted myself. V: So, you viewed the ICD as potentially saving your life?

R.B.: "I didn't want to be dead". I wanted to stick around to see my grand baby".

V: Was there anything that concerned you when you were thinking about it, or was it not a complex decision?

R.B. Well, I had to quit work. That wasn't easy. I had been a welder forever. Now, when I go to visit the plant and see my buddies, they have to shut off all machinery just to visit with me. Dr. -- told me "Would you rather be working or be dead?". You've got to look at 
Example of Stage II of Heightening Awareness with properties of perceiving new candor and strongly recommending an ICD

\section{\#8- R.B.}

V: So, I know that coming to the decision to have an ICD (implantable defibrillator) can be rather difficult. Tell me about how your arrived at the decision to have one implanted.

R.B.: "They told me I had no option". I blew that front part of my heart out. It was dead. I was afraid l'd have another heart attack if I exerted myself. V: So, you viewed the ICD as potentially saving your life?

R.B.: "I didn't want to be dead". I wanted to stick around to see my grand baby".

V: Was there anything that concerned you when you were thinking about it, or was it not a complex decision?

R.B. Well, I had to quit work. That wasn't easy. I had been a welder forever. Now, when I go to visit the plant and see my buddies, they have to shut off all machinery just to visit with me. Dr. -.- told me "Would you rather be working or be dead?". You've got to look at 
Examples of Stage IV: Living in New Assurance with the property of downplaying the process

Maybe if it was my only option or die sort of thing. But I don't
know.

V: Did you feel that you had enough information to make the decision regarding the $I C D$ ?

M.G. Yes, I had enough information. I understood . I had those doctors for a long time. They know what they are talking about. And I'm glad I did it. It was no big deal. "I'd rather have this than go to the dentist"

\section{$47 M G$}

SR: It was my decision. I knew how my family felt. It isn't all about me, but I made the decision on my own. It hasn't been a big deal. I do worry at times about it going off. It's more of a mental thing. I'm doing good. No regrets. 
114

Examples of decliner field notes

That's about it. He spoke again about letting nature take its course.

J.L. went on to say that "nothing has changed" (over the years since he w: diagnosed with heart disease and heart failure). He said he had not had a "recurrence". He said that if he felt poorly, if he had had "another incider had "three heart attacks", maybe he would have considered it. "If it's not broken...." He smiled as if to finish the saying. He said "hard to see taking step like that". He referred to the ICD as "stepping out of normality"

Ac o RN

$V: T e l l$ me About you decision $x$ wT accept an ICS

RN: They just Never combined ar I seeded if. I petrine $*$ I still do. They comedn't guarantee me I id wen wiley need, it. I tad dome veal anything. May se you go attar you ge $\angle+C\left(L_{S}\right)$ are yoluind $x$ me lice, "It card typuren" Dim not unsliced regrets 


\section{Appendix C}

\section{We WestVirginiaUniversity}

School of Nursing

Vera Barton-Caro RN, MSN, FNP-BC, CHFN, PhD Candidate

Phone: $304-650-0888$

Email: verabarcar1@comcast.net

Exploring Heart Failure Patient Decision Making Surrounding Primary Prevention

Implantable Cardioverter Defibrillators

Information Sheet

You are being asked to participate in a study about how heart failure patients make the decision to accept or decline implantation of an implantable cardioverter defibrillator (ICD). The purpose of the study is to explore the decision-making process of adult heart failure patients who have met the qualifications for and been offered preventative ICD therapy. This study fulfills the requirements to obtain a PhD degree under the supervision of Dr. Alvita Nathaniel.

For this study, you will be asked a simple question about how you arrived at the decision to accept or decline an ICD". The interviews will be conducted in a comfortable, private place at a time that is convenient for you. Information about your identity or your participation in the study will not be shared with anyone except the faculty advisor for this PhD student. To make sure that the information you share is represented accurately, the researcher may take brief notes during the interview. After the interview, the researcher will write notes about your responses to questions. Your name will not be attached to these notes. If you request, the researcher can provide a copy of the interview notes to you.

It is your choice to participate in the study or not. You also have the choice once the interview has begun to continue or withdraw from the study without penalty to yourself. You are free to answer the questions in any way you like.

Office of the Dean

6700 Health Sciences South 
There are no anticipated risks to you for participating in this study. There are no anticipated costs to your participating in the study except for any travel expense such as gasoline and mileage to and from the interview.

The potential benefits of participating in this study are to society, science, and nursing knowledge. You may provide valuable information about the decision-making process of heart failure patients considering ICD therapy.

West Virginia University's Independent Review Board (IRB)'s acknowledgement of this study is on file. If you wish any additional information regarding your rights as a research participant, you may contact the West Virginia University Compliance Officer by calling 304-293-7073 or emailing irb@mail.wvu.edu. You may also contact the faculty advisor for this doctoral student, Dr. Alvita Nathaniel, by calling 304-347-1224 or emailing anathaniel@hsc.wvu.edu.

If you wish to volunteer to participate in this study, please call or email Vera Barton-Caro at the numbers provided on the front of this information sheet. 


\section{Appendix D}

\section{WestVirginiaUniversity \\ School of Nursing}

\section{Confidential Personal Information}

Date

Participant \#

1. In what year were you born?

year

2. What is your gender?

口 Male

$\square$ Female

\section{What was the highest grade you completed in school?}

$\square$ Less than high school graduate

․ High school graduate or GED certificate

$\square$ Some college

$\square$ College graduate

․ Any post-graduate work

4. Are you currently working?
ㅁ. Yes - Full time
口 Yes - Part time
$\square$ No - Retired
$\square$ No - Unemployed
№ - On Disability
․ No-Student
ㅁ No-Homemaker
ㅁ Other:

5. In what year were you diagnosed with heart failure (your best guess)?

year

Office of the Dean

6700 Health Sciences South

PO Box 9600 
6. In what year were you offered an internal device (ICD/ defibrillator) to shock your heart (your best guess)?

$$
\text { year }
$$

7. Who first talked to you about an internal device (ICD/defibrillator) to shock your heart?
$\square$ Cardiologist
․ Electrophysiologist/ EP cardiologist
Primary Care physician
$\square$ Nurse Practitioner, Physician's Assistant
$\square$ Nurse
$\square$ Other

8. If you have a device, has it ever shocked you?
$\square$ Yes
$\square$ No
$\square$ I don't have a device

9. Would you like us to send you a copy of the results from this study when we are finished with the entire study?

$\square$ Yes

If yes, please list mailing address:

If you prefer to be contacted by email, please list your email address below: 


\title{
Appendix E
}

\author{
WestVirginiaUniversity \\ School of Nursing \\ Vera Barton-Caro RN, MSN, FNP-BC, CHFN, PhD Candidate \\ Phone: $304-650-0888$ \\ Email: verabarcar1@comcast.net \\ Exploring Heart Failure Patient Decision Making Surrounding Primary Prevention \\ Implantable Cardioverter Defibrillators \\ Site Approval
}

As owner of Richard F. Terry, MD, Inc., I support Vera Barton-Caro in her use of a private area in our clinic to conduct interviews for her research study, "Exploring Heart Failure Patient Decision Making Surrounding Primary Prevention Implantable Cardioverter Defibrillators". I understand that the purpose of this study is to learn from heart failure patients about their decision-making process surrounding whether to accept or decline primary prevention ICD implantation.

I understand that the participants for this study will voluntarily offer to participate after being given detailed information about the study. The participants will be adult heart failure patients who have met the indications for primary prevention ICD implantation and who have been offered the therapy by a provider.

I understand that West Virginia University's Internal Review Board's acknowledgement of this study is on file. I understand that I may contact the West Virginia University Research Compliance Office by calling 304-293-7073 or emailing irb@mail.wvu.edu for further information on this study. I also understand that I may call the faculty advisor for this investigator, Dr. Alvita Nathaniel, by calling 304-347-1224 or emailing anathaniel@hsc.wvu.edu.

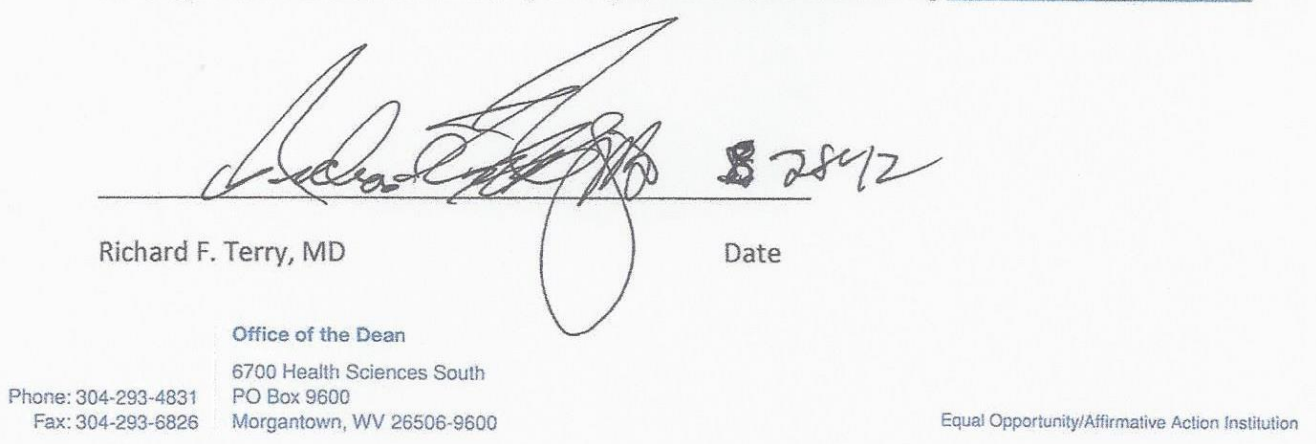




\title{
Appendix F
}

\author{
WestVirginiaUniversity \\ School of Nursing \\ Vera Barton-Caro RN, MSN, FNP-BC, CHFN, PhD Candidate \\ Phone: $304-650-0888$ \\ Email: verabarcar1@comcast.net \\ Exploring Heart Failure Patient Decision Making Surrounding Primary Prevention \\ Implantable Cardioverter Defibrillators
}

Site Approval

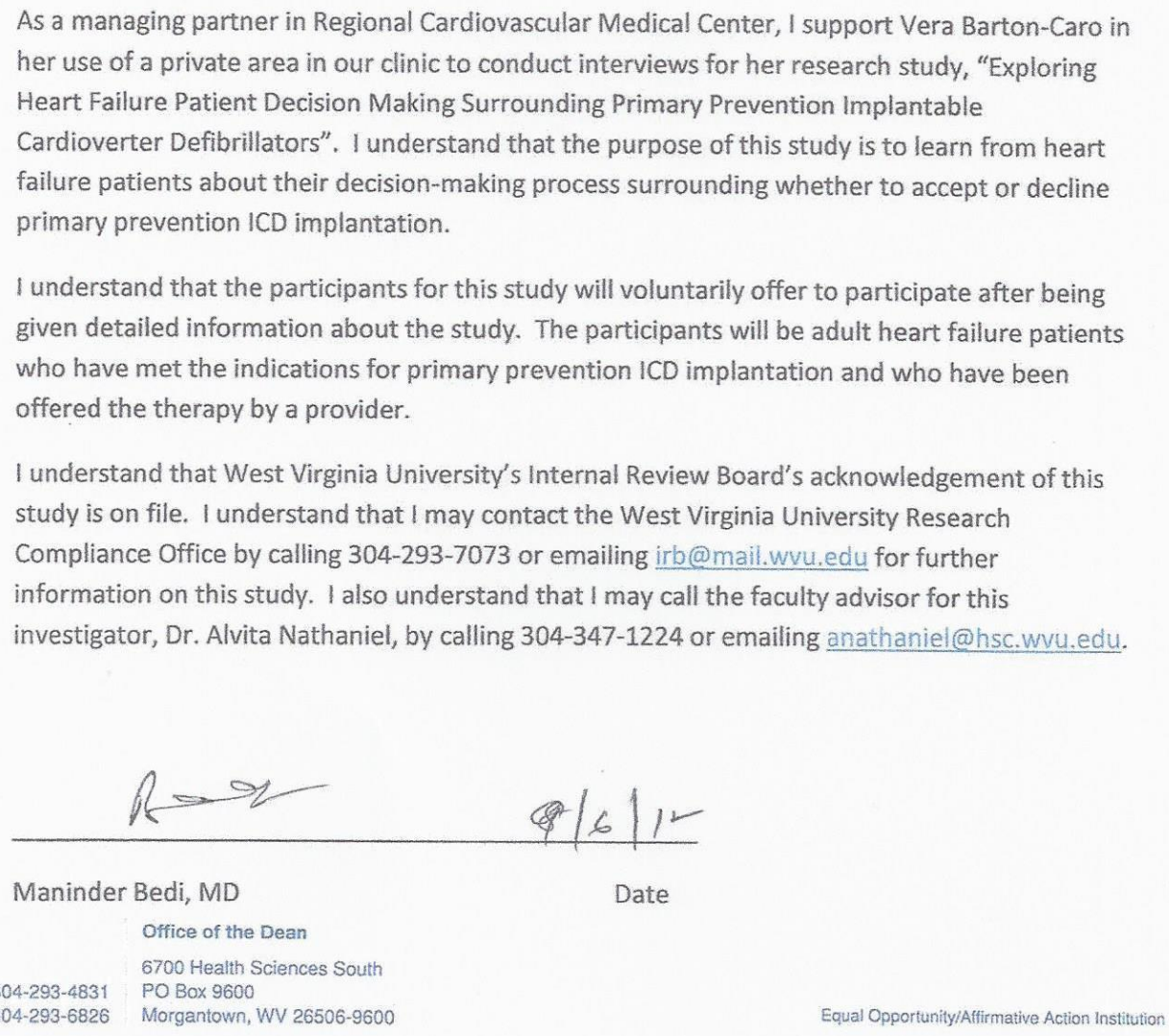




\section{Appendix G}

\section{West VirginiaUniversity \\ School of Nursing}

Vera Barton-Caro RN, MSN, FNP-BC, CHFN, PhD Candidate

Phone: $304-650-0888$

Email:verabarcar1@comcast.net

Exploring Heart Failure Patient Decision Making Surrounding Primary Prevention

Implantable Cardioverter Defibrillators

Site Approval

As owner of Robert J. Fanning, Jr. DO Cardiology, I support Vera Barton-Caro in her use of a private area in our clinic to conduct interviews for her research study, "Exploring Heart Failure Patient Decision Making Surrounding Primary Prevention Implantable Cardioverter Defibrillators". I understand that the purpose of this study is to learn from heart failure patients about their decision-making process surrounding whether to accept or decline primary prevention ICD implantation.

I understand that the participants for this study will voluntarily offer to participate after being given detailed information about the study. The participants will be adult heart failure patients who have met the indications for primary prevention ICD implantation and who have been offered the therapy by a provider.

I understand that West Virginia University's Internal Review Board's acknowledgement of this study is on file. I understand that I may contact the West Virginia University Research Compliance Office by calling 304-293-7073 or emailing irb@mail.wvu.edu for further information on this study. I also understand that I may call the faculty advisor for this investigator, Dr. Alvita Nathaniel, by calling 304-347-1224 or emailing anathaniel@hsc.wvu.edu.

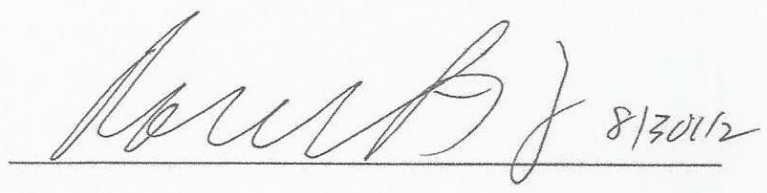

Robert J. Fanning, Jr, DO

Date

6700 Health Sciences South 


\title{
Appendix H
}

\section{West VirginiaUniversity \\ School of Nursing}

Vera Barton-Caro RN, MSN, FNP-BC, CHFN, PhD Candidate

Phone: $304-650-0888$

Email: verabarcar1@comcast.net

\author{
Exploring Heart Failure Patient Decision Making Surrounding Primary Prevention \\ Implantable Cardioverter Defibrillators \\ Site Approval
}

\begin{abstract}
As a managing partner in Frazier-Hart, Inc., I support Vera Barton-Caro in her use of a private area in our clinic to conduct interviews for her research study, "Exploring Heart Failure Patient Decision Making Surrounding Primary Prevention Implantable Cardioverter Defibrillators". I understand that the purpose of this study is to learn from heart failure patients about their decision-making process surrounding whether to accept or decline primary prevention ICD implantation.
\end{abstract}

I understand that the participants for this study will voluntarily offer to participate after being given detailed information about the study. The participants will be adult heart failure patients who have met the indications for primary prevention ICD implantation and who have been offered the therapy by a provider.

I understand that West Virginia University's Internal Review Board's acknowledgement of this study is on file. I understand that I may contact the West Virginia University Research Compliance Office by calling 304-293-7073 or emailing irb@mail.wvu.edu for further information on this study. I also understand that I may call the faculty advisor for this investigator, Dr. Alvita Nathaniel, by calling 304-347-1224 or emailing anathaniel@hsc.wvu.edu.

\section{desing m}

John S. Wilson, MD

Date

6700 Health Sciences South

Phone: $304-293-4831$ PO Box 9600

Fax: 304-293-6826 Morgantown, WV 26506-9600

Equal Opportunity'Affirmative Action Institution 


\section{Appendix I}

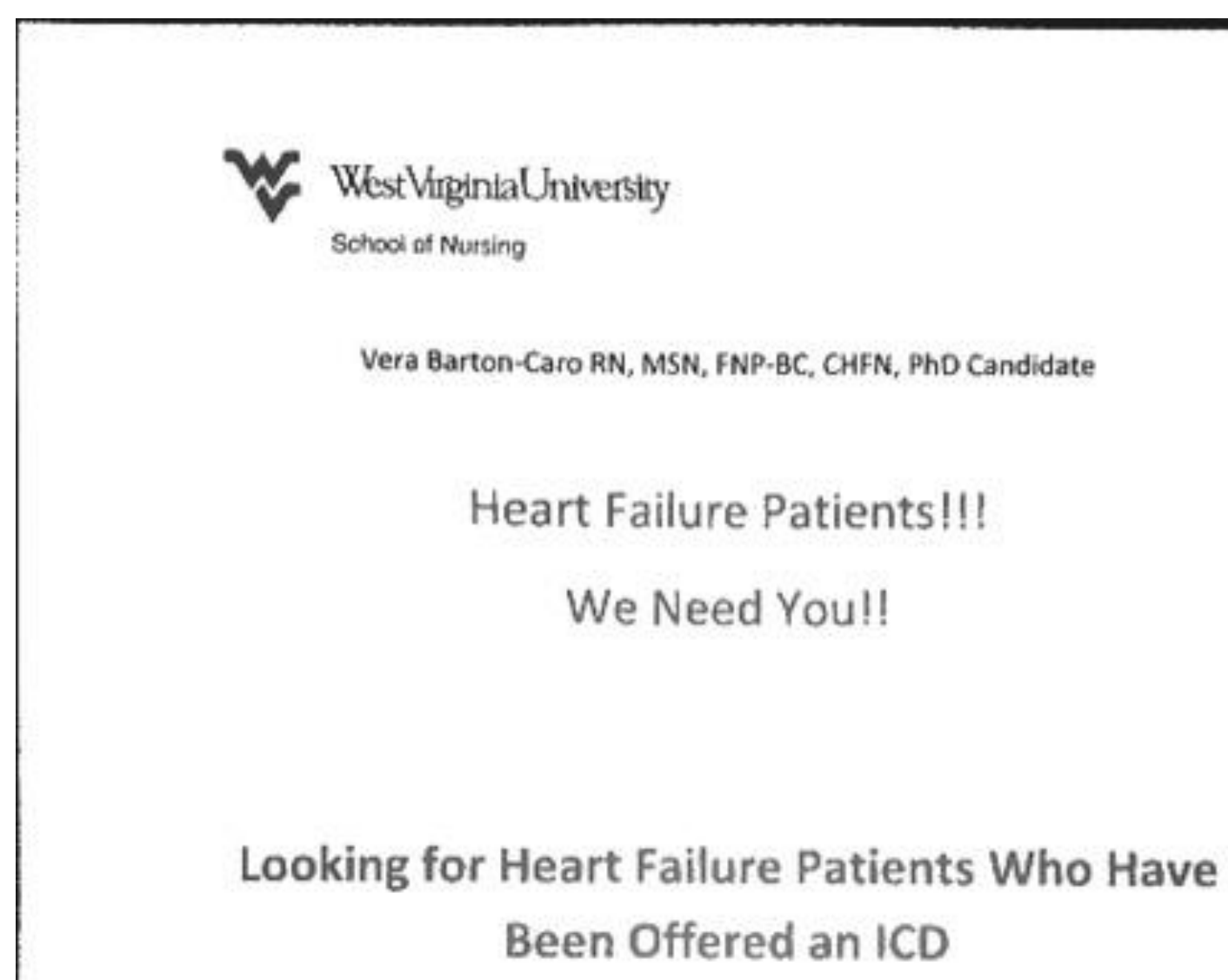

I am a Nursing PhD student researcher conducting a study: "Exploring Heart Failure Patient Decision Making Surrounding Primary Prevention Implantable Cardioverter Defibrillators". The study will consist of one interview expected to take approximately 45 minutes to one hour. For more information, please call Vera Barton-Caro at 304-650-0888 or email: verabarcar1@comcast.net.

The West Virginia University iRs acknowledges the study.
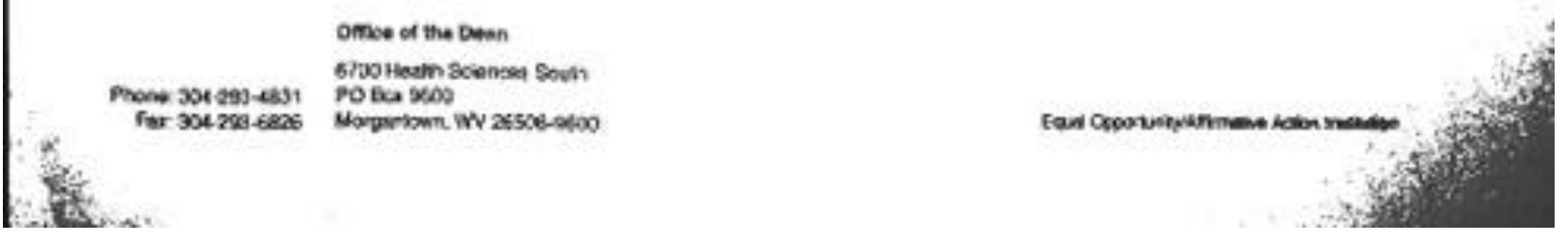


\section{Appendix J}

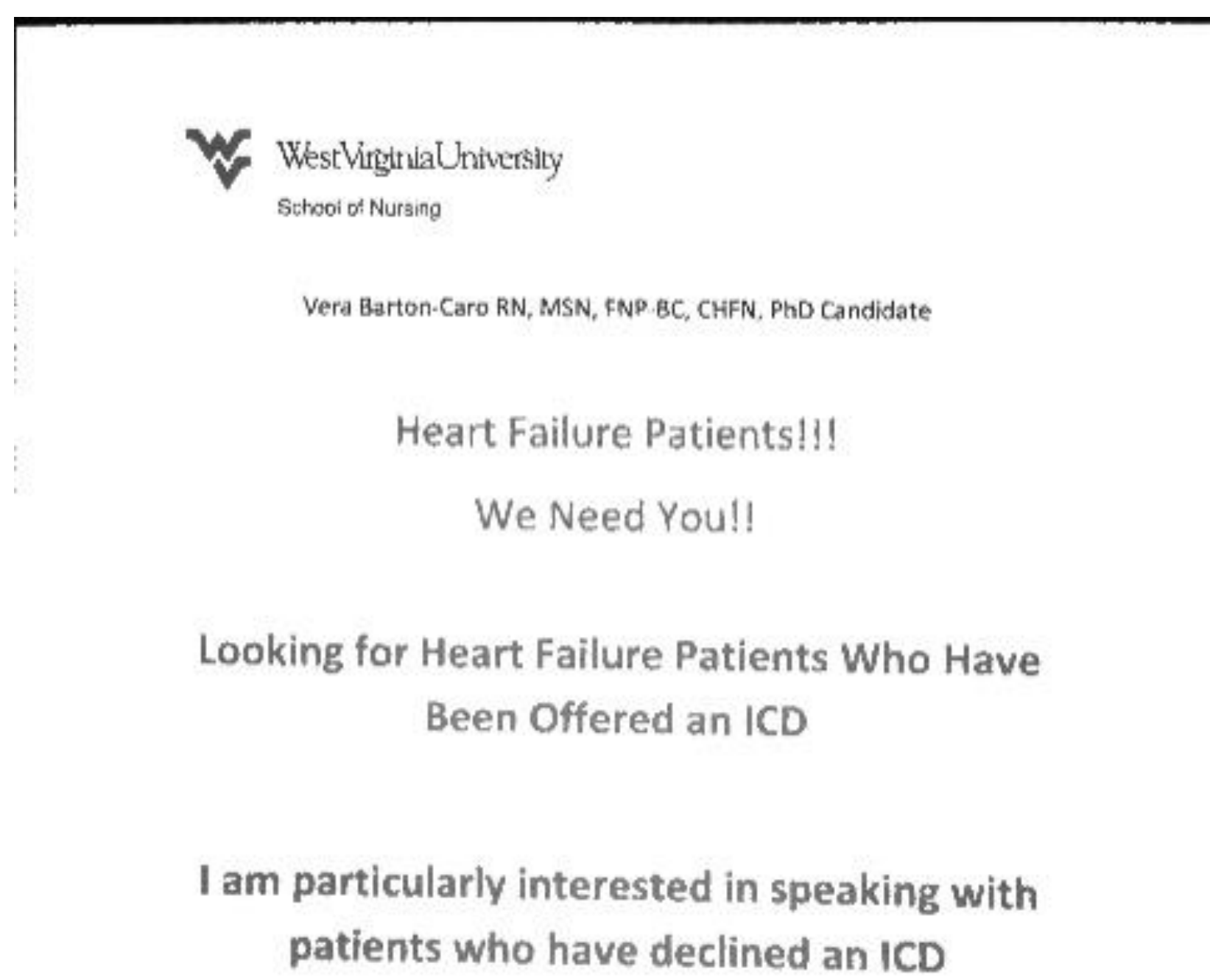

I am a Nursing PhD student researcher conducting a study: "Exploring Heart Failure Patient Decision Making Surrounding Primary Prevention Implantabie Cardloverter Defibrillators ${ }^{\circ}$. The study will consist of one interview expected to take approximately 45 minutes to one hour. for more information, please call Vera Barton-Caro at 304-650-0888 or email: verabursar1@ comicast.nct.

West Virginia University IRB acknowledges the study

Ovelce of the Dear

aros itahth biancia Souh

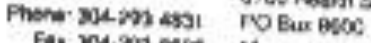

Fas 304 2ajtesst Movaliown Wv aboskgeos

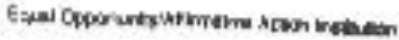


